\title{
Radionuclide Transport in the Vicinity of the Repository and Associated Complementary Cumulative Distribution Functions in the 1996 Performance Assessment for the Waste Isolation Pilot Plant
}

\author{
C.T. Stockman ${ }^{2}$, J.W. Garner ${ }^{b}$, J.C. Helton ${ }^{c}$, J. D. Johnson ${ }^{\text {d }}$, A. Shinta ${ }^{e}$, and L.N. Smith ${ }^{f}$ \\ aSandia National Laboratories, Albuquerque, NM 87185 USA; bPiru Associates, Albuquerque, NM 87106 \\ USA; 'Department of Mathematics, Arizona State University, Tempe, AZ 85287 USA; dGRAM, Inc., \\ Albuquerque, NM 87112 USA; ${ }^{e}$ Applied Physics, Albuquerque, NM 87106 USA; f Comforce, Albuquerque,

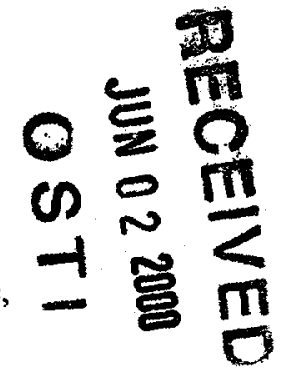 \\ NM 87110 USA
}

\begin{abstract}
The following topics related to radionuclide transport in the vicinity of the repository in the 1996 performance assessment for the Waste Isolation Pilot Plant are presented: (i) mathematical description of models, (ii) uncertainty and sensitivity analysis results arising from subjective (i.e., epistemic) uncertainty for individual releases, (iii) construction of complementary cumulative distribution functions (CCDFs) arising from stochastic (i.e., aleatory) uncertainty, and (iv) uncertainty and sensitivity analysis results for CCDFs. The presented results indicate that no releases to the accessible environment take place due to radionuclide movement through the anhydrite marker beds, through the Dewey Lake Red Beds or directly to the surface, and also that the releases to the Culebra Dolomite are small. Even when the effects of uncertain analysis inputs are taken into account, the CCDFs for release to the Culebra Dolomite fall to the left of the boundary line specified in the U.S. Environmental Protection Agency's standard for the geologic disposal of radioactive waste (40 CFR 191, 40 CFR 194).
\end{abstract}

Key Words: Aleatory uncertainty, compliance certification application, epistemic uncertainty, Latin hypercube sampling, Monte Carlo, performance assessment, radioactive waste, risk, radionuclide transport, stochastic uncertainty, subjective uncertainty, transuranic waste, Waste Isolation Pilot Plant, 40 CFR 191, 40 CFR 194.

Please send page proof to:

Jon C. Helton

Department 6848, MS 0779

Sandia National Laboratories

Albuquerque, NM 87185-0779, USA

Phone: $505-284-4808$

Fax: 505-844-2348

email: jchelto@sandia.gov 


\section{DISCLAIMER}

This report was prepared as an account of work sponsored by an agency of the United States Government. Neither the United States Government nor any agency thereof, nor any of their employees, make any warranty, express or implied, or assumes any legal liability or responsibility for the accuracy, completeness, or usefulness of any information, apparatus, product, or process disclosed, or represents that its use would not infringe privately owned rights. Reference herein to any specific commercial product, process, or service by trade name, trademark, manufacturer, or otherwise does not necessarily constitute or imply its endorsement, recommendation, or favoring by the United States Government or any agency thereof. The views and opinions of authors expressed herein do not necessarily state or reflect those of the United States Government or any agency thereof. 


\section{DISCLAIMER}

Portions of this document may be illegible in electronic image products. Images are produced from the best available original document. 


\section{Introduction}

The Waste Isolation Pilot Plant (WIPP) is under development by the U.S. Department of Energy (DOE) for the geologic disposal of transuranic waste. This article describes the modeling of radionuclide releases from the repository due to transport by groundwater flow and the construction of associated complementary cumulative distribution functions (CCDFs) for radionuclide releases to the Culebra Dolomite. The presented models and results constitute part of the 1996 performance assessment (PA) for the WIPP and support a compliance certification application (CCA) by the DOE to the U.S. Environmental Protection Agency (EPA) for the certification of the WIPP for the disposal of transuranic waste. ${ }^{1,2}$ Results described in this article are used in the construction of CCDFs for comparison with the boundary line specified by the EPA in 40 CFR $191 .^{2-5}$

Two types of release modes to the accessible environment are considered in the 1996 WIPP PA: (i) direct release to the accessible environment, and (ii) groundwater release to the accessible environment. The direct releases involve radionuclide movements to the accessible environment that take place at the time of a drilling intrusion (i.e., cuttings, cavings, spallings, direct brine release) and are discussed in other articles. ${ }^{6-8}$ The groundwater releases involve the much slower releases that take place to the accessible environment due to radionuclide transport in flowing groundwater and are the subject of this article and a following article. ${ }^{9}$ In particular, the present article involves radionuclide transport in the vicinity of the repository and the following article $^{9}$ involves radionuclide transport to the accessible environment in the Culebra Dolomite.

At a conceptual level, the 1996 WIPP PA is underlain by three entities (EN1, EN2, EN3): EN1, a probabilistic characterization of the likelihood of different futures occurring at the WIPP site over the next $10,000 \mathrm{yr}$ (Sect. 3, Ref. 10); EN2, a procedure for estimating the radionuclide releases to the accessible environment associated with each of the possible futures that could occur at the WIPP site over the next 10,000 yr (Sect. 4, Ref. 10); and EN3, a probabilistic characterization of the uncertainty in the parameters used in the definitions of EN1 and EN2 (Sect. 5, Ref. 10). All three of these entities play a role in the radionuclide transport results presented in this article. In particular, the following topics are considered: (i) models for radionuclide transport in the vicinity of the repository, which constitute part of EN2 (Sect. 4, Ref. 10); (ii) construction of CCDFs for radionuclide releases in the vicinity of the repository, which involves the probability space for stochastic uncertainty associated with EN1 (Sect. 3, Ref. 10; Ref. 11); and (iii) uncertainty and sensitivity analysis to assess the implications of uncertain analysis inputs, which involves the probability space associated with EN3 (Sect. 5, Ref. 10; Ref. 12).

When viewed formally, EN2 is defined by a function $f$ of the form 


$$
\begin{aligned}
f\left(\mathbf{x}_{s t}\right)= & f_{C}\left(\mathbf{x}_{s t}\right)+f_{S P}\left[\mathbf{x}_{s t}, f_{B}\left(\mathbf{x}_{s t}\right)\right]+f_{D B R}\left\{\mathbf{x}_{s t}, f_{S P}\left[\mathbf{x}_{s t}, f_{B}\left(\mathbf{x}_{s t}\right)\right], f_{B}\left(\mathbf{x}_{s t}\right)\right\} \\
& +f_{M B}\left[\mathbf{x}_{s t}, f_{B}\left(\mathbf{x}_{s t}\right)\right]+f_{D L}\left[\mathbf{x}_{s t}, f_{B}\left(\mathbf{x}_{s t}\right)\right]+f_{S}\left[\mathbf{x}_{s t}, f_{B}\left(\mathbf{x}_{s t}\right)\right] \\
& +f_{S-T}\left\{\mathbf{x}_{s t, 0}, f_{S-F}\left(\mathbf{x}_{s t, 0}\right), f_{N-P}\left[\mathbf{x}_{s t}, f_{B}\left(\mathbf{x}_{s t}\right)\right]\right\}
\end{aligned}
$$

where $\mathbf{x}_{s t} \sim$ particular future under consideration, $\mathbf{x}_{s t, 0} \sim$ future involving no drilling intrusions but a mining event at the same time $t_{\min }$ as in $\mathbf{x}_{s t}, f_{C}\left(\mathbf{x}_{s t}\right) \sim$ cuttings and cavings release to accessible environment for $\mathbf{x}_{s t}$ calculated with CUTTINGS_S, $f_{B}\left(\mathbf{x}_{s t}\right) \sim$ two-phase flow results calculated for $\mathbf{x}_{s t}$ with BRAGFLO; in practice, $f_{B}\left(\mathbf{x}_{s t}\right)$ is a vector containing a large amount of information), $f_{S P}\left[\mathbf{x}_{s t}, f_{B}\left(\mathbf{x}_{s t}\right)\right] \sim$ spallings release to accessible environment for $\mathbf{x}_{s t}$ calculated with the spallings model contained in CUTTINGS_S; this calculation requires BRAGFLO results (i.e., $\left.f_{B}\left(\mathbf{x}_{s t}\right)\right)$ as input, $f_{D B R}\left\{\mathbf{x}_{s t}, f_{S P}\left[\mathbf{x}_{s t}, f_{B}\left(\mathbf{x}_{s t}\right)\right], f_{B}\left(\mathbf{x}_{s t}\right)\right\} \sim$ direct brine release to accessible environment for $\mathbf{x}_{s t}$ calculated with a modified version of BRAGFLO designated BRAGFLO_DBR; this calculation requires spallings results obtained from CUTTINGS_S (i.e., $f_{S P}\left[\mathbf{x}_{s t}, f_{B}\left(\mathbf{x}_{s t}\right)\right]$ ) and BRAGFLO results (i.e., $f_{B}\left(\mathbf{x}_{s t}\right)$ ) as input, $f_{M B}\left[\mathbf{x}_{s t}, f_{B}\left(\mathbf{x}_{s t}\right)\right] \sim$ release through anhydrite marker beds to accessible environment for $\mathbf{x}_{s t}$ calculated with NUTS; this calculation requires BRAGFLO results (i.e., $f_{B}\left(\mathbf{x}_{s t}\right)$ ) as input, $f_{D L}\left[\mathbf{x}_{s t}, f_{B}\left(\mathbf{x}_{s t}\right)\right] \sim$ release through Dewey Lake Red Beds to accessible environment for $\mathbf{x}_{s t}$ calculated with NUTS; this calculation requires BRAGFLO results (i.e., $\left.f_{B}\left(\mathbf{x}_{s t}\right)\right)$ as input, $f_{S}\left[\mathbf{x}_{s t}, f_{B}\left(\mathbf{x}_{s t}\right)\right] \sim$ release to land surface due to brine flow up a plugged borehole for $\mathbf{x}_{s t}$ calculated with NUTS or PANEL; this calculation requires BRAGFLO results (i.e., $f_{B}\left(\mathbf{x}_{S t}\right)$ ) as input, $f_{S-F}\left(\mathbf{x}_{s t, 0}\right) \sim$ Culebra flow field calculated for $\mathbf{x}_{s t, 0}$ with SECOFL2D, $f_{N-P}\left[\mathbf{x}_{s t}, f_{B}\left(\mathbf{x}_{s t}\right)\right] \sim$ release to Culebra for $\mathbf{x}_{s t}$ calculated with NUTS or PANEL as appropriate; this calculation requires BRAGFLO results (i.e., $f_{B}\left(\mathbf{x}_{s t}\right)$ ) as input, $f_{S-T}\left\{\mathbf{x}_{s t, 0}, f_{S-F}\left(\mathbf{x}_{s t, 0}\right), f_{N-P}\left[\mathbf{x}_{s t}, f_{B}\left(\mathbf{x}_{s t}\right)\right]\right\} \sim$ groundwater transport release through Culebra to accessible environment calculated with SECOTP2D; this calculation requires SECOFL2D results (i.e., $f_{S-F}\left(\mathbf{x}_{s t, 0}\right)$ ) and NUTS or PANEL results (i.e., $\left.f_{N-P}\left[\mathbf{x}_{s t}, f_{B}\left(\mathbf{x}_{s t}\right)\right]\right)$ as input; $\mathbf{x}_{s t, 0}$ is used as an argument to $f_{S-T}$ because drilling intrusions are assumed to cause no perturbations to the flow field in the Culebra (Sect. 4 , Ref. 10).

The particular components of $f$ in Eq. (1) considered in this presentation are $f_{M B}, f_{D L}, f_{S}$ and $f_{N-P}$, with $f_{M B}, f_{D L}$ and $f_{S}$ corresponding to the estimation of releases to the accessible environment due to radionuclide transport through anhydrite marker beds, through the Dewey Lake Red Beds and to the surface, respectively, and $f_{N-P}$ corresponding to the estimation of releases to the Culebra Dolomite. The components $f_{S-F}$ and $f_{S-T}$ in Eq. (1) correspond to the estimation of brine flow in the Culebra Dolomite and radionuclide releases to the accessible environment due to radionuclide transport through the Culebra Dolomite, respectively, and are discussed in Ref. 9. The mathematical formulations of the other components of $f$ appearing in Eq. (1) (i.e., $f_{C}, f_{B}, f_{S P}, f_{D B R}$ ) are described in other articles. $6,8,13$ 
The computational evaluation of $f_{M B}, f_{D L}$ and $f_{S}$ is carried out by the NUTS program and uses brine flow results calculated with the BRAGFLO program (Fig. 2, Table 2, Ref. 10; Ref. 13). The computational evaluation of $f_{N-P}$ is carried out by the NUTS or PANEL program depending on the particular situation (i.e., value for $\mathbf{x}_{s t}$ ) under consideration and, again, uses brine flow results calculated with the BRAGFLO program. The NUTS program, and hence the definitions of $f_{M B}, f_{D L}, f_{S}$ and $f_{N-P}$ (when appropriate) is underlain by a system of partial differential equations described in Sects. 2-4; the PANEL program, and hence the definition of $f_{N-P}$ (when appropriate), is underlain by a system of ordinary differential equations as described in Sects. 5-7; and both NUTS and PANEL are underlain by radionuclide solubilities as described in Sect. 2 .

At a conceptual level, determination of the CCDFs for releases to the accessible environment associated with $f_{M B}, f_{D L}$ and $f_{S}$ and also to the Culebra Dolomite for $f_{N-P}$ involves evaluation of the following integral (Sect. 4, Ref. 10):

$$
\operatorname{prob}_{M}(\operatorname{Rel}>R)=\int_{\delta_{s t}} \delta_{R}\left\{f_{M}\left[\mathbf{x}_{s t}, f_{B}\left(\mathbf{x}_{s t}\right)\right]\right\} d_{s t}\left(\mathbf{x}_{s t}\right) d V_{s t}
$$

where $M=M B, D L, S$ or $N-P$ depending on whether $f_{M B}, f_{D L}, f_{S}$ or $f_{N-P}$ is under consideration, $\delta_{R}\left\{f_{M}\left[\mathbf{x}_{s t}, f_{B}\left(\mathbf{x}_{s t}\right)\right]\right\}=1$ if $f_{M}\left[\mathbf{x}_{s t}, f_{B}\left(\mathbf{x}_{s t}\right)\right]>R$ and 0 if $f_{M}\left[\mathbf{x}_{s t}, f_{B}\left(\mathbf{x}_{s t}\right)\right] \leq R, d_{s t}$ is the density function associated with the probability space $\left(\mathrm{S}_{s t}, \& s t, p_{s t}\right)$ for stochastic uncertainty (Sect. 3, Ref. 10; Ref. 11), and $\operatorname{prob}_{M}(R e l>R)$ is the probability that a release greater than size $R$ will occur. Typically, $R$ is expressed in the normalized units defined by the EPA (Eq. (1), Ref. 10), although other possibilities exist (e.g., releases of individual radionuclides in Ci's or Bq's). In practice, the preceding integral is too complex to allow a closed-form evaluation. As a result, the 1996 WIPP PA uses the Monte Carlo procedure indicated below to estimate this integral (Sect. 4, Ref. 10; Sects. 10, 11, Ref. 11):

$$
\operatorname{prob}_{M}(\operatorname{Rel}>R) \doteq \sum_{i=1}^{n S} \delta_{R}\left\{f_{M}\left[\mathbf{x}_{s t, i}, f_{B}\left(\mathbf{x}_{s t, i}\right)\right]\right\} / n S,
$$

where $\mathbf{x}_{s t, i}, i=1,2, \ldots, n S=10,000$, corresponds to a random sample of size $n S=10,000$ from the sample space $\mathrm{S}_{s t}$ associated with the probability space $\left(\mathrm{S}_{s t}, \mathcal{L} \quad s t, p_{s t}\right)$ for stochastic uncertainty. The evaluation of the preceding approximation to produce CCDFs for $f_{N-P}$ is discussed in Sect. 9. The corresponding CCDFs for $f_{M B}, f_{D L}$ and $f_{S}$ are degenerate (i.e., have a probability of zero of exceeding a release of size zero) as these release modes produced no releases to the accessible environment in the 1996 WIPP PA (Sect. 10). The construction of CCDFs for the other release modes is discussed in additional articles. ${ }^{6,8,9,14}$

When the effects of imprecisely-known analysis inputs are included, the representations for the release modes under consideration become $f_{M}\left[\mathbf{x}_{s t}, \mathbf{x}_{s u}, f_{B}\left(\mathbf{x}_{s t}, \mathbf{x}_{s u}\right)\right]$ for $M=M B, D L, S$ or $N-P$, where $\mathbf{x}_{s u}$ is an element of the 
sample space $\mathrm{S}_{s u}$ associated with the probability space $\left(\mathrm{S}_{s u}, \&_{s u}, p_{s u}\right)$ for subjective uncertainty (Sect. 5, Ref. 10; Ref. 12). The possible values for $\mathbf{x}_{s u}$ lead to distributions of releases for both specific futures $\mathbf{x}_{s t}$ and also for the CCDFs that result from integrating over all possible values for $\mathbf{X}_{s t}$. In the 1996 WIPP PA, these distributions are approximated by using Latin hypercube sampling ${ }^{15}$ to generate a mapping from $\mathrm{S}_{s u}$ to analysis outcomes of interest (Sect. 5, Ref. 10; Sect. 8, Ref. 12). The generation and presentation of this mapping is usually referred to as uncertainty analysis. Once generated, this mapping can be explored with sensitivity analysis techniques based on examination of scatterplots, regression analysis, and correlation analysis (Sect. 3.5, Ref. 16). Uncertainty and sensitivity analysis results for releases to the Culebra are presented in Sects. 8 and 9. As previously indicated, releases through the anhydrite marker beds, through the Dewey Lake Red Beds and to the surface were zero even when the effects of subjective uncertainty were incorporated into the analysis. Uncertainty and sensitivity analysis results for the other release modes are available in additional articles. $6,8,9,14,17,18$

This article is based on material contained in Sect. 4.3, Sect. 4.4 and Chapt. 11 of Ref. 19.

\section{NUTS: Mathematical Description}

The following system of partial differential equations is used to model radionuclide transport in the vicinity of the repository for E0, E1 and E2 conditions, where E0 designates undisturbed conditions, E1 designates a single drilling intrusion through the repository that penetrates pressurized brine in the Castile Fm, and E2 designates a single drilling intrusion through the repository that does not penetrate pressurized brine in the Castile Fm:

$$
\begin{gathered}
-\nabla \cdot \alpha \mathbf{v}_{b} C_{b l}+\alpha S_{l}=\alpha \frac{\partial}{\partial t}\left(\phi S_{b} C_{b l}\right)+\left(\alpha \phi S_{b} C_{b l}\right) \lambda_{l}-\alpha \phi S_{b} \sum_{p \in P(l)} C_{b p} \lambda_{p} \\
-S_{l}=\frac{\partial}{\partial t}\left(C_{s l}\right)+C_{s l} \lambda_{l}-\sum_{p \in P(l)} C_{s p} \lambda_{p}
\end{gathered}
$$

for $l=1,2, \ldots, n R$, where $\mathbf{v}_{b}=$ Darcy velocity vector $\left(\left(\mathrm{m}^{3} / \mathrm{m}^{2}\right) / \mathrm{s}=\mathrm{m} / \mathrm{s}\right.$ ) for brine (supplied by BRAGFLO from solution of Eqs. (2) - (7) of Ref. 13), $C_{b l}=$ concentration $\left(\mathrm{kg} / \mathrm{m}^{3}\right)$ of radionuclide $l$ in brine, $C_{s l}=$ concentration $\left(\mathrm{kg} / \mathrm{m}^{3}\right)$ of radionuclide $l$ in solid phase (i.e., not in brine), with concentration defined with respect to total (i.e., bulk) formation volume (only used in repository; see Fig. 1, Ref. 13), $S_{l}=$ linkage term $\left(\left(\mathrm{kg} / \mathrm{m}^{3}\right) / \mathrm{s}\right)$ due to dissolution/precipitation between radionuclide $l$ in brine and in solid phase (see Eqs. (6) - (9)), $\phi=$ porosity (supplied by BRAGFLO from solution of Eqs. (2) - (7) of Ref. 13), $S_{b}$ = brine saturation (supplied by BRAGFLO from solution of Eqs. (2) - (7) of Ref. 13), $\lambda_{l}=$ decay constant $\left(\mathrm{s}^{-1}\right)$ for radionuclide $l, P(l)=\{p$ : radionuclide $p$ is a parent of radionuclide $l\}, n R=$ number of radionuclides, and $\alpha$ is the dimension dependent geometry factor in Eq. (8) of Ref. 13. The 1996 WIPP PA uses a 2-dimensional representation for fluid flow and radionuclide transport in the vicinity of the repository with $\alpha$ defined by the element depths in Fig. 2 of Ref. 13. Although omitted from the 
notation for brevity, the terms $\alpha, \mathbf{v}_{b}, C_{b l}, C_{s l}, S_{l}, \phi$ and $S_{b}$ are functions $\alpha(x, y), \mathbf{v}_{b}(x, y, t), C_{b l}(x, y, t), C_{s l}(x, y, t)$, $S_{l}(x, y, t), \phi(x, y, t)$ and $S_{b}(x, y, t)$ of time $t$ and the spatial variables $x, y$. The two preceding equations are defined and solved on the same computational grid used with BRAGFLO for the solution of Eqs. (2) - (7) of Ref. 13 (Fig. 1, Ref. 13).

Radionuclides are present in both brine (Eq. (4)) and in an immobile solid phase (Eq. (5)). Radionuclide transport takes place only by brine flow (Eq. (4)). A maximum radionuclide concentration in brine is assumed for each element (see $S_{T}(B r, O x, E l)$ in Table 1). Then, each individual radionuclide equilibrates between the brine and solid phases on the basis of the maximum concentration of its associated element and the mole fractions of other isotopes of this element that are included in the calculation. The linkage between the brine and solid phases in Eqs. (4) and (5) is accomplished by the term $S_{l}$, where

$$
\begin{aligned}
S_{l}= & \delta(\tau-t) \operatorname{Dif}\left(S_{T}, C_{b, E l(l)}\right) M F_{s l} \\
& \text { if } 0 \leq \operatorname{Dif}\left(S_{T}, C_{b, E l(l)}\right) \leq C_{s, E l(l)} /\left(\phi S_{b}\right), 0<S_{b} \\
= & \delta(\tau-t)\left[C_{s, E l(l)} /\left(\phi S_{b}\right)\right] M F_{s l} \\
& \text { if } 0 \leq C_{s, E l(l)} /\left(\phi S_{b}\right)<\operatorname{Dif}\left(S_{T}, C_{b, E l(l)}\right), 0<S_{b} \\
= & \delta(\tau-t) \operatorname{Dif}\left(S_{T}, C_{b, E l(l)}\right) M F_{b l} \\
& \text { if } \operatorname{Dif}\left(S_{T}, C_{b, E l(l)}\right)<0,0<S_{b} \\
=0 & \text { otherwise }
\end{aligned}
$$

with

$S_{T}[\operatorname{Br}(t), O x(l), E l(l)]=$ maximum concentration $\left(\mathrm{kg} / \mathrm{m}^{3}\right)$ of element $E l(l)$ in oxidation statement $O x(l)$ in brine type $B r(t)$, where $E l(l)$ denotes the element of which radionuclide $l$ is an isotope, $O x(l)$ denotes the oxidation state in which element $E l(l)$ is present, and $\operatorname{Br}(t)$ denotes the type of brine present in the repository at time $t$ (see Table 1 for definition of $S_{T}(B r, O x, E l)$ in units of $\mathrm{mol} / \mathrm{l}$; a conversion to $\mathrm{kg} / \mathrm{m}^{3}$ is required for use in conjunction with Eqs. (6) - (9) through the definition of $\operatorname{Dif}\left(S_{T}, C_{b, E l(l)}\right)$ in Eq. (10))

$C_{b, E l(l)}=$ concentration $\left(\mathrm{kg} / \mathrm{m}^{3}\right)$ of element $E l(l)$ in brine (i.e., sum of concentrations of radionuclides that are isotopes of same elements as radionuclide $l$, where $k \in \mathrm{E}(l)$ only if $k$ is an isotope of element $E l(l))$

$$
=\sum_{k \in E(l)} C_{b k}
$$




$$
\begin{aligned}
\operatorname{Dif}\left(S_{T}, C_{b, E l(l)}\right)= & \text { difference }\left(\mathrm{kg} / \mathrm{m}^{3}\right) \text { between maximum concentration of element } E l(l) \text { in brine and existing } \\
& \text { concentration of element } E l(l) \text { in brine } \\
= & S_{T}[B r(t), O x(l), E l(l)]-C_{b, E l(l)} \\
M F_{p l}= & \text { mole fraction of radionuclide } l \text { in phase } p \text {, where } p=b \sim \text { brine and } p=s \sim \text { solids } \\
= & C_{p l} C M_{l} / \sum_{k \in E(l)} C_{b k} C M_{k} \\
C M_{l}= & \text { conversion factor }(\text { mole/kg) from kilograms to moles for radionuclide } l \\
\delta(\tau-t)= & \text { Dirac delta function }\left(\mathrm{s}^{-1}\right)\left(\text { i.e., } \delta(\tau-t)=0 \text { if } \tau \neq t \text { and } \int_{-\infty}^{\infty} \delta(\tau-t) d \tau=1\right) .
\end{aligned}
$$

Although omitted for brevity, the terms $S_{l}, C_{b, E l(l)}, C_{s, E l(l)}, M F_{s l}, M F_{b l}$, $\phi$ and $S_{b}$ are functions of time $t$ and spatial variables $x, y$. The Dirac delta function, $\delta(\tau-t)$, appears in Eqs. $(6)-(8)$ to indicate that the adjustments to concentration are implemented instantaneously within the numerical solution of Eqs. (4) - (5) whenever a concentration imbalance is observed.

The velocity vector $v_{b}$ in Eq. (4) is defined in Eq. (4.2.71) of Ref. 13 and is obtained from the numerical solution of Eqs. (2) - (7) of Ref. 13. If B denotes an arbitrary boundary (e.g., the land withdrawal boundary) in the domain of Eq. (4) (i.e., Fig. 1, Ref. 13), then the cumulative transport of $C_{l}(t, \mathrm{~B})$ of radionuclide $l$ from time 0 to time $t$ across $\mathrm{B}$ is given by

$$
C_{l}(t, \mathrm{~B})=\int_{0}^{t}\left[\int_{\mathrm{B}} C_{l}(x, y, t) \alpha(x, y) \mathbf{v}_{b}(x, y, t) \bullet \mathbf{n}(x, y) d s\right] d t
$$

where $\mathbf{n}(x, y)$ is an outward pointing unit normal vector and $\int_{3} \sim d s$ denotes a line integral over $\mathrm{B}$.

The system in Eqs. (4) - (5) models advective radionuclide transport due to the velocity vector $\mathbf{v}_{b}$. Although the effects of solubility limits are considered, no chemical or physical retardation is included in the model. Also, molecular diffusion is not included in the model, with this omission having little effect as the radionuclides under consideration have molecular diffusion coefficients on the order of $10^{-10} \mathrm{~m}^{2} / \mathrm{s}$ and thus can be expected to move approximately $10 \mathrm{~m}$ over $10,000 \mathrm{yr}$ due to molecular diffusion. Mechanical dispersion is also not included, with this omission having little effect on the final results due to the uniform initial radionuclide concentrations assumed within the repository and the use of time-integrated releases in assessing compliance with 40 CFR 191.13 (Refs. 4, 5). 


\section{NUTS: Radionuclides Transported}

The WIPP is projected to contain 135 distinct radionuclides. ${ }^{22-24}$ Of these, 47 are regulated by 40 CFR 191 , with 25 having more than $0.001 \mathrm{EPA}$ units at some point in time over the $10,000 \mathrm{yr}$ regulatory period (Table 2). In addition, several unregulated isotopes with short half-lives exist that have significant inventory and decay to regulated radionuclides. Inclusion of these radionuclides resulted in a list of 33 radionuclides for possible radionuclide transport in the vicinity of the repository (Table 2 ).

With the exceptions of ${ }^{14} \mathrm{C},{ }^{137} \mathrm{Cs},{ }^{147} \mathrm{Pm},{ }^{90} \mathrm{Sr}$ and ${ }^{232} \mathrm{U}$, the radionuclides in Table 2 belong to the following decay chains:

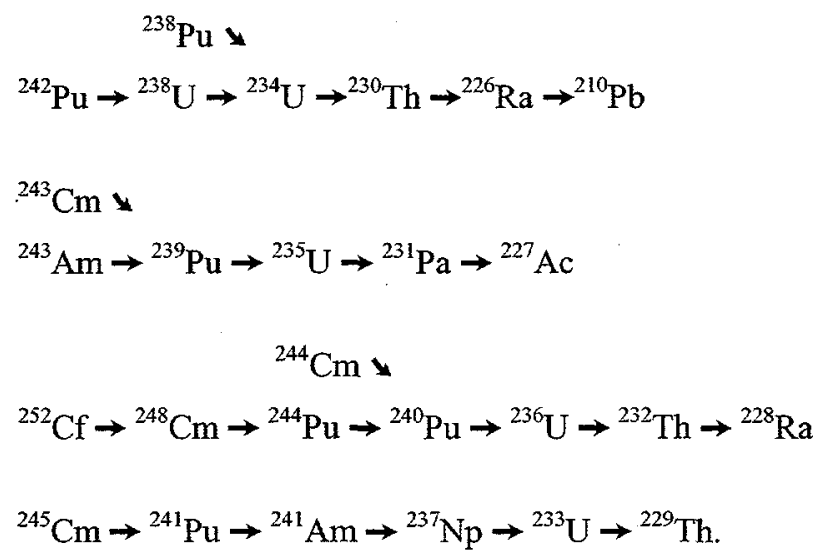

As solution of Eqs. (4) - (5) for this many radionuclides and decay chains is a very time-consuming process, the number of radionuclides for direct inclusion in the analysis had to be reduced. To this end, the indicated radionuclides and decay chains were carefully examined to determine the minimum number of radionuclides required to appropriately assess the WIPP's compliance with 40 CFR 191.

Initially, radionuclides with low EPA inventories or short half-lives were dropped from consideration. In particular, radionuclides having maximum EPA inventories less than or equal to the maximum inventory of ${ }^{237} \mathrm{~Np}$ were dropped from consideration. The sum of the maximum EPA units dropped from consideration was 1.6 EPA units, which is approximately $0.01 \%$ of the total EPA units in the repository. Nearly the entire inventory of these radionuclides would have to be released from the repository to produce a situation with the potential to cause a violation of 40 CFR 191. If conditions occurred that could cause such a large release of these radionuclides, then large releases of other more important radionuclides would also occur and dominate the size of the total release.

Although ${ }^{137} \mathrm{Cs}$ and ${ }^{90} \mathrm{Sr}$ have large initial inventories, they were dropped from consideration because of the rapidity with which their initial inventories decayed to less than $1 \mathrm{EPA}$ unit (i.e., $136 \mathrm{yr}$ for ${ }^{137} \mathrm{Cs}$ and 128 yr for

${ }^{90} \mathrm{Sr}$ ). Short-lived, and therefore unregulated radionuclides, at the top of decay chains were examined to determine if their decay could significantly increase the inventory of important radionuclides, with this examination resulting in 
the decision to retain ${ }^{241} \mathrm{Pu}$ for inclusion in the analysis. At this point, the following 10 radionuclides accounting for $98.9 \%$ of the initial EPA units in the waste remained (Fig. 1):

$$
\begin{aligned}
& { }^{238} \mathrm{Pu} \rightarrow{ }^{234} \mathrm{U} \rightarrow{ }^{230} \mathrm{Th} \\
& { }^{241} \mathrm{Pu} \rightarrow{ }^{241} \mathrm{Am} \rightarrow{ }^{233} \mathrm{U} \rightarrow{ }^{229} \mathrm{Th} \\
& { }^{242} \mathrm{Pu},{ }^{240} \mathrm{Pu},{ }^{239} \mathrm{Pu} .
\end{aligned}
$$

The remaining 10 radionuclides were then further reduced by combining radionuclides that have similar decay and transport properties. In particular, ${ }^{234} \mathrm{U},{ }^{230} \mathrm{Th}$ and ${ }^{239} \mathrm{Pu}$ were used as surrogates for the groups $\left\{{ }^{234} \mathrm{U},{ }^{233} \mathrm{U}\right\}$, $\left\{{ }^{230} \mathrm{Th},{ }^{229} \mathrm{Th}\right\}$ and $\left\{{ }^{242} \mathrm{Pu},{ }^{239} \mathrm{Pu},{ }^{240} \mathrm{Pu}\right\}$, with the initial inventories of ${ }^{234} \mathrm{U},{ }^{230} \mathrm{Th}$ and ${ }^{239} \mathrm{Pu}$ being redefined to account for the additional radionuclide(s) in each group. In redefining the initial inventories, the individual radionuclides were combined on either a mole or Curie basis (i.e., moles added and then converted back to Curies or Curies added directly). In each case, the method that maximized the combined inventory was used, i.e.; ${ }^{233} \mathrm{U}$ was Curie added to ${ }^{234} \mathrm{U},{ }^{240} \mathrm{Pu}$ was Curie added to ${ }^{239} \mathrm{Pu}$, ${ }^{242} \mathrm{Pu}$ was mole added to ${ }^{239} \mathrm{Pu}$, and ${ }^{229} \mathrm{Th}$ was Curie added to

${ }^{230} \mathrm{Th}$. In addition, ${ }^{241} \mathrm{Pu}$ was mole added to ${ }^{241} \mathrm{Am}$ because it has a half life of 14 years and will quickly decay to ${ }^{241} \mathrm{Am}$, and neglect of this ingrowth would underestimate the ${ }^{241} \mathrm{Am}$ inventory by about $3 \%$ (Table 3 ). The outcome of this process was the following 5 radionuclides and 3 simplified decay chains:

$$
{ }^{241} \mathrm{Am},{ }^{238} \mathrm{Pu} \rightarrow{ }^{234} \mathrm{U} \rightarrow{ }^{230} \mathrm{Th},{ }^{239} \mathrm{Pu},
$$

which were then used with Eqs. (4) - (5) for transport in the vicinity of the repository and also for transport in the Culebra Dolomite ${ }^{9}$, with Pu-238 omitted from transport in the Culebra due to its short half life (i.e., $87.7 \mathrm{yr}$ ).

\section{NUTS: Numerical Solution}

Eqs. (4) - (5) are numerically solved by the NUTS program 20,25 on the same computational grid (Fig. 1, Ref. 13) used by BRAGFLO in the solution of Eqs. (2) - (7) of Ref. 13. In the solution procedure, Eq. (4) is numerically solved with $S_{l}=0$ for each time step, with the instantaneous updating of concentrations indicated in Eqs. (6) - (9) and the appropriate modification to $C_{S l}$ in Eq. (5) taking place after the time step. The solution is carried out for the 5 radionuclides indicated in Eq. (19).

The initial value and boundary value conditions used with Eqs. (4) - (5) are given in Table 4. At time $t=0$ (i.e., year 2033), the total inventory of each radionuclide is assumed to be in brine; the solubility constraints associated with Eqs. (6) - (9) then immediately adjust the values for $C_{b l}(x, y, t)$ and $C_{s l}(x, y, t)$ for consistency with the constraints imposed by $S_{[}[B r(t), O x(l), E l(l)]$ and available radionuclide inventory.

The $n R$ partial differential equations in Eq. (4) are discretized in two dimensions and then developed into a linear system of algebraic equations for numerical implementation. The following conventions are used in the 
representation of each discretized equation: (i) the subscript $b$ is dropped from $C_{b l}$, with the result that the unknown function is represented by $C_{l}$, (ii) a superscript $n$ denotes time $\left(t_{n}\right)$, with the assumption that the solution $C_{l}$ is known at time $t_{n}$ and is to be advanced (i.e., computed) at time $t_{n+1}$, (iii) the grid indices are $i$ in the $x$-direction, $j$ in the $y$-direction, and are identical with the BRAGFLO grid indices; fractional indices refer to quantities evaluated at grid block interfaces, and (iv) each time step by NUTS is equal to 20 BRAGFLO time steps, which results because BRAGFLO reported (i.e., stored) results (i.e., $\mathbf{v}_{b}, \phi, S_{b}$ ) every 20 time steps. The following finite difference discretization is used for the $l^{\text {th }}$ equation in each grid block $i, j$ :

$$
\begin{aligned}
& q_{b, i+1 / 2, j}^{n+1} C_{l, i+1 / 2, j}^{n+1}-q_{b, i-1 / 2, j}^{n+1} C_{l, i-1 / 2, j}^{n+1}+q_{b, i, j+1 / 2}^{n+1} C_{l, i, j+1 / 2}^{n+1}-q_{b, i, j-1 / 2}^{n+1} C_{l, i, j-1 / 2}^{n+1}= \\
& \frac{V_{R, i, j}}{\Delta t}\left[\left\{\phi_{i, j} S_{b_{i, j}} C_{l, i, j}\right\}^{n+1}-\left\{\phi_{i, j} S_{b_{i, j}} C_{l, i, j}\right\}^{n}\right]+V_{R, i, j}\left\{\phi_{i, j} S_{b_{i, j}} C_{l, i, j}\right\}^{n+1} \lambda_{l}-V_{R, i, j}\left(\phi_{i, j} S_{b_{i, j}}\right)^{n+1} \sum_{p \in P(l)} C_{p, i, j}^{n+1} \lambda_{p},
\end{aligned}
$$

where $q_{b}$ is the grid block interfacial brine flow rate $\left(\mathrm{m}^{3} / \mathrm{s}\right)$ and $V_{R}$ is the grid block volume $\left(\mathrm{m}^{3}\right)$. The quantity $q_{b}$ is based on $v_{b}$ and $\alpha$ in Eq. (4), and the quantity $V_{R}$ is based on grid block dimensions (Fig. 1, Ref. 13) and $\alpha$.

The interfacial values of concentration in Eq. (21) are discretized using the one-point upstream weighting method (Ref. 26), which results in

$$
\begin{aligned}
& q_{b, i+1 / 2, j}^{n+1}\left(\omega_{i+1} C_{l, i, j}^{n+1}+\left(1-\omega_{i+1}\right) C_{l, i+1, j}^{n+1}\right)-q_{b, i-1 / 2, j}^{n+1}\left(\omega_{i} C_{l, i-1, j}^{n+1}+\left(1-\omega_{i}\right) C_{l, i, j}^{n+1}\right) \\
& +q_{b, i, j+1 / 2}^{n+1}\left(\omega_{j+1} C_{l, i, j}^{n+1}+\left(1-\omega_{j+1}\right) C_{l, i, j+1}^{n+1}\right)-q_{b, i, j-1 / 2}^{n+1}\left(\omega_{j} C_{b, i, j-1}^{n+1}+\left(1-\omega_{j}\right) C_{l, i, j}^{n+1}\right) \\
& =\frac{V_{R, i, j}}{\Delta t}\left[\left\{\phi_{i, j} S_{b_{i, j}} C_{l, i, j}\right\}^{n+1}-\left\{\phi_{i, j} S_{b_{i, j}} C_{l, i, j}\right\}^{n}\right]+V_{R, i, j}\left\{\phi_{i, j} S_{b_{i, j}} C_{l, i, j}\right\}^{n+1} \lambda_{l} \\
& -V_{R, i, j}\left(\phi_{i, j} S_{b_{i, j}}\right)^{n+1} \sum_{p \in P(l)} C_{p, i, j}^{n+1} \lambda_{p},
\end{aligned}
$$

where $\omega$ derives from the upstream weighting for flow between adjacent grid blocks and is defined by

$$
\omega_{i}= \begin{cases}1 & \text { if flow is from grid block } i-1, j \text { to grid block } i, j \\ 0 & \text { otherwise }\end{cases}
$$


$\omega_{j}= \begin{cases}1 & \text { if flow is from grid block } i, j-1 \text { to grid block } i, j \\ 0 & \text { otherwise. }\end{cases}$

By collecting similar terms, Eq. (22) can be represented by the linear equation

$$
A C_{l, i, j-1}^{n+1}+B C_{l, i-1, j}^{n+1}+D C_{l, i, j}^{n+1}+E C_{l, i+1, j}^{n+1}+F C_{l, i, j+1}^{n+1}=R_{l, i, j}
$$

where

$$
\begin{gathered}
A=-\omega_{j} q_{b, i, j-1 / 2}^{n+1}, B=-\omega_{i} q_{b, i-1 / 2, j}^{n+1}, E=\left(1-\omega_{i+1}\right) q_{b, i+1 / 2, j}^{n+1}, F=\left(1-\omega_{j+1}\right) q_{b, i, j+1 / 2}^{n+1}, \\
\begin{array}{c}
D=-\left(1-\omega_{j}\right) q_{b, i, j-1 / 2}^{n+1}-\left(1-\omega_{i}\right) q_{b, i-1 / 2, j}^{n+1}+\omega_{j+1} q_{b, i, j+1 / 2}^{n+1}+\omega_{i+1} q_{j, i+1 / 2}^{n+1}, \\
-\frac{V_{R, i, j}}{\Delta t}\left\{\phi_{i, j} S_{b_{i, j}}\right\}^{n+1}+V_{R, i, j}\left\{\phi_{i, j} S_{b_{i, j}}\right\}^{n+1} \lambda_{l} \\
R_{l, i, j}=-\frac{V_{R, i, j}}{\Delta t}\left\{\phi_{i, j} S_{b_{i, j}} C_{l, i, j}\right\}^{n}-V_{R, i, j}\left(\phi_{i, j} S_{b_{i, j}}\right)^{n+1} \sum_{p \in P(l)} C_{p, i, j}^{n+1} \lambda_{p} .
\end{array}
\end{gathered}
$$

Given the form of Eq. (24), the solution of Eq. (4) has now been reduced to the solution of $n R \times n G$ linear algebraic equations in $n R \times n G$ unknowns, where $n R$ is the number of equations for each grid block (i.e., the number of radionuclides) and $n G$ is the number of grid blocks into which the spatial domain is discretized (Fig. 1, Ref. 13).

The system of partial differential equations in Eq. (4) is strongly coupled because of the contribution from parental decay to the equation governing the immediate daughter. Consequently, a sequential method is used to solve the system in which radionuclide concentrations are solved for by starting at the top of a decay chain and working down from parent to daughter. This implies that when solving Eq. (24) for the $t^{\text {th }}$ isotope concentration, all parent concentrations occurring in the right hand side term $R$ are known. The resulting system of equations is then linear in the concentrations of the $l^{\text {th }}$ isotope. As a result, solution of Eq. (4) is reduced from the solution of one algebraic equation at each time step with $n R \times n G$ unknowns to the solution of $n R$ algebraic equations each with $n G$ unknowns at each time step, which can result in a significant computational savings.

The matrix resulting from one-point upstream weighting has the following structural form for a $3 \times 3$ system of grid blocks and a similar structure for a larger number of grid blocks: 


\begin{tabular}{|l|lllllllll|}
\hline & 1 & 2 & 3 & 4 & 5 & 6 & 7 & 8 & 9 \\
\hline 1 & $\mathrm{X}$ & $\mathrm{X}$ & 0 & $\mathrm{X}$ & & & & & \\
2 & $\mathrm{X}$ & $\mathrm{X}$ & $\mathrm{X}$ & 0 & $\mathrm{X}$ & & & & \\
3 & 0 & $\mathrm{X}$ & $\mathrm{X}$ & 0 & 0 & $\mathrm{X}$ & & & \\
4 & $\mathrm{X}$ & 0 & 0 & $\mathrm{X}$ & $\mathrm{X}$ & 0 & $\mathrm{X}$ & & \\
5 & & $\mathrm{X}$ & 0 & $\mathrm{X}$ & $\mathrm{X}$ & $\mathrm{X}$ & 0 & $\mathrm{X}$ & \\
6 & & & $\mathrm{X}$ & 0 & $\mathrm{X}$ & $\mathrm{X}$ & 0 & 0 & $\mathrm{X}$ \\
7 & & & & $\mathrm{X}$ & 0 & 0 & $\mathrm{X}$ & $\mathrm{X}$ & 0 \\
8 & & & & & $\mathrm{X}$ & 0 & $\mathrm{X}$ & $\mathrm{X}$ & $\mathrm{X}$ \\
9 & & & & & & $\mathrm{X}$ & 0 & $\mathrm{X}$ & $\mathrm{X}$ \\
\hline
\end{tabular}

where $X$ designates possible nonzero matrix entries, and 0 designates zero entries. Entries outside of the banded structure are zero. Because of this structure, a banded direct elimination solver (Sect. 8.2.1, Ref. 26) is used to solve the linear system for each radionuclide. The bandwidth is minimized by indexing equations first in the coordinate direction having the minimum number of grid blocks. The coefficient matrix is stored in this banded structure and all infill coefficients calculated during the elimination procedure are contained within the band structure. Therefore, for the matrix system in two dimensions, a pentadiagonal matrix of dimension $I B W \times n G$ is inverted instead of a full $n G \times n G$ matrix, where $I B W$ is the band width.

The numerical implementation of Eq. (5) enters the solution process through an updating of the radionuclide concentrations in Eq. (23) between each time step as indicated in Eqs. (6) - (9).

The numerical solution of Eqs. (4) and (5) also generates the concentrations required for the numerical evaluation of the integral that defines $C_{l}(t, \mathrm{~B})$ in Eq. (13).

Additional information on NUTS and its use in the 1996 WIPP PA can be found in the NUTS users manual25 and in the analysis package for Salado transport calculations. ${ }^{20}$ Further, additional information on dissolved and colloidal actinides is given in Ref. 27.

\section{PANEL: Mathematical Description}

A relatively simple mixed-cell model is used for radionuclide transport in the vicinity of the repository when connecting flow between two drilling intrusions into the same waste panel is assumed to take place (i.e., an E2E1 intrusion). With this model, the amount of radionuclide $l$ contained in a waste panel is represented by

$$
d A_{l} / d t=-r_{b} C_{b l}-\lambda_{l} A_{l}+\sum_{p \in P(l)} \lambda_{p} A_{p}
$$


where $A_{l}(t)=$ amount $(\mathrm{mol})$ of radionuclide $l$ in waste panel at time $t, C_{b l}(t)=$ concentration $\left(\mathrm{mol} / \mathrm{m}^{3}\right)$ of radionuclide $l$ in brine in waste panel at time $t$ (see Eqs. (26) $-(27)), r_{b}(t)=$ rate $\left(\mathrm{m}^{3} / \mathrm{s}\right)$ at which brine flows out of the repository at time $t$ (supplied by BRAGFLO from solution of Eqs. (2) - (7) of Ref. 13), and $\lambda_{l}$ and $\mathrm{P}(l)$ are defined in conjunction with Eqs. (4) - (5).

The brine concentration $C_{b l}$ in Eq. (25) is defined by

$$
\begin{aligned}
C_{b l}(t)= & S_{T}[B r(t), O x(l), E l(l)] M F_{l}(t) \\
& \text { if } S_{T}[B r(t), O x(l), E l(l)] \leq \sum_{k \in E(l)} A_{k}(t) / V_{b}(t) \\
= & A_{l}(t) / V_{b}(t), \\
& \text { if } \sum_{k \in E(l)} A_{k}(t) / V_{b}(t)<S_{T}[B r(t), O x(l), E l(l)]
\end{aligned}
$$

where

$M F_{l}(t)=$ mole fraction of radionuclide $l$ in waste panel at time $t$

$$
=A_{l}(t) / \sum_{k \in E(l)} A_{k}(t)
$$

$V_{b}(t)=$ volume $\left(\mathrm{m}^{3}\right)$ of brine in waste panel at time $t$ (supplied by BRAGFLO from solution of Eqs. (2) - (7) of Ref. 13),

and $S_{7}[\operatorname{Br}(t), O x(l), E l(l)]$ and $\mathrm{E}(l)$ are defined in conjunction with Eqs. (6) - (10). For use in Eqs. (26) and (27), $S_{T}[B r(t), O x(l), E l(l)]$ must be expressed in units of molll. In words, $C_{b l}(t)$ is defined to be the maximum brine concentration specified in Table 1 if there is sufficient radionuclide inventory in the waste panel to generate this concentration (Eq. (26)); otherwise, $C_{b l}(t)$ is defined by the concentration that results when all the relevant element in the waste panel is placed in solution (Eq. (27)).

$$
\begin{aligned}
& \text { Given } r_{b} \text { and } C_{b l} \text {, evaluation of the integral } \\
& R_{l}(t)=\int_{b}^{t} r_{b} C_{b l} d t
\end{aligned}
$$

provides the cumulative release $R_{l}(t)$ of radionuclide $l$ from the waste panel through time $t$.

The preceding model was used in two ways in the 1996 WIPP PA. First, Eq. (29) was used to estimate releases associated with E2E1 intrusions (Sect. 8). Second, with $r_{b}$ set to a very small number and $V_{b}$ set to a fixed value, 
Eqs. (26) - (27) were used to estimate radionuclide concentrations for use in the estimation of direct brine releases (Sect. 10, Ref. 8).

\section{PANEL: Radionuclides Transported}

When used for E2E1 intrusions, the results in Eqs. (25) - (29) were calculated for all isotopes of americium, curium, neptunium, plutonium, thorium and uranium in Table 2. Then, the release was converted to ${ }^{234} \mathrm{U},{ }^{239} \mathrm{Pu}$,

${ }^{230} \mathrm{Th}$ and ${ }^{241} \mathrm{Am}$ as indicated in Table 3 for transport in the Culebra. When used to support the calculation of direct brine releases, Eqs. (25) - (27) were used to obtain time-dependent concentrations for all isotopes of the preceding elements in Table 2 that have EPA release limits. Then, these individual concentrations were used to obtain an overall concentration (EPA units $/ \mathrm{m}^{3}$ ).

\section{PANEL: Numerical Solution}

The results in Eqs. (25) - (29) are numerically evaluated by the PANEL model. ${ }^{28}$ For E2E1 intrusions, the initial values are the inventories of the isotopes of americium, curium, neptunium, plutonium, thorium and uranium in Table 2 at the time of the $\mathrm{E} 1$ intrusion; these inventories for intrusions at 100,350 and 10,000 $\mathrm{yr}$ are listed in Table 2. For use as part of the direct brine release calculations, the initial values are the values for $A_{l}(0)$ (i.e., for $t=$ $0 \mathrm{yr}$ ) in Table 2 for the radionuclides with EPA release limits.

A discretization based on $50 \mathrm{yr}$ or smaller time steps is used by PANEL to evaluate the results in Eqs. (25) (29). Specifically, Eq. (25) is evaluated with the approximation

$$
\left.A_{l}\left(t_{n+1}\right)=A_{l}\left(t_{n}\right)-\left[\int_{t_{n}}^{n+1} r_{b}(\tau) d \tau\right]\right] C_{b l}\left(t_{n}\right)-A_{l}\left(t_{n}\right) \exp \left(-\lambda_{l} \Delta t\right)+G_{l}\left(t_{n}, t_{n+1}\right)
$$

where $G_{l}\left(t_{n}, t_{n+1}\right)=$ gain in radionuclide $l$ due to the decay of precursor radionuclides between $t_{n}$ and $t_{n+1}$ (see Eq. (31)) and $\Delta t=t_{n+1}-t_{n}=50 \mathrm{yr}$. As the solution progresses, values for $C_{b l}\left(t_{n}\right)$ are updated in consistency with Eqs. (26) - (27) and the products $r_{b}\left(t_{n}\right) C_{b l}\left(t_{n}\right)$ are accumulated to provide an approximation to $R_{l}$ in Eq. (29).

The term $G_{l}\left(t_{n}, t_{n+1}\right)$ in Eq. (30) is evaluated with the Bateman equations, ${ }^{29}$ with PANEL programmed to handle up to 4 succeeding generations of a given radionuclide (i.e., decay chains of length 5). As a single example, if radionuclide $l$ is the third radionuclide in a decay chain (i.e., $l=3$ ) and the two preceding radionuclides in the decay chain are designated by $l=1$ and $l=2$, then 


$$
\begin{aligned}
G_{3}\left(t_{n}, t_{n+1}\right)= & \lambda_{2} A_{2}\left(t_{n}\right)\left[\exp \left(-\lambda_{2} \Delta t\right)-\exp \left(-\lambda_{3} \Delta t\right)\right] /\left(\lambda_{3}-\lambda_{2}\right) \\
& +\lambda_{1} \lambda_{2} A_{1}\left(t_{n}\right)\left\{\left[\exp \left(-\lambda_{1} \Delta t\right)\right] /\left[\left(\lambda_{2} \lambda_{1}\right)\left(\lambda_{3} \lambda_{1}\right)\right]\right. \\
& +\left[\exp \left(-\lambda_{2} \Delta t\right)\right] /\left[\left(\lambda_{3}-\lambda_{2}\right)\left(\lambda_{1}-\lambda_{2}\right)\right] \\
& \left.+\left[\exp \left(-\lambda_{3} \Delta t\right)\right] /\left[\left(\lambda_{1}-\lambda_{3}\right)\left(\lambda_{2}-\lambda_{3}\right)\right]\right\}
\end{aligned}
$$

in Eq. (30).

Additional information on PANEL and its use in the 1996 WIPP PA calculations can be found in the PANEL user's manual ${ }^{28}$ and the analysis package for Salado transport calculations. ${ }^{20}$

\section{Release to Culebra: Uncertainty and Sensitivity Analysis}

Radionuclide releases to the Culebra Dolomite were calculated with the NUTS and PANEL programs for the 300 Latin hypercube sample (LHS) elements in Eq. (7) of Ref. 12. In turn, these programs used brine flow patterns calculated by BRAGFLO for the corresponding sample elements as input (Table 6, Ref. 11). Six sets of BRAGFLO calculations were used to support the estimation of radionuclide releases to the Culebra: E0 (i.e., undisturbed conditions), E1 intrusion at $350 \mathrm{yr}, \mathrm{E} 1$ intrusion at $1000 \mathrm{yr}, \mathrm{E} 2$ intrusion at $350 \mathrm{yr}, \mathrm{E} 2$ intrusion at $1000 \mathrm{yr}$, and E2E1 intrusion with the $\mathrm{E} 2$ intrusion at $800 \mathrm{yr}$ and the $\mathrm{E} 1$ intrusion at $2000 \mathrm{yr}$ (Table 5). In turn, the preceding BRAGFLO calculations were used to supply brine flows for use in calculations with NUTS or PANEL (Table 5). In particular, the BRAGFLO results for EO conditions were used as input to calculations with NUTS for radionuclide transport under undisturbed conditions. Further, the BRAGFLO results for E1 and E2 intrusions at 350 yr were used as input to NUTS calculations for intrusions at $100 \mathrm{yr}$ and also at $350 \mathrm{yr}$. For the $100 \mathrm{yr}$ intrusion, the flow pattern used in NUTS subsequent to the intrusion is assumed to be the same as the flow pattern predicted by BRAGFLO subsequent to an intrusion at $350 \mathrm{yr}$. Similarly, the BRAGFLO results for E1 and E2 intrusions at $1000 \mathrm{yr}$ were used as input to NUTS calculations for intrusions at 1000,3000,5000, 7000 and $9000 \mathrm{yr}$, with the calculations for transport subsequent to intrusions at $3000,5000,7000$ and $9000 \mathrm{yr}$ performed with the flow patterns obtained from $1000 \mathrm{yr}$ on in the BRAGFLO calculations. As described in Table 6 of Ref. 11, each potential NUTS calculation was preceded by a preliminary screening calculation to determine if a full NUTS calculation was required, with full NUTS calculations only being performed for sample elements that had the potential to result in radionuclide releases to the Culebra or the accessible environment. Finally, the BRAGFLO results for the E2E1 intrusion were used as input to PANEL for calculations in which the second (i.e., E1) intrusion was assumed to be in place at 100,350, 1000, 2000, 4000, 6000 and $9000 \mathrm{yr}$. Again, the assumption is made that the flow patterns after the intrusions at 100, 350, 1000, 4000,6000 and $9000 \mathrm{yr}$ are the same as the flow patterns after $2000 \mathrm{yr}$ in the BRAGFLO calculation for the E2E1 intrusion.

Radionuclide release from the repository to the Culebra depends on both the amount of brine flow and the amount of radionuclide that can be transported in this flow. Radionuclides are assumed to exist in five states that can 
be transported from the repository by flowing groundwater: dissolved, humic colloids, microbial colloids, mineral fragment colloids, and actinide intrinsic colloids. Typically, the concentration in each of these states is a function of one or more sampled variables (Table 1, Fig. 2). The "Total" concentrations in Fig. 2 are the concentrations used in the NUTS and PANEL calculations to determine releases from the repository to the Culebra. In the computational implementation of the analysis, the concentrations in Fig. 2 are only realized in individual computational cells if there is adequate inventory in the cell to produce this concentration; otherwise, the concentration is set by assuming all of the relevant element is present in the brine contained in that cell. The effect of inventory depletion due to radioactive decay can be seen in the structure of the total concentration curves in Fig. 14 of Ref. 8. Further, the concentrations are a function of whether repository conditions are dominated by Salado or Castile brine (Table 1).

Radionuclide releases to the Culebra only occur for sample elements for which BRAGFLO predicts nonzero brine flows from the repository to the Culebra. For most sample elements, brine flow from the repository is zero or very small (Fig. 44, Ref. 18) and so little or no radionuclide transport takes place (Fig. 3). For E1 and E2E1 intrusions, most of the release takes place over a relatively short period of time and then continues at a reduced rate or stops entirely. This behavior results from (i) an initial $200 \mathrm{yr}$ period during which an open borehole exists between the repository and the brine pocket, (ii) a subsequent $1000 \mathrm{yr}$ period in which the borehole over its entire length has permeability $k=10^{x}, x=B H P R M$ (see Table 1, Ref. 12, for the definition of $B H P R M$ and other variables discussed in this presentation), and (iii) a reduction of the permeability below the repository to $k=10^{x} / 10, x=$ BHPRM, after 1200 yr (Table 8, Ref. 13). For the E2E1 intrusion and a few sample elements, a release occurs before the E1 intrusion due to brine flow up the borehole associated with the preceding E2 intrusion. Most sample elements result in little or no release for E1 and E2E1 intrusions due to limited brine flow (Fig. 44, Ref. 18). Even fewer sample elements result in releases for E2 intrusions; again, this is due to limited brine flow from the repository to the Culebra (Fig. 44, Ref. 18). However, given equal-sized brine flows, an E2 intrusion will produce a larger release than an E1 or E2E1 intrusion because solubilities in Salado-dominated brines are higher than solubilities in Castile-dominated brines (Fig. 2). This behavior results in the largest release curves in Fig. 3 for E2 intrusions exceeding the largest release curves for E1 and E2E1 intrusions.

Results are presented in Fig. 3 for only two of the intrusion times used in the NUTS and PANEL calculations indicated in Table 5. A summary of the cumulative releases over 10,000 yr for all intrusion times is given in Fig. 4. As should be the case, the size of the release decreases with increasing intrusion time due to increased time for radioactive decay and decreased time for transport from the repository to the Culebra. However, at all times, most sample elements result in no significant releases to the Culebra.

The total normalized releases in Figs. 3 and 4 are based on Am-241, Pu-238, Pu-239, U-234 and Th-230 (Figs. 5 - 7). At early times (i.e., 100 and $350 \mathrm{yr}$ ), the release tends to be dominated by Am-241, with an additional contribution from Pu-238 at very early times. With increasing time, Am-241 is lost due to decay and the release is dominated by $\mathrm{Pu}-239$ due to its long half life and large inventory. 
The occurrence of releases for E2 intrusions is dominated by BHPRM (Fig. 8). For small values of BHPRM, there is not enough flow down the borehole to fill the intruded waste panel with brine and so a release up the borehole to the Culebra will not take place (Sect. 6, Ref. 18). A similar effect also occurs for the logarithm of anhydrite permeability (ANHPRM) (Fig. 8).

For E1 intrusions, releases tend to be associated with larger values for the logarithm of the bulk compressibility of the brine pocket (BPCOMP) (Fig. 9). This association occurs because increasing BPCOMP tends to increase the brine flows from the brine pocket to the repository (Fig. 11, Ref. 18), thus increasing the likelihood that the intruded waste panel will fill with brine. There is also a tendency for the size of the release to the Culebra to increase as BHPRM increases (Fig. 9). This effect results because increasing BHPRM increases both the amount of brine that flows down the borehole from overlying formations and the amount of brine that flows up the borehole from the brine pocket. However, due to the effects of BPCOMP, less influence is exerted by BHPRM in determining whether or not a release occurs than is the case for the E2 intrusion.

Due to the large number of zero releases, a stepwise regression analysis is not very revealing as a sensitivity analysis procedure for E1 and E2 intrusions. However, the greater number of nonzero releases associated with E2E1 intrusions makes stepwise regression analysis a possibility for this intrusion mode (Table 6). The regression analyses in Table 6 were performed with the STEPWISE program, ${ }^{30,31}$ rank-transformed data, ${ }^{32}$ and the requirements that a variable have an $\alpha$-value of 0.02 to enter a regression model and an $\alpha$-value of 0.05 to be retained in a regression model (Sect. 3.5, Ref. 16).

In constructing the regression models in Table 6, the candidate independent variables included the original sampled variables and also the solubilities for individual elements (i.e., SOLAMC, SOLPUC, SOLTHC, SOLUC, where $A M, P U, T H$ and $U$ designate americium, plutonium, thorium and uranium, respectively, and $C$ designates Castile brine; see Table 6, Ref. 8). As a reminder, elemental solubilities change as a function of brine type (i.e., Salado or Castile) and several sampled variables (Table 1). By including the actual solubilities used in the PANEL calculations for E2E1 intrusions rather than only the sampled variables, the effects of the actual solubility used in the calculation will be shown. In interpreting the analysis results, two properties of the analysis should be kept in mind. First, calculations for E2E1 intrusions use the solubilities for Castile brine. Second, the solubilities in Tables 1 and 6 are only realized if there is a sufficient quantity of the element in the waste panel; otherwise, the amount of material that can go into solution is limited by the amount present. Such inventory limits occur for both Am-241 and Pu-238.

The regressions in Table 6 for the individual radionuclides and also for the total release in EPA units are very similar. In particular, the releases are dominated by BHPRM and BPCOMP, with the size of the release tending to increase as each of these variables increases. These positive effects result because increasing BHPRM tends to increase the rate at which the intruded waste panel fills with brine due to flow down the borehole, and increasing BPCOMP tends to increase the rate at which the intruded waste panel fills with brine due to flow up the borehole 
from the brine pocket. Also, increasing BHPRM reduces resistance to flow in the borehole from the brine pocket to the waste panel and also from the waste panel to the Culebra. The third variable selected in most analyses is the solubility for the radionuclide under consideration (i.e., SOLAMC, SOLPUC or SOLUC), with release size tending to increase as solubility increases. However, the effect of solubility is less than that of BHPRM and BPCOMP, which is due in part to the significant number of observations that have no brine flow, and hence no radionuclide release, to the Culebra.

In addition, positive effects are indicated for initial pressure in brine pocket (BPINTPRS), pointer variable for selection of brine pocket volume (BPVOL) and $A N H P R M$, and negative effects are indicated for corrosion rate for steel under inundated conditions in the absence of $\mathrm{CO}_{2}(W G R C O R)$ and pointer variable for microbial degradation of cellulose (WMICDFLG) (Table 6). Increasing BPINTPRS and BPVOL increases the amount of brine that flows from the brine pocket to the repository (Table 4, Ref. 18), and increasing ANHPRM increases the amount of brine that flows from the anhydrite marker beds to the repository (Table 2, Ref. 18; also Tables 8.2.2, 8.2.3, Ref. 19). In both cases, the ultimate effect is to increase the rate at which the intruded waste panel fills with brine. In contrast, increasing WGRCOR and WMICDFLG decreases the rate at which the waste panel fills with brine. For WGRCOR, this effect results from an increased loss of brine due to corrosion; it is also possible that the resultant increased gas flow up the borehole may retard the filling of the waste panel due to brine flow down the borehole. For WMICDFLG, the negative effect results primarily from reduced brine flow during the initial 200 yr period that an open borehole is assumed to exist between the brine pocket and the waste panel (Fig. 7, Ref. 18).

For perspective, scatterplots for BHPRM, BPCOMP and the Am-241 release are given in Fig. 10. No releases tend to result for small values of $B H P R M$ and $B P C O M P$ due to a failure to fill the intruded waste panel with brine. Further, given that a release takes place, the size of this release tends to increase as each of BHPRM and BPCOMP increases. Similar patterns also occur for the other radionuclides and the total release. The uncertainty that derives from BHPRM and BPCOMP tends to swamp out the uncertainty associated with solubilities (Fig. 11). In particular, although a positive relationship can be discerned between solubility and the size of the nonzero releases, there is a large amount of variation around this trend.

\section{Release to Culebra: CCDFs}

The CCDFs for release to the accessible environment are constructed conditionally on individual LHS elements by randomly sampling futures from the probability space $\left(\mathrm{S}_{s t}, \&_{s t}, p_{s t}\right)$ associated with stochastic uncertainty as indicated in Eq. (3) (Sects. 10, 11, Ref. 11). The outcomes of this procedure for cuttings, spallings and direct brine release are presented in other articles. 6,8 For groundwater releases to the accessible environment due to transport through the Culebra, a two-step procedure is used. First, time-dependent release rates to the Culebra are constructed for each isotope and each randomly sampled future (Tables 7,8). Second, these release rates are then used in 
conjunction with Culebra transport results calculated with the SECOTP2D program to estimate a normalized release to the accessible environment for each randomly sampled future. ${ }^{9}$ Once these normalized releases are estimated, construction of the CCDF for transport through the Culebra to the accessible environment is straightforward. This section considers only the first step of this procedure, the determination of time-dependent release rates to the Culebra.

The actual radionuclide releases into the Culebra calculated with NUTS and PANEL use the "Total" concentrations in Fig. 2. The division of the release into dissolved and colloidal components in Table 8 is done to facilitate later transport calculations in the Culebra ${ }^{9}$ and has no effect on the release into the Culebra. The fractions $f C E O, f C E 1$ and $f C E 2$ in Table 7 are used to partition the release into the Culebra back into its dissolved and colloidal components. Humic colloids are assumed to transport exactly the same as dissolved radionuclides ${ }^{33}$, with the result that $f C E 0, f C E 1$ and $f C E 2$ are set to 0 for humic colloids. In the computational implementation of the analysis for transport in the Culebra described in Ref. 9, this results in the same SECOTP2D results being used for both dissolved radionuclides and humic colloids. Values for $f C E 1$ and $f C E 2$ are obtained by forming the ratio of corresponding colloidal and total concentrations in Fig. 2 (Fig. 12). As E0 and E2 conditions are both dominated by Salado brine, $f C E O$ is assumed to equal corresponding values for $f C E 2$, although the definition of $f C E O$ has no impact on the analysis because no releases to the Culebra occur for undisturbed conditions.

Conditional on a given LHS element and a given future of the form in Eq. (1) of Ref. 11, $c R T(j, k, 10,000)$ in Table 8 gives the total cumulative release to the Culebra over 10,000 yr of element $k$ of decay chain $j$. These individual releases can then be converted into a total normalized release, which is used in the construction of the corresponding CCDF for normalized release to the Culebra. This construction follows the same procedure and uses the same randomly-sampled futures as used to construct CCDFs for cuttings, spallings and direct brine release. ${ }^{6,8}$ Specifically, 10,000 randomly-sampled futures are generated for each LHS element (Sect. 10, Ref. 11); the corresponding 10,000 normalized releases to the Culebra are evaluated (Table 8), and the resultant CCDF is constructed (Sect. 11, Ref. 11) (Fig. 13), which results in 100 CCDFs for each of the three replicates (Sect. 8, Ref. 12).

With one exception, all the CCDFs in the left frame of Fig. 13 fall beneath the boundary line for release to the accessible environment. As a reminder, a release to the Culebra at the repository is not a release to the accessible environment. The boundary line specified in 40 CFR 191.13(a) is referred to to help the reader assess how much attenuation might be required during transport in the Culebra to result in compliance. As shown by Fig. 13, most sample elements produce releases into the Culebra that would require no attenuation to be in compliance with 40 CFR 191.13(a). A similar pattern is also shown by the other two replicates (Fig. 14), with three CCDFs crossing the boundary line for replicate R2 and no CCDFs crossing for replicate R3 (although 2 CCDFs come close to the boundary line). 
The distributions of CCDFs in Figs. 13 and 14 show a distinct structure, with one group (Group 1) of CCDFs emerging from the ordinate at a probability close to 1, another group (Group 2) emerging at a probability close to 0.25 , and a final group (Group 3) emerging at probabilities close to 0.15 . There are only a few Group 1 CCDFs. These CCDFs result from sample elements that have a nonzero E2 release. Their relatively low likelihood of occurring (i.e., 15 out of 300 sample elements) results because most sample elements result in no brine release, and hence no radionuclide release, to the Culebra for E2 intrusions. However, due to the high drilling rate, an E2 release to the Culebra is almost certain to take place (i.e., a probability very close to 1) if E2 intrusions result in brine flow from the repository to the Culebra. The relatively large releases for Group 1 CCDFs derives from two sources. First, releases for E2 intrusions are calculated with the solubilities for Salado dominated brines, which tend to be higher than the solubilities for Castile dominated brines (Fig. 14, Ref. 8). Second, an additional E2 release is included for the first intrusion into each waste panel for a given future $\mathbf{x}_{s t}$ (Table 8). As a result, the release to the Culebra for a typical future $\mathbf{x}_{s t}$ will be the sum of a number of individual E2 releases. Again, the high drilling rate results in most futures involving intrusions into a number of different waste panels (Table 1, Ref. 11).

The Group 2 CCDFs result from LHS elements that have E1 releases to the Culebra but no E2 releases. As the probability of a given drilling intrusion penetrating pressured brine is 0.08 (actually, an E1 intrusion only occurs if the borehole penetrates a nondepleted pressurized brine pocket and plugging pattern 2 is used, which makes the effective probability of penetrating pressurized brine approximately $(0.08)(0.68) \doteq 0.05$; see Sects. $3.5,3.6$, Ref. 11), these CCDFs emerge from the ordinate at a lower probability than the Group 1 CCDFs. The Group 2 CCDFs tend to have smaller releases than the Group $1 \mathrm{CCDFs}$ for two reasons. First, the E1 releases used in the construction of the Group 2 CCDFs are calculated with solubilities for Castile dominated brine, which tend to be lower than the solubilities for Salado dominated brine used in the calculation of E2 releases (Fig. 14, Ref. 8). Second, the likelihood of futures $\mathbf{x}_{s t}$ that have multiple intrusions that give rise to releases to the Culebra is less for the Group 2 CCDFs than for the Group 1 CCDFs. Each E1 intrusion associated with a future $\mathbf{x}_{s t}$ gives rise to either an E1 or an E2E1 release (Table 8). However, because the probability of penetrating pressurized brine is 0.08 , a given future will not have very many intrusions that penetrate pressurized brine (Table 2, Ref. 11). In contrast, the typical future will have many $\mathrm{E} 2$ intrusions that penetrate different waste panels.

The Group 3 CCDFs result from LHS elements that have E2E1 releases but no E1 or E2 releases. Because E2E1 releases require two drilling intrusions into a waste panel with at least one of these intrusions penetrating pressurized brine, the Group $3 \mathrm{CCDF}$ s emerge from the ordinate at a lower probability than the Group $2 \mathrm{CCDFs}$. As for the Group 2 CCDFs, the releases for Group 3 CCDFs are calculated with solubilities for Castile dominated brines. Due to the requirement for multiple drilling intrusions into a single waste panel to produce an E2E1 release (Table 8), individual futures are less likely to have multiple releases in the construction of Group 3 CCDFs than in the construction of Group 2 CCDFs. 
The Group 3 CCDFs show an interesting structure, with most CCDFs having an abrupt change in slope at probabilities of approximately 0.04 and 0.02 . As examination of Fig. 15 shows, this behavior is due to Am-241, with the Am-241 CCDFs showing a pattern that exactly matches the indicated changes in slope. These changes in slope are probably resulting from a change in the dissolved concentration of Am-241 from being solubility limited (i.e., by SOLAMC) to being inventory limited (Fig. 14, Ref. 8). When concentration is solubility limited, the size of an E2E1 release changes smoothly as a function of the time of the intrusion that produces the E2E1 conditions; similarly when concentration is inventory limited, the size of an E2E1 release again changes smoothly as a function of the time of the intrusion that produces the E2E1 conditions. It is the switch from futures with releases dominated by inventory limited concentrations to futures with releases dominated by solubility limited concentrations that may be producing the changes in slope. It is also possible that the pattern may be due in part to futures that have different numbers of E2E1 intrusions.

The $90^{\text {th }}$ and $50^{\text {th }}$ quantile curves for release to the Culebra are quite stable across the three replicates (Fig. 16); the $10^{\text {th }}$ quantile is degenerate for all three replicates (i.e., replicates R1, R2 and R3 produce 27, 25 and 25 degenerate CCDFs, respectively). In contrast, the location of the mean for releases above 0.1 EPA units shows a considerable amount of variability across the three replicates (Fig. 16). The mean above about 1.0 EPA units for each replicate is being determined by a few (i.e., 1, 2 or 3) CCDFs. As a result, the means for the individual replicates and the mean across all three replicates are being determined by a few outliers and, thus, tend to be unstable. The nonrepresentativeness of the means for release to the Culebra provides an indication of why means associated with skewed distributions are not very informative quantities. Typically, selected quantiles provide more insight into the nature of a distribution, and especially a skewed distribution, than a mean.

As shown by the distributions in Fig. 15, Am-241 and Pu-239 are the dominant contributors to the CCDFs for release to the Culebra, with the largest releases coming from Pu-239. Lesser contributions are made by Th-230 and U-234, with the contribution from Th-230 tending to be larger than that from U-234.

As was done for the cuttings, spallings and blowout release CCDFs, ${ }^{6,8}$ a sensitivity analysis can be performed on the expected release to the Culebra for the CCDFs for the individual isotopes and also for the CCDFs for total release (Table 9). The dominant variables are BHPRM and BPCOMP, with these variables consistently selected first and second in the regression analyses in Table 9. The expected values increase as each of BHPRM and BPCOMP increases. The positive effect for BHPRM results from facilitating the filling of the repository due to brine flow down an intruding borehole and reducing resistance to flow both into the repository from a brine pocket and from the repository to the Culebra. The positive effect for $B P C O M P$ results from increasing brine flow from a brine pocket to the repository and then from the repository to the Culebra. Typically, small positive effects are indicated for the solubilities for the individual elements (i.e., SOLAMC, SOLPU, SOLUC). As most releases occur in association with drilling intrusions involving pressurized brine, it is the solubilities for Castile dominated brines that are being selected in the regression analyses. In addition, positive effects are also indicated for BPINTPRS, BPVOL and 
ANHPRM. Increasing each of these variables tends to increase the amount of brine entering the repository (Table 3 , Ref. 18). Negative effects are indicated for $W G R C O R$ and WMICDFLG. Increasing WGRCOR tends to decrease the amount of brine in the repository by increasing the amount of brine that is consumed by corrosion. Increasing WMICDFLG tends to decrease the amount of brine in the repository by preventing brine flow from the brine pocket to the repository during the $200 \mathrm{yr}$ period subsequent to an E1 intrusion in which an open borehole exists between the repository and the brine pocket (Fig. 7, Ref. 18).

For perspective, scatterplots involving BHPRM, BPCOMP and total release to the Culebra are given in Fig. 17. In consistency with the regression results (Table 9), the release tends to increase as BHPRM and BPCOMP increase. Further, zero releases tend to be associated with small values for these variables, with the association being more pronounced for small values of BHPRM.

\section{Other Release Pathways}

No releases occurred above the Culebra due to brine flow up the shaft or a borehole; thus, $f_{D L}$ and $f_{S}$ in Eq. (1) are zero in the 1996 WIPP PA. No substantive releases to the marker beds were observed (Fig. 18); further, no numerically significant releases to the accessible environment due to transport through marker beds took place, with the result that $f_{M B}$ in Eq. (1) is also zero.

\section{Discussion}

At a conceptual level, radionuclide releases in the vicinity of the repository were treated in the same manner as direct releases to the accessible environment. Thus, the general comments made in the discussions for the direct releases also apply to releases in the vicinity of the repository. 6,8

No releases to the accessible environment took place due to radionuclide movement through the anhydrite marker beds, through the Dewey Lake Red Beds or directly to the surface. Further, releases to the Culebra Dolomite were small. Even when the effects of both subjective and stochastic uncertainty are taken into account, the CCDFs for radionuclide releases to the Culebra generally fall below the boundary line specified by the EPA in 40 CFR 191 . Thus, the 1996 WIPP PA indicates that compliance with 40 CFR 191 can be achieved without the retarding effects of the Culebra.

Whether or not a radionuclide release to the Culebra occurs for a given drilling intrusion is dominated by whether or not the repository fills with brine. If the repository does not fill with brine; then inflowing brine from either the anhydrite marker beds or the brine pocket in the Castile Fm cannot flow from the repository to the Culebra; rather, this brine will simply spread out in the repository. 
For E2 intrusions (i.e., drilling intrusions that do no penetrate pressurized brine in the Castile Fm), borehole permeability $(B H P R M)$ is the dominate factor in determining whether or not a release to the Culebra will occur. In particular, high values for $B H P R M$ permit sufficient brine to flow down the borehole to fill the repository (Sect. 6 , Ref. 18) and also reduce resistance to brine flow up the borehole once the repository (or, at least, the intruded waste panel) is brine saturated. Due to the high permeabilities assigned to the disturbed rock zone in the 1996 WIPP PA, there is significant connectivity between the waste panels (Sect. 8, Ref. 18); thus, brine flowing into the repository may not remain in the waste panel that it enters.

For E1 intrusions (i.e., drilling intrusions that penetrate pressurized brine in the Castile Fm), brine pocket compressibility (BPCOMP) also affects brine flow from the repository to the Culebra due to its influence on the amount of brine that flows from the brine pocket to the repository. Further, BHPRM affects E1 intrusions for the same reasons that it affects $\mathrm{E} 2$ intrusions and also by reducing resistance to brine flow from the brine pocket to the repository. For E1 intrusions in the 1996 WIPP PA, an open borehole is assumed to exist between the brine pocket and the repository for $200 \mathrm{yr}$ after the drilling intrusion (Table 8, Ref. 13), with substantial brine flow from the brine pocket to the repository taking place over this 200 yr period. However, this flow is prevented when sufficiently high pressures exist in the repository over the $200 \mathrm{yr}$ period that the open borehole exists, with the existence of such pressures being determined primarily by the extent to which the microbial degradation of cellulose (WMICDFLG) takes place (Sect. 7, Ref. 18). The indicated effects for BHPRM, BPCOMP and WMICDFLG derive from subjective uncertainty.

The 1996 WIPP PA also considers E2E1 intrusions (i.e., an E2 intrusion followed by an E1 intrusion into the same waste panel). The brine flows from the brine pocket to the repository and also from the repository to the Culebra tend to be larger for E2E1 intrusions than for E1 intrusions because the initial E2 intrusion has the potential to lower repository pressure and thus allow more brine flow from the brine pocket to the repository during the $200 \mathrm{yr}$ period that an open borehole exists.

For a given brine flow to the Culebra, the size of the associated radionuclide release is determined by radionuclide solubility (i.e., SOLAMC, SOLPUC, SOLTHC, SOLUC, SOLAMS, SOLPUS, SOLTHS, SOLUS; see Table 6, Ref. 8). The largest brine releases to the Culebra tend to occur for E1 and E2E1 intrusions; however, the largest radionuclide releases occur for E2 intrusions. This reversal occurs because the solubilities for Saladodominated brines (i.e., SOLAMS, SOLPUS, SOLTHS, SOLUS) tend to be higher than the solubilities for Castiledominated brines (i.e., SOLAMC, SOLPUC, SOLTHC, SOLUC), with the higher Salado-dominated solubilities being used in the calculation of releases to the Culebra for $\mathrm{E} 2$ intrusions and the lower Castile-dominated solubilities being used in the calculation of releases to the Culebra for E1 and E2E1 intrusions (Fig. 2). In contrast, E1 and E2E1 intrusions are more likely to result in radionuclide releases to the Culebra than E2 intrusions because, when the effects of subjective uncertainty are taken into account, E1 and E2E1 intrusions are more likely to have nonzero brine flows from the repository to the Culebra. 
The uncertainty in the radionuclide solubilities derives from subjective uncertainty. However, whether Saladodominated or Castile-dominated solubilities will be used in conjunction with a given drilling intrusion in the construction of CCDFs for release to the Culebra derives from stochastic uncertainty. In particular, drilling intrusion properties associated with the vector $\mathbf{x}_{s t}$ from the sample space $\mathrm{S}_{s t}$ for stochastic uncertainty determines the solubilities used in conjunction with each drilling intrusion associated with $\mathbf{x}_{s t}$. Further, such solubilities may be time-dependent due to radionuclide depletion resulting from radioactive decay (i.e., SOLAMC, SOLPUC, ..., SOLUS are maximum solubilities that are only realized if sufficient radionuclide inventory is present) or the change of a given drilling intrusion from an E2 intrusion to an E2E1 intrusion due to the occurrence of a later E1 intrusion in the same waste panel.

The radionuclide releases to the Culebra obtained in the 1996 WIPP PA are smaller than the releases obtained in earlier PAs. $34-36$ This decrease is due primarily to reduced solubilities and smaller brine flows from the repository to the Culebra.

Ultimately, radionuclide releases to the Culebra have no effect on assessing compliance with the EPA's release limits in 40 CFR 191 in the 1996 WIPP Pa because no radionuclide transport was predicted to take place from the release point in the Culebra above the repository to the boundary with the accessible environment. ${ }^{9}$

\section{Acknowledgment}

Work performed for Sandia National Laboratories (SNL), which is a multiprogram laboratory operated by Sandia Corporation, a Lockheed Martin Company, for the United States Department of Energy under contract DE-AC04-94AL85000. Review provided at SNL by M. Chavez, C. Crawford and M.S. Tierney. Editorial support provided by L. Harrison, T. Allen and H. Radke of Tech Reps, Inc.

\section{References}

1. U.S. Department of Energy, Title 40 CFR Part 191 Compliance Certification Application for the Waste Isolation Pilot Plant, DOE/CAO-1996-2184, Volumes I-XXI, U.S. Department of Energy, Carlsbad Area Office, Carlsbad, NM, 1996.

2. Howard, B.A., Crawford, M.B., Galson, D.A., \& Marietta, M.G., Regulatory Basis for the Waste Isolation Pilot Plant Performance Assessment, Reliability Engineering and System Safety (in this issue).

3. U.S. Environmental Protection Agency, 40 CFR Part 191: Environmental Standards for the Management and Disposal of Spent Nuclear Fuel, High-Level and Transuranic Radioactive Wastes; Final Rule, Federal Register, 1985, 50(182), 38066-38089.

4. U.S. Environmental Protection Agency, 40 CFR Part 191: Environmental Radiation Protection Standards for the Management and Disposal of Spent Nuclear Fuel, High-Level and Transuranic Radioactive Wastes; Final Rule, Federal Register, 1993, 58(242), 66398-66416. 
5. U.S. Environmental Protection Agency, 40 CFR Part 194: Criteria for the Certification and Re-Certification of the Waste Isolation Pilot Plant's Compliance With the 40 CFR Part 191 Disposal Regulations; Final Rule, Federal Register, 1996, 61(28), 5224-5245.

6. Berglund, J.W., Garner, J.W., Helton, J.C., Johnson, J.D., \& Smith, L.N., Direct Releases to the Surface and Associated Complementary Cumulative Distribution Functions in the 1996 Performance Assessment for the Waste Isolation Pilot Plant: Cuttings, Cavings and Spallings, Reliability Engineering and System Safety (in this issue).

7. Knowles, M.K., Hansen, F.D., Thompson, T.W., Gross, M.B., \& Schatz, J.F., Review and Perspectives on Spallings Releases in the 1996 Performance Assessment for the Waste Isolation Pilot Plant, Reliability and System Safety (in this issue).

8. Stoelzel, D.M., O'Brien, D.G., Garner, J.W., Helton, J.C., Johnson, J.D., \& Smith, L.N., Direct Releases to the Surface and Associated Complementary Cumulative Distribution Functions in the 1996 Performance Assessment for the Waste Isolation Pilot Plant: Direct Brine Releases, Reliability Engineering and System Safety (in this issue).

9. Ramsey, J.L., Blaine, R., Gamer, J.W., Helton, J.C., Johnson, J.D., Smith, L.N., \& Wallace, M., Radionuclide and Colloid Transport in the Culebra Dolomite and Associated Complementary Cumulative Distribution Functions in the 1996 Performance Assessment for the Waste Isolation Pilot Plant, Reliability Engineering and System Safety (in this issue).

10. Helton, J.C., Anderson, D.R., Basabilvazo, G., Jow, H.-N., \& Marietta, M.G., Conceptual Structure of the 1996 Performance Assessment for the Waste Isolation Pilot Plant, Reliability Engineering and System Safety (in this issue).

11. Helton, J.C., Davis, F.J., \& Johnson, J.D., Characterization of Stochastic Uncertainty in the 1996 Performance Assessment for the Waste Isolation Pilot Plant, Reliability Engineering and System Safety (in this issue).

12. Helton, J.C., Martell, M.-A., \& Tierney, M.S., Characterization of Subjective Uncertainty in the 1996 Performance Assessment for the Waste Isolation Pilot Plant, Reliability Engineering and System Safety (in this issue).

13. Vaughn, P., Bean, J.E., Helton, J.C., Lord, M.E., MacKinnon, R.J., \& Schreiber, J.D., Representation of TwoPhase Flow in the Vicinity of the Repository in the 1996 Performance Assessment for the Waste Isolation Pilot Plant, Reliability Engineering and System Safety (in this issue).

14. Helton, J.C., Anderson, D.R., Basabilvazo, G., Jow, H.-N., \& Marietta, M.G., Summary Discussion of the 1996 Performance Assessment for the Waste Isolation Pilot Plant, Reliability Engineering and System Safety (in this issue).

15. McKay, M.D., Beckman, R.J., \& Conover, W.J., A Comparison of Three Methods for Selecting Values of Input Variables in the Analysis of Output from a Computer Code, Technometrics, 1979, 21(2), 239-245.

16. Helton, J.C., Uncertainty and Sensitivity Analysis Techniques for Use in Performance Assessment for Radioactive Waste Disposal, Reliability Engineering and System Safety, 1993, 42(2-3), 327-367.

17. Helton, J.C., Bean, J.E., Economy, K., Garner, J.W., MacKinnon, R.J., Miller, J., Schreiber, J.D., \& Vaughn, P., Uncertainty and Sensitivity Analysis for Two-Phase Flow Conditions in the Vicinity of the Repository in the 1996 Performance Assessment for the Waste Isolation Pilot Plant: Undisturbed Conditions, Reliability Engineering and System Safety (in this issue).

18. Helton, J.C., Bean, J.E., Economy, K., Garner, J.W., MacKinnon, R.J., Miller, J., Schreiber, J.D., \& Vaughn, P., Uncertainty and Sensitivity Analysis for Two-Phase Flow in the Vicinity of the Repository in the 1996 
Performance Assessment for the Waste Isolation Pilot Plant: Disturbed Conditions, Reliability Engineering and System Safety (in this issue).

19. Helton, J.C., Bean, J.E., Berglund, J.W., Davis, F.J., Economy, K., Garner, J.W., Johnson, J.D., MacKinnon, R.J., Miller, J., O'Brien, D.G., Ramsey, J.L., Schreiber, J.D., Shinta, A., Smith, L.N., Stoelzel, D.M., Stockman, C., \& Vaughn, P., Uncertainty and Sensitivity Analysis Results Obtained in the 1996 Performance Assessment for the Waste Isolation Pilot Plant, SAND98-0365, Sandia National Laboratories, Albuquerque, NM, 1998.

20. Stockman, C., Shinta, A., \& Garner, J.W., Analysis Package for the Salado Transport Calculations (Task 2) of the Performance Assessment Analyses Supporting the Compliance Certification Application, Sandia WIPP Central Files WPO \# 40515, Sandia National Laboratories, Albuquerque, NM, 1996.

21. Siegel, M.D., Solubility Parameters for Actinide Source Term Look-Up Tables. Records package. Sandia WIPP Central Files WPO \# 35835, Sandia National Laboratories, Albuquerque, NM, 1996.

22. U.S. Department of Energy, Transuranic Waste Baseline Inventory Report (Revision 2), DOE/CAO-95-1121, Revision 2., U.S. Department of Energy, Carlsbad Area Office, Carlsbad, NM, 1995.

23. Sanchez, L.C., Liscum-Powell, J., Rath, J.S., \& Trellue, H.R., WIPP PA Analysis Report for EPAUNI: Estimating Probability Distribution of EPA Unit Loading in the WIPP Repository for Performance Assessment Calculations, Version 1.01. Sandia WIPP Central Files WPO \# 43843. Sandia National Laboratories, Albuquerque, NM, 1997.

24. Sanchez, L., Drez, P.E., Rath, J.S., \& Trellue, H.R., Radioactive and Nonradioactive Waste Intended for Disposal at the Waste Isolation Pilot Plant, Reliability Engineering and System Safety (in this issue).

25. WIPP PA, NUTS, Version 2.02 User's Manual, Sandia WIPP Central Files WPO \#37927, Sandia National Laboratories, Albuquerque, NM, 1996.

26. Aziz, K., \& Settari, A., Petroleum Reservoir Simulation, Applied Science Publishers, London; Elsevier, New York, 1979.

27. Stockman, C.T., \& Moore, R.C., Use of Dissolved and Colloidal Actinide Parameters Within the 1996 Waste Isolation Pilot Plant Compliance Certification Application, SAND98-1062C, Sandia National Laboratories, Albuquerque, NM, 1998.

28. WIPP PA, PANEL, Version 3.60, User's Manual, Sandia WIPP Central Files WPO \#37361, Sandia National Laboratories, Albuquerque, NM, 1996.

29. Bateman, H., The Solution of a System of Differential Equations Occurring in the Theory of Radioactive Transformations, Proceedings of the Cambridge Philosophical Society, 1910, 15(5), Pt. 5, 423-427.

30. Iman, R.L., Davenport, J.M., Frost, E.L., \& Shortencarier, M.J., Stepwise Regression with PRESS and Rank Regression (Program and User's Guide), SAND79-1472, Sandia National Laboratories, Albuquerque, NM, 1980.

31. WIPP PA (Performance Assessment), STEPWISE, Version 2.20, User's Manual, Document Version 1. Sandia WIPP Central Files WPO \# 27768, Sandia National Laboratories, Albuquerque, NM, 1995.

32. Iman, R.L., \& Conover, W.J., The Use of the Rank Transform in Regression, Technometrics, 1979, 21(4), 499-509.

33. Papenguth, H.W., Development of Parameter Values Describing Colloidal Actinide Retardation in the Culebra Dolomite, Document in Records Package: Colloidal Actinide Retardation Parameters. Sandia WIPP Central Files WPO \# 38173, Sandia National Laboratories, Albuquerque, NM, 1996. 
34. Helton, J.C., Garner, J.W., Marietta, M.G., Rechard, R.P., Rudeen, D.K., \& Swift, P.N., Uncertainty and Sensitivity Analysis Results Obtained in a Preliminary Performance Assessment for the Waste Isolation Pilot Plant, Nuclear Science and Engineering, 1993, 114(4), 286-331.

35. Helton, J.C., Anderson, D.R., Baker, B.L., Bean, J.E., Berglund, J.W., Beyeler, W., Garner, J.W., Iuzzolino, H.J., Marietta, M.G., Rechard, R.P., Roache, P.J., Rudeen, D.K., Schreiber, J.D., Swift, P.N., Tierney, M.S., \& Vaughn, P., Effect of Alternative Conceptual Models in a Preliminary Performance Assessment for the Waste Isolation Pilot Plant, Nuclear Engineering and Design, 1995, 154(3), 251-344.

36. Helton, J.C., Anderson, D.R., Baker, B.L., Bean, J.E., Berglund, J.W., Beyeler, W., Economy, K., Garner, J.W., Hora, S.C., Iuzzolino, H.J., Knupp, P., Marietta, M.G., Rath, J., Rechard, R.P., Roache, P.J., Rudeen, D.K., Salari, K., Schreiber, J.D., Swift, P.N., Tierney, M.S., \& Vaughn, P., Uncertainty and Sensitivity Analysis Results Obtained in the 1992 Performance Assessment for the Waste Isolation Pilot Plant, Reliability Engineering and System Safety, 1996, 51(1), 53-100. 
Figure Captions

Fig. 1. Time-dependent radionuclide inventories expressed in EPA units (i.e., the normalized units used in showing compliance with 191.13(a)) for entire repository (Refs. 21, 22): (1a) radionuclides included in groundwater transport calculations, and (1b) radionuclides not included in groundwater transport because of low inventory or short half-life. All radionuclides shown are included in estimates of cuttings and cavings and spallings; direct brine releases included all except Sr-90, Cs-137, Pb-210, Ra-226, and Pa-231.

Fig. 2. Elemental concentrations (EPA units $/ \mathrm{m}^{3}$ ): (2a) Salado-dominated brines, and (2b) Castile-dominated brines (key: Am, Pu, Th, U correspond to americium, plutonium, thorium, uranium; DIS, HUM, MIC, MIN, INT, TOT correspond to dissolved, humic colloids, microbial colloids, mineral fragment colloids, actinide intrinsic colloids and total).

Fig. 3. Cumulative normalized release from repository to Culebra Dolomite for E1, E2 and E2E1 intrusions at 350 and $1000 \mathrm{yr}$.

Fig. 4. Cumulative normalized releases over 10,000 yr from repository to Culebra Dolomite for E1, E2 and E2E1 intrusions, with the indicated intrusion times corresponding to the time of the E1 intrusion for the E2E1 intrusion.

Fig. 5. Cumulative normalized releases of individual isotopes over 10,000 yr from repository to Culebra Dolomite for E1 intrusions at 350 and $1000 \mathrm{yr}$.

Fig. 6. Cumulative normalized releases of individual isotopes over $10,000 \mathrm{yr}$ from repository to Culebra Dolomite for $\mathrm{E} 2$ intrusions at 350 and $1000 \mathrm{yr}$.

Fig. 7. Cumulative normalized releases of individual isotopes over 10,000 yr from repository to Culebra Dolomite for E2E1 intrusions with the E1 intrusion at 350 and $1000 \mathrm{yr}$.

Fig. 8. Scatterplots for normalized release to Culebra Dolomite over $10,000 \mathrm{yr}$ for an E2 intrusion at $1000 \mathrm{yr}$ versus BHPRM and ANHPRM.

Fig. 9. Scatterplots for normalized release to Culebra Dolomite over $10,000 \mathrm{yr}$ for an E1 intrusion at $1000 \mathrm{yr}$ versus $B P C O M P$ and $B H P R M$.

Fig. 10. Scatterplots for normalized release of Am-241 to Culebra Dolomite over 10,000 yr for an E2E1 intrusion with the $\mathrm{E} 1$ intrusion occurring at $1000 \mathrm{yr}$ versus $B H P R M$ and BPCOMP.

Fig. 11. Scatterplots for normalized release of individual radionuclides (i.e., Am-241, Pu-239, U-234, Th-230) to Culebra Dolomite over 10,000 yr for an E2E1 intrusion with the E1 intrusion occurring at $1000 \mathrm{yr}$ versus the solubility for the individual radionuclides (i.e., SOLAMC, SOLPUC, SOLUC, SOLTHC in Table 6, Ref. 8).

Fig. 12. Fraction of total radionuclide concentration in brine (EPA units $/ \mathrm{m}^{3}$ ) attached to microbial, mineral fragment and actinide intrinsic colloids: (12a) Salado-dominated brines, and (12b) Castile-dominated brines (key: $\mathrm{Am}, \mathrm{Pu}, \mathrm{Th}, \mathrm{U}$ correspond to americium, plutonium, thorium, uranium; MICF, MINF, INTF correspond to microbial fraction, mineral fragment fraction, actinide intrinsic fraction).

Fig. 13. Distribution of CCDFs for normalized release to Culebra Dolomite over 10,000 yr: (13a) CCDFs for replicate $\mathrm{R} 1$, and (13b) mean and percentile curves obtained by pooling replicates $\mathrm{R} 1, \mathrm{R} 2$ and $\mathrm{R} 3$.

Fig. 14. Distributions of CCDFs for normalized release to the Culebra Dolomite over 10,000 yr: (14a) replicate R2, and (14b) replicate R3.

Fig. 15. Distributions of CCDFs for replicate $\mathrm{R} 1$ for normalized release of individual radionuclides (dissolved and colloidally-transported) to Culebra Dolomite over 10,000 yr.

Fig. 16. Outcome of replicated sampling for distribution of CCDFs for normalized release to the Culebra Dolomite over 10,000 yr: (16a) mean and percentile curves for individual replicates, and (16b) confidence intervals (CIs) on mean curve obtained from the three replicates. 
Fig. 17. Scatterplots for expected normalized releases associated with individual CCDFs for total release to the Culebra Dolomite versus BHPRM and BPCOMP.

Fig. 18. Normalized inventory in marker beds (TEPATMBT): (18a) for undisturbed conditions, and (18b) an E1 intrusion at $1000 \mathrm{yr}$ into lower waste panel. 

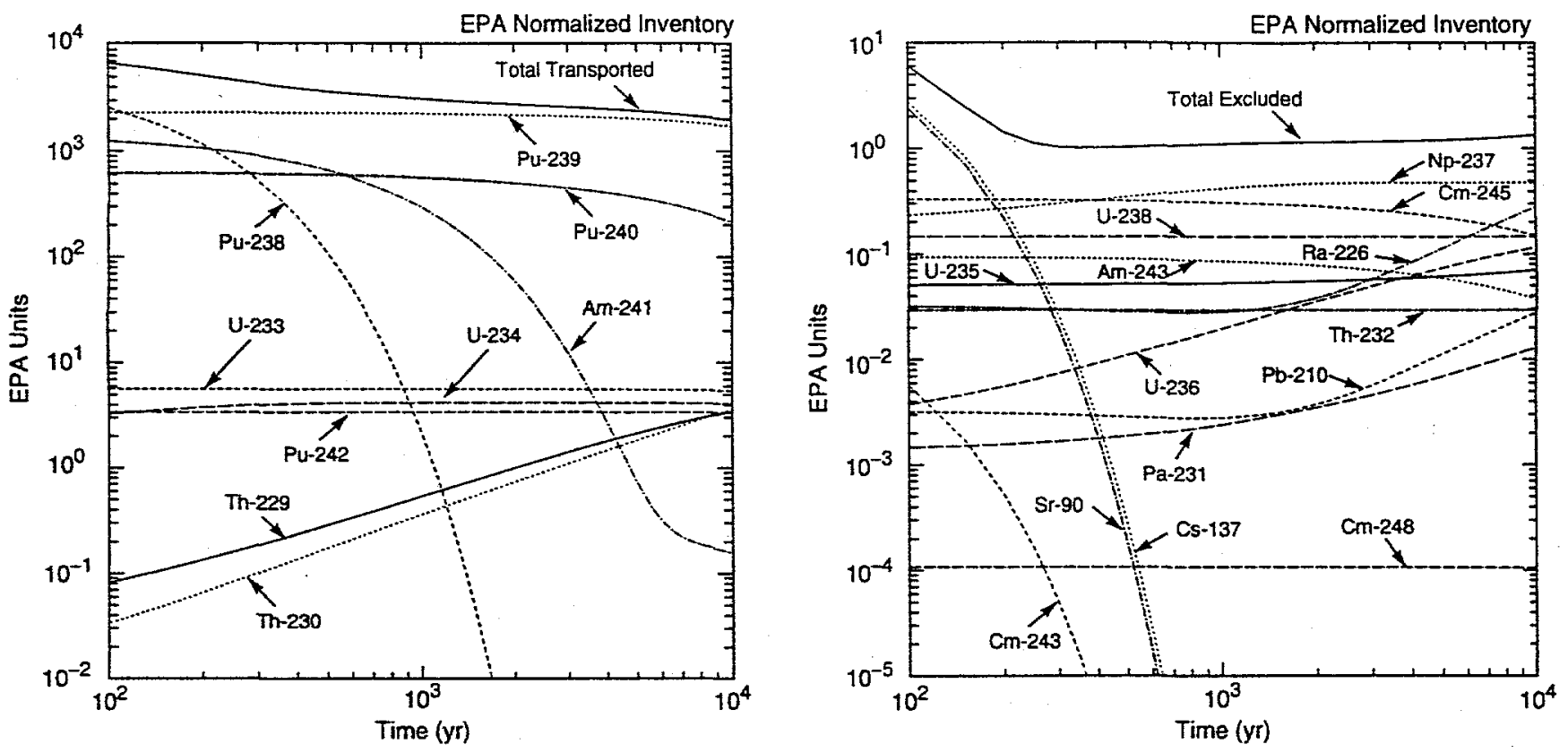

TRI-6342-5247-1

Fig. 1. Time-dependent radionuclide inventories expressed in EPA units (i.e., the normalized units used in showing compliance with 191.13(a)) for entire repository (Refs. 21, 22): (1a) radionuclides included in groundwater transport calculations, and (1b) radionuclides not included in groundwater transport because of low inventory or short half-life. All radionuclides shown are included in estimates of cuttings and cavings and spallings; direct brine releases included all except $\mathrm{Sr}-90, \mathrm{Cs}-137, \mathrm{~Pb}-210, \mathrm{Ra}-226$, and Pa-231.
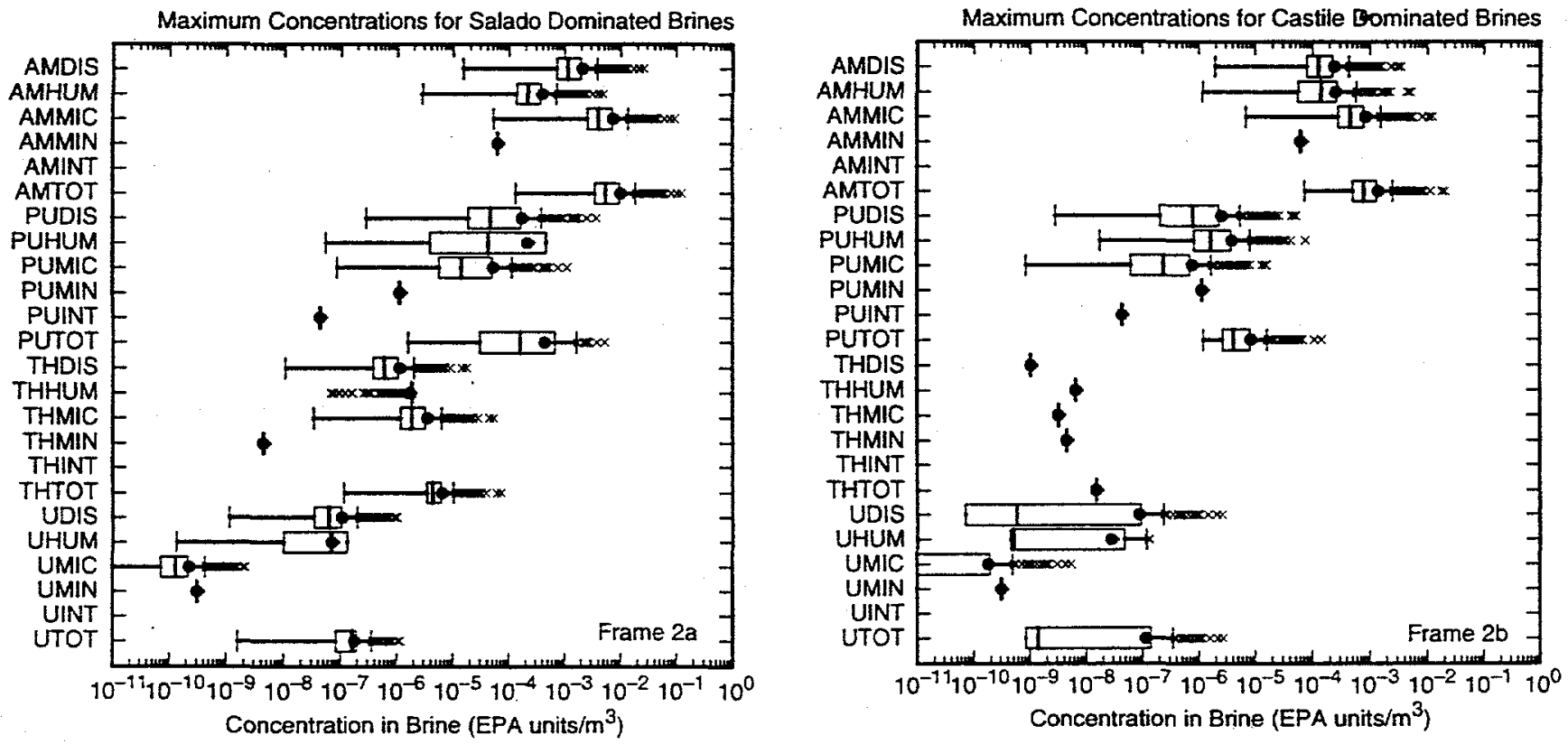

TA1-6342-5151-1

Fig. 2. Elemental concentrations (EPA units $/ \mathrm{m}^{3}$ ): (2a) Salado-dominated brines, and (2b) Castile-dominated brines (key: Am, Pu, Th, U correspond to americium, plutonium, thorium, uranium; DIS, HUM, MIC, MIN, INT, TOT correspond to dissolved, humic colloids, microbial colloids, mineral fragment colloids, actinide intrinsic colloids and total). 
NUTS (E1 at 350 yr, R1)

Total Isotope Activity up Borehole at Rustler/Culebra Interiace

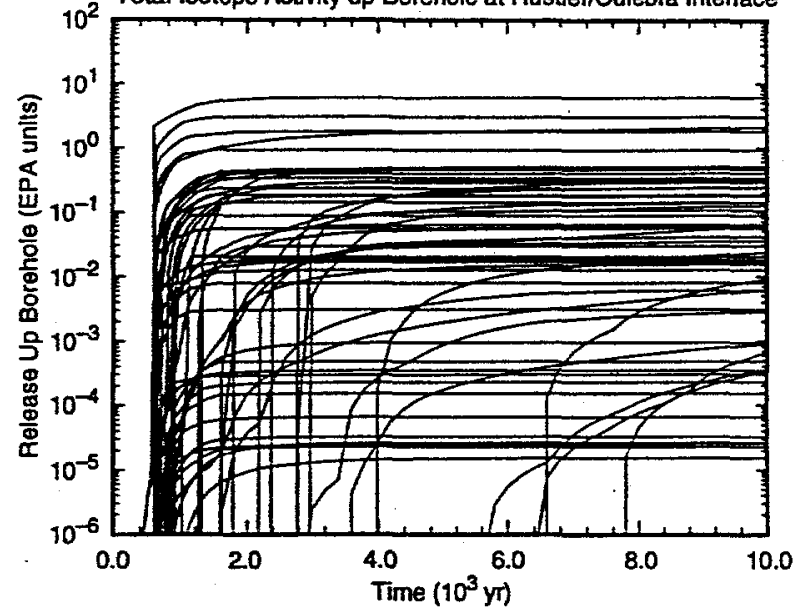

NUTS (E2 at $350 \mathrm{yr}, \mathrm{R} 1$ )

2. Total Isotope Activity up Borehole at Rustler/Culebra Interface

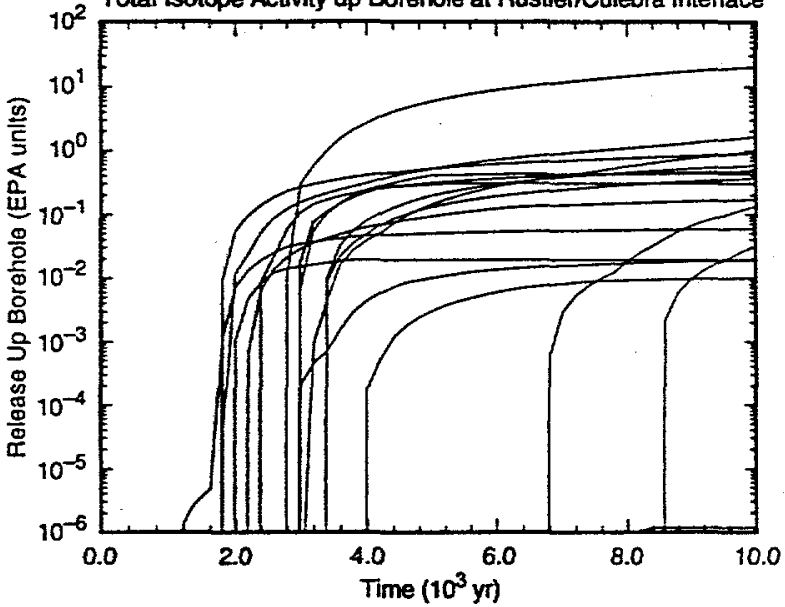

PANE (E2E1 with E1 at $350 y$, R1)

Total isotope Activity up Borehole at Rustler/Culebra Interface

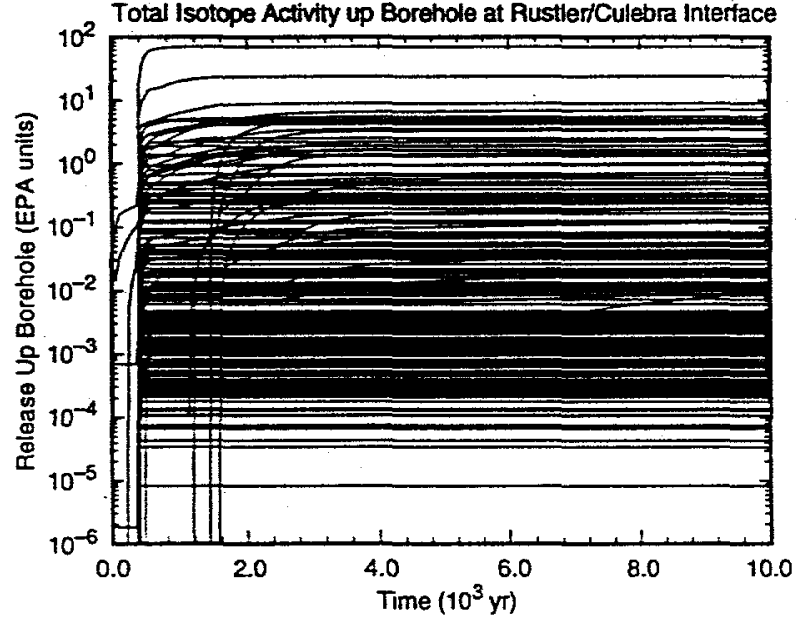

NUTS (E1 at 1000 yr, R1)

Total Isolope Activity up Borehole at Rustler/Culebra Interface

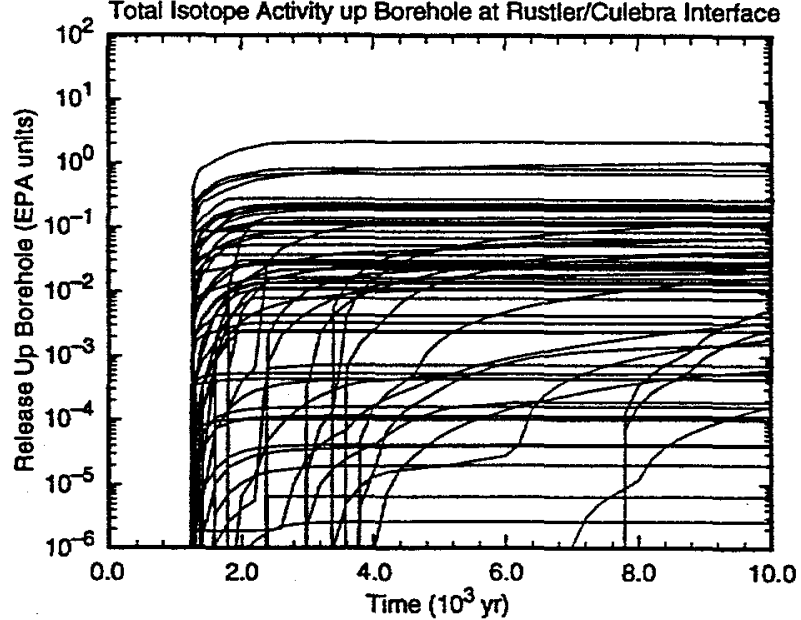

NUTS (E2 at 1000 yr, R1)

Total Isotope Activity up Borehole at Rustler/Culebra Interface

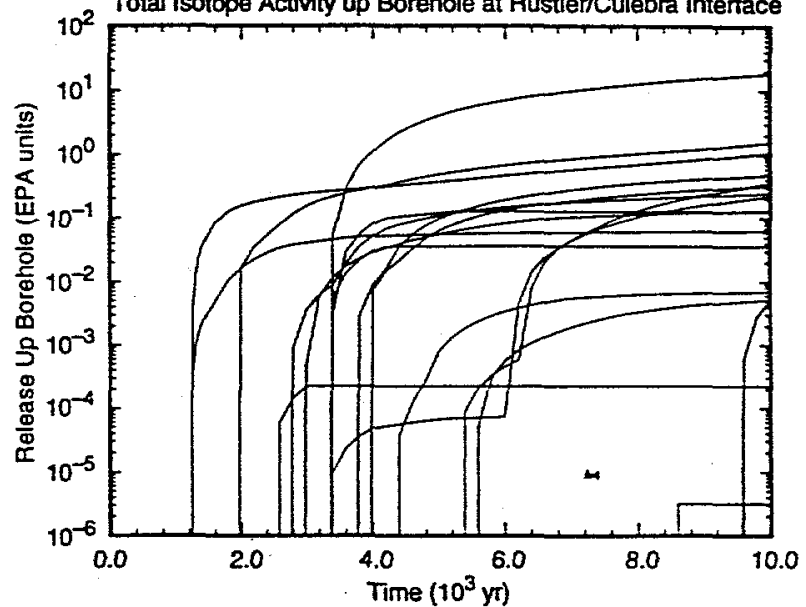

PANEl (E2E1 with E1 at $1000 \mathrm{yr}, \mathrm{R1}$ )

Total Isotope Activity up Borehole at Rustler/Culebra Intertace

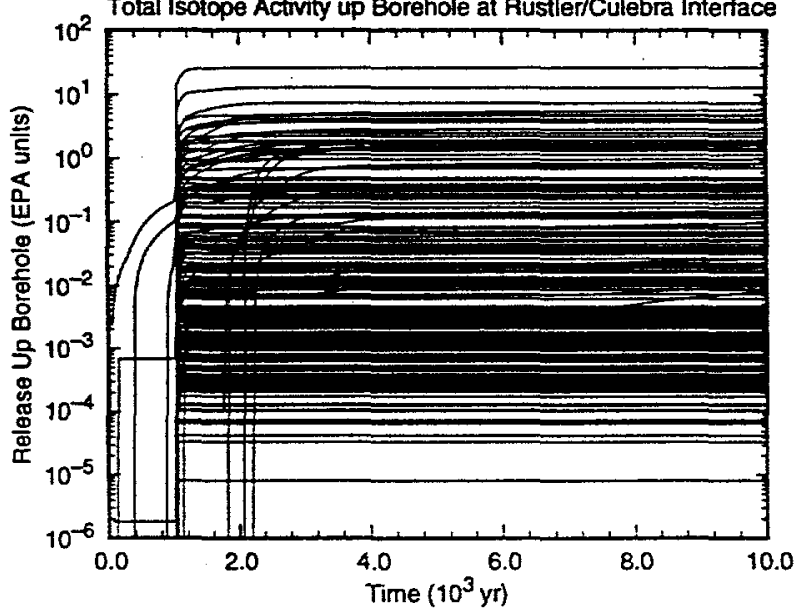

TRI-6342-5152-0

Fig. 3. Cumulative normalized release from repository to Culebra Dolomite for E1, E2 and E2E1 intrusions at 350 and $1000 \mathrm{yr}$. 
NUTS (E1, R1, R2, R3)

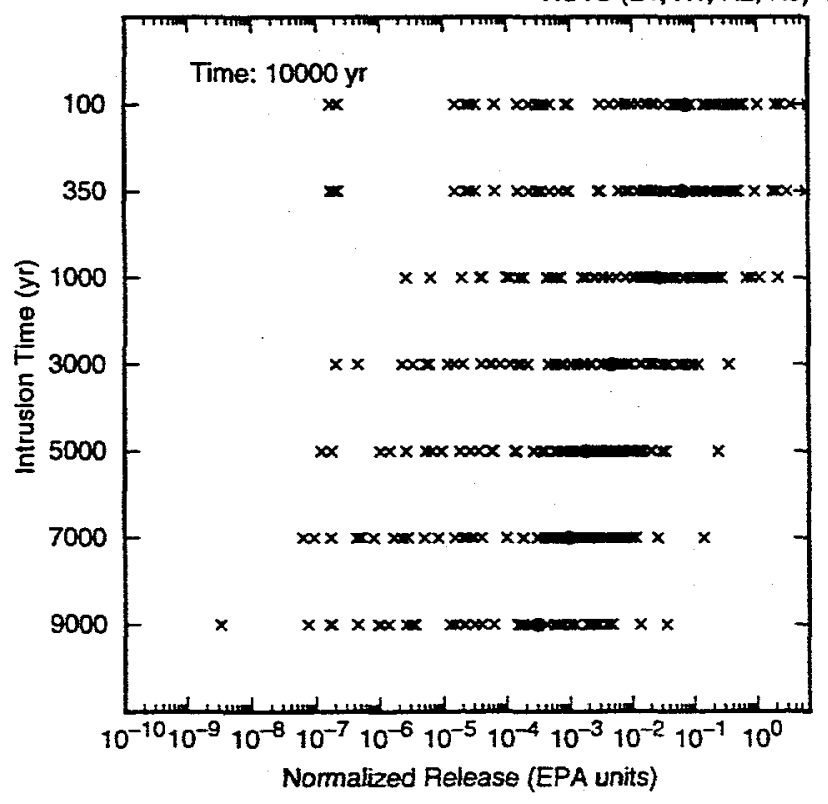

NUTS (E2, R1, R2, R3)

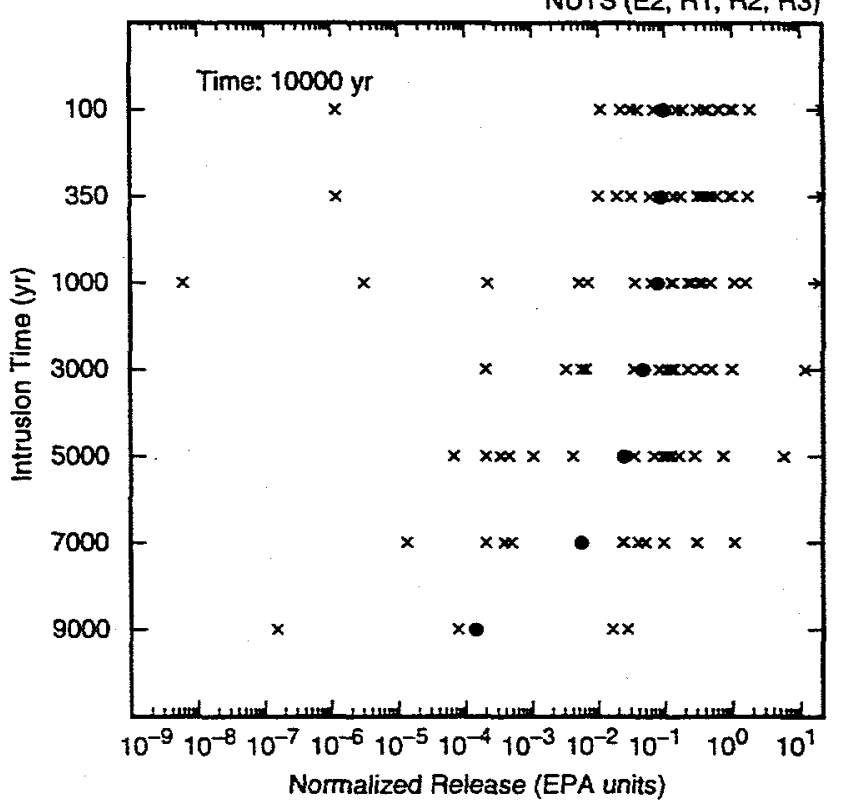

PANEL (E2E1, R1, R2, R3)

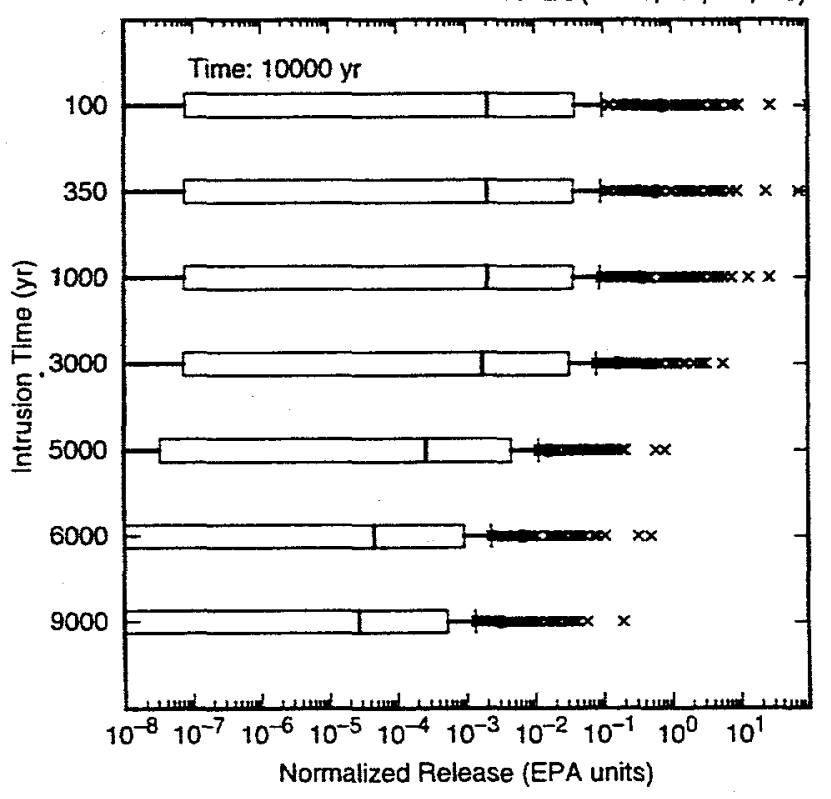

TRI-6342-5153-0

Fig. 4. Cumulative normalized releases over 10,000 yr from repository to Culebra Dolomite for E1, E2 and E2E1 intrusions, with the indicated intrusion times corresponding to the time of the E1 intrusion for the E2E1 intrusion. 

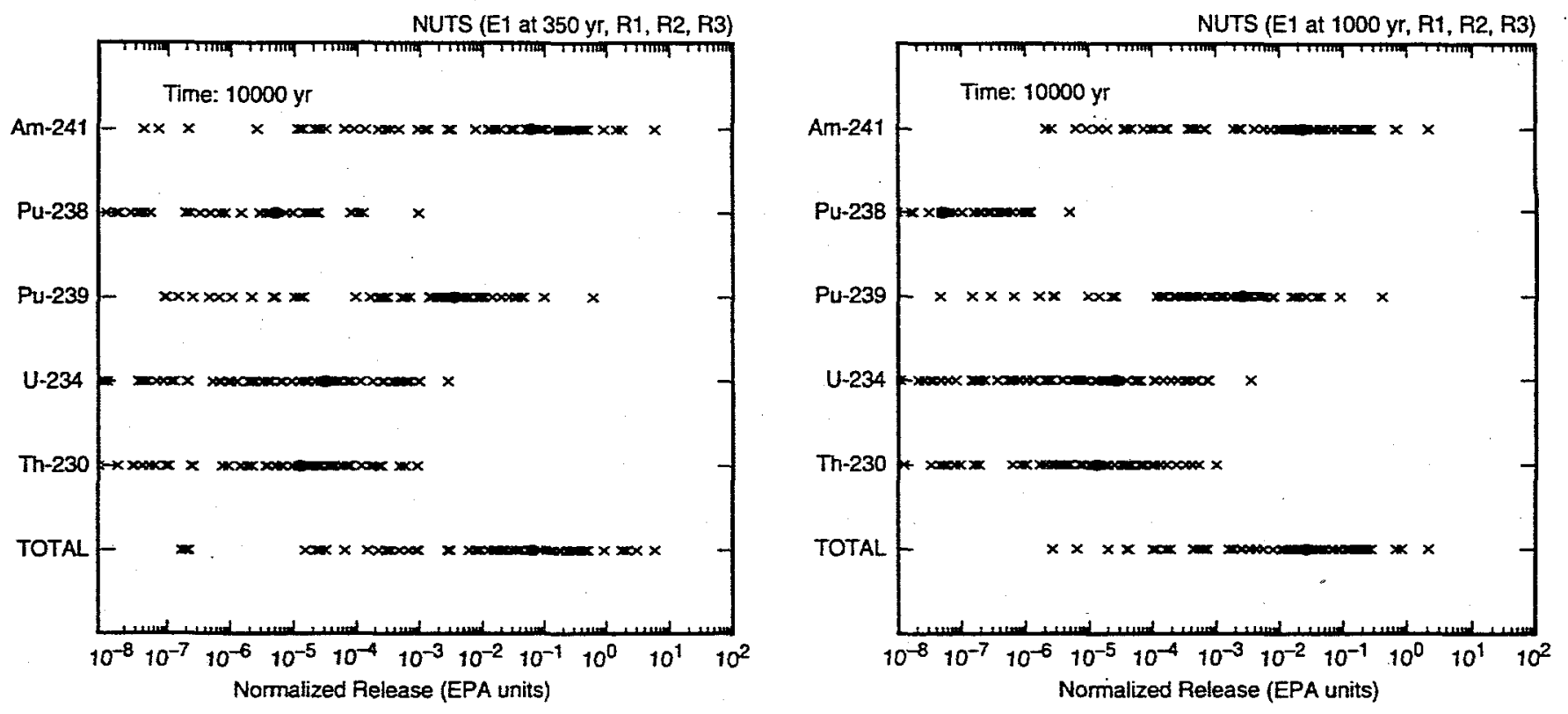

TRI-6342-5154-D

Fig. 5. Cumulative normalized releases of individual isotopes over $10,000 \mathrm{yr}$ from repository to Culebra Dolomite for $\mathrm{E} 1$ intrusions at 350 and $1000 \mathrm{yr}$.
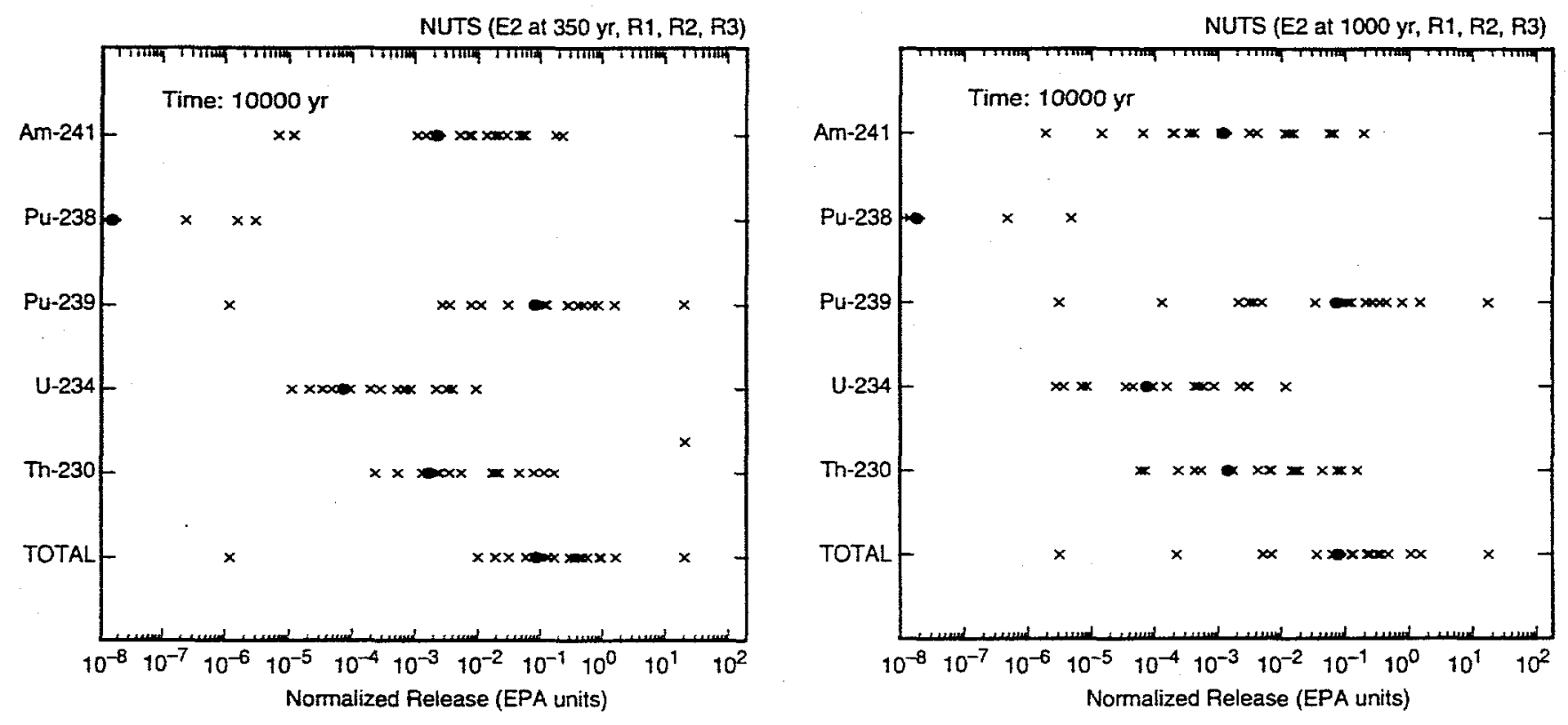

TRI-6342-5155-0

Fig. 6. Cumulative normalized releases of individual isotopes over 10,000 yr from repository to Culebra Dolomite for E2 intrusions at 350 and $1000 \mathrm{yr}$. 
PANEL (E2E1 with E1 at $350 \mathrm{yr}, \mathrm{R1}, \mathrm{R2}, \mathrm{R3}$ )

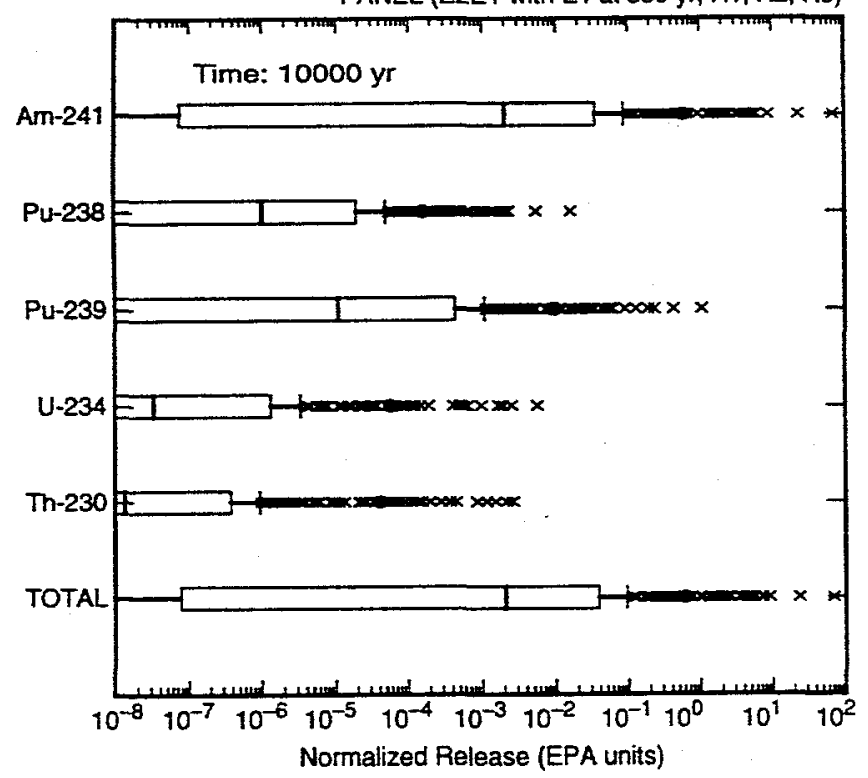

PANEL (E2E1 with E1 at $1000 \mathrm{yr}, \mathrm{R1}, \mathrm{R2}, \mathrm{R3}$ )

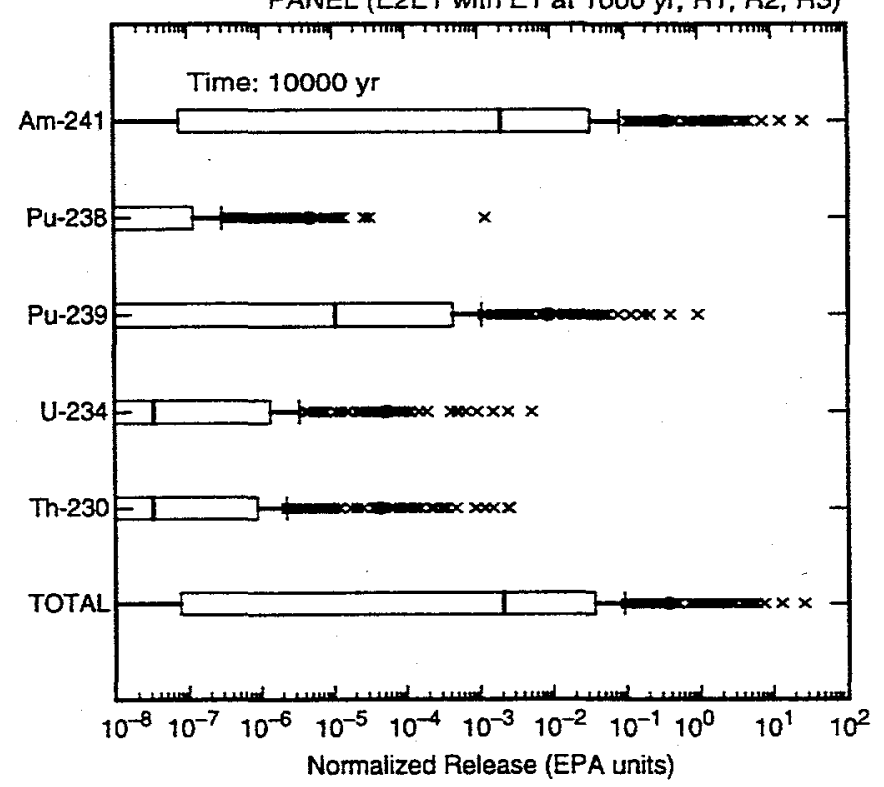

TR!-6342-5156-0

Fig. 7. Cumulative normalized releases of individual isotopes over 10,000 yr from repository to Culebra Dolomite for E2E1 intrusions with the E1 intrusion at 350 and $1000 \mathrm{yr}$.
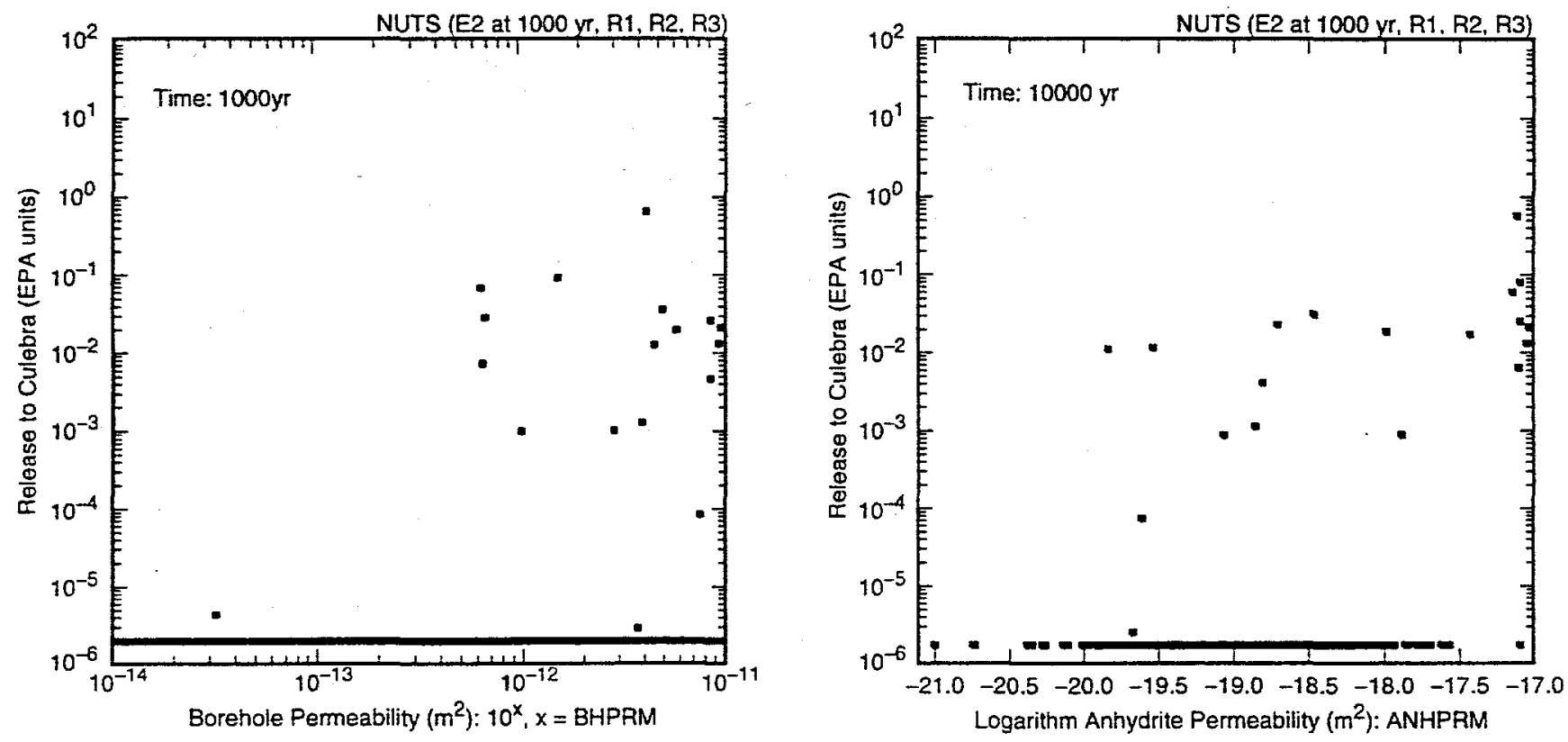

TRI-6342-5157-0

Fig. 8. Scatterplots for normalized release to Culebra Dolomite over 10,000 yr for an E2 intrusion at $1000 \mathrm{yr}$ versus BHPRM and ANHPRM. 

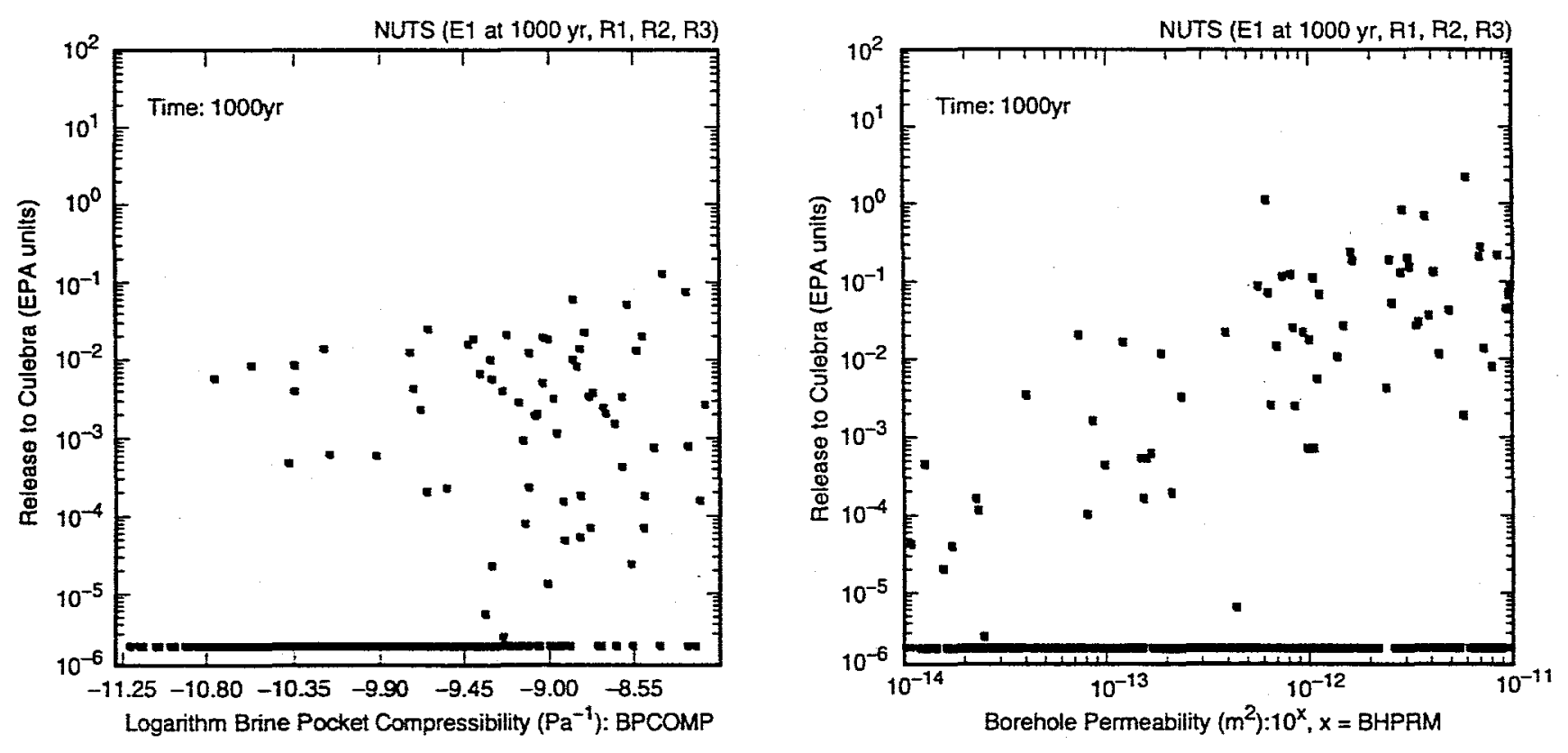

TR1-6342-5158-0

Fig. 9. Scatterplots for normalized release to Culebra Dolomite over 10,000 yr for an E1 intrusion at $1000 \mathrm{yr}$ versus $B P C O M P$ and $B H P R M$.
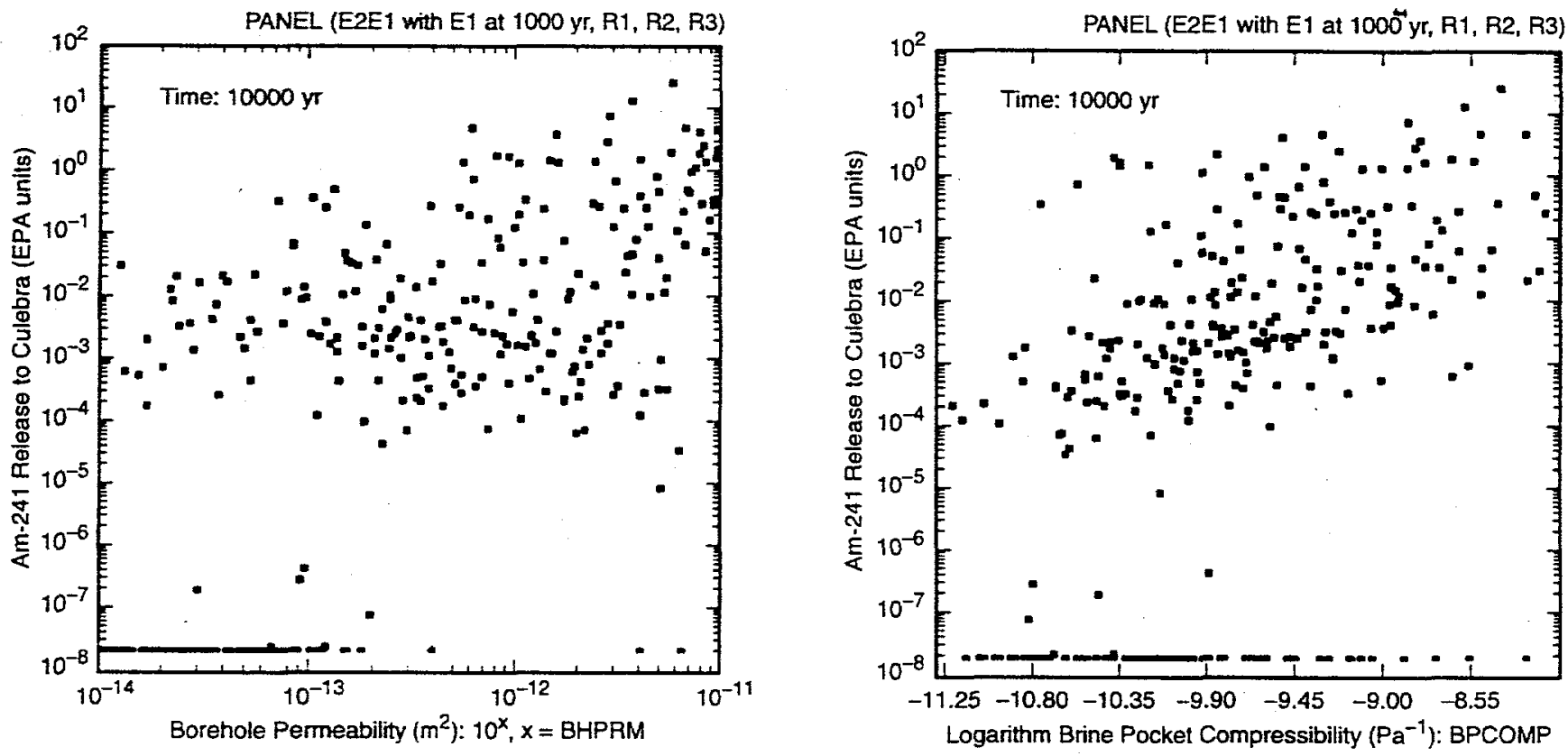

TA1-6342-4994-0

Fig. 10. Scatterplots for normalized release of Am-241 to Culebra Dolomite over 10,000 yr for an E2E1 intrusion with the $\mathrm{E} 1$ intrusion occurring at $1000 \mathrm{yr}$ versus $B H P R M$ and $B P C O M P$. 

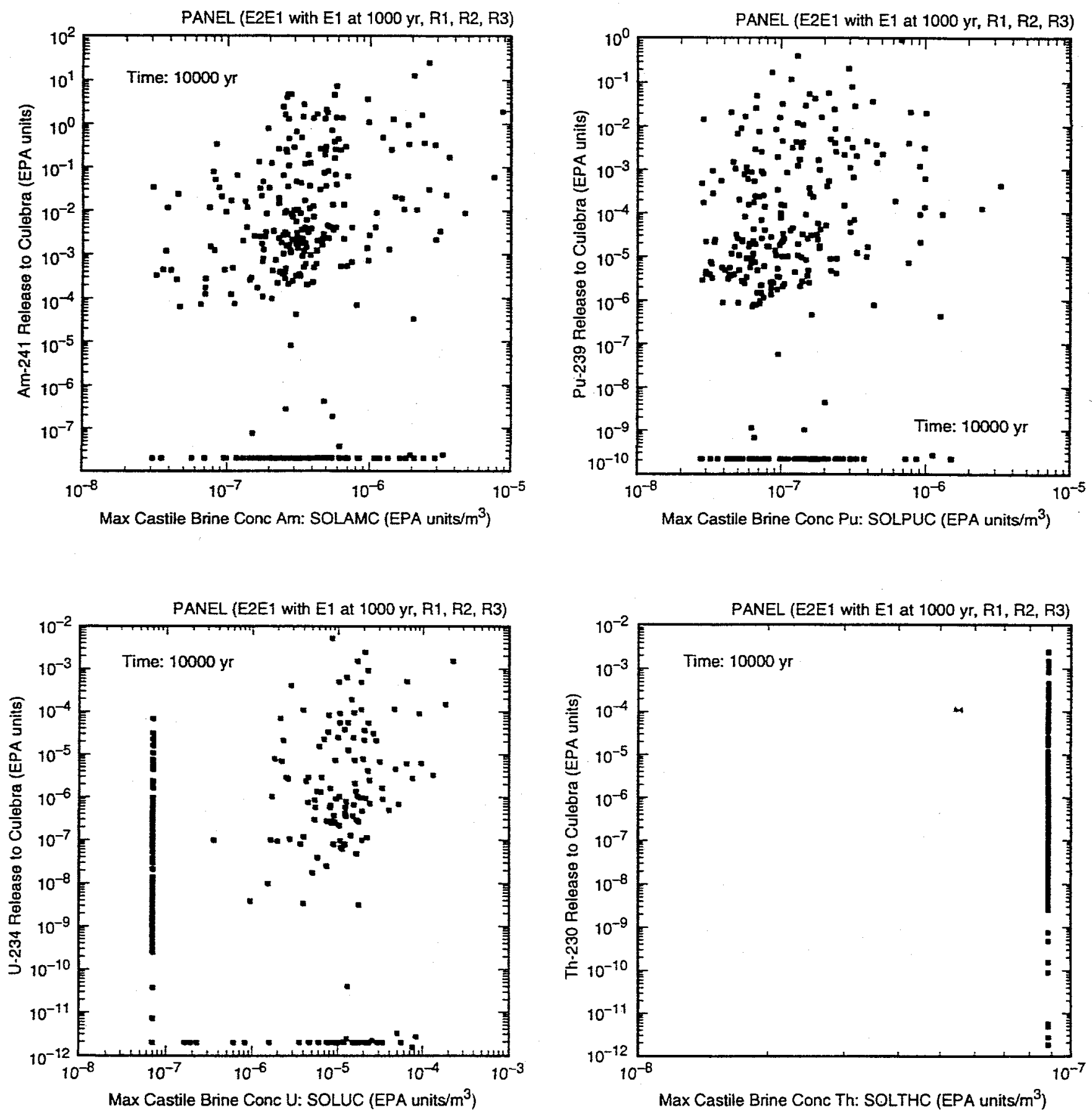

TRI-6342-4995-0

Fig. 11. Scatterplots for normalized release of individual radionuclides (i.e., Am-241, Pu-239, U-234, Th-230) to Culebra Dolomite over 10,000 yr for an E2E1 intrusion with the E1 intrusion occurring at $1000 \mathrm{yr}$ versus the solubility for the individual radionuclides (i.e., SOLAMC, SOLPUC, SOLUC, SOLTHC in Table 6, Ref. 8). 

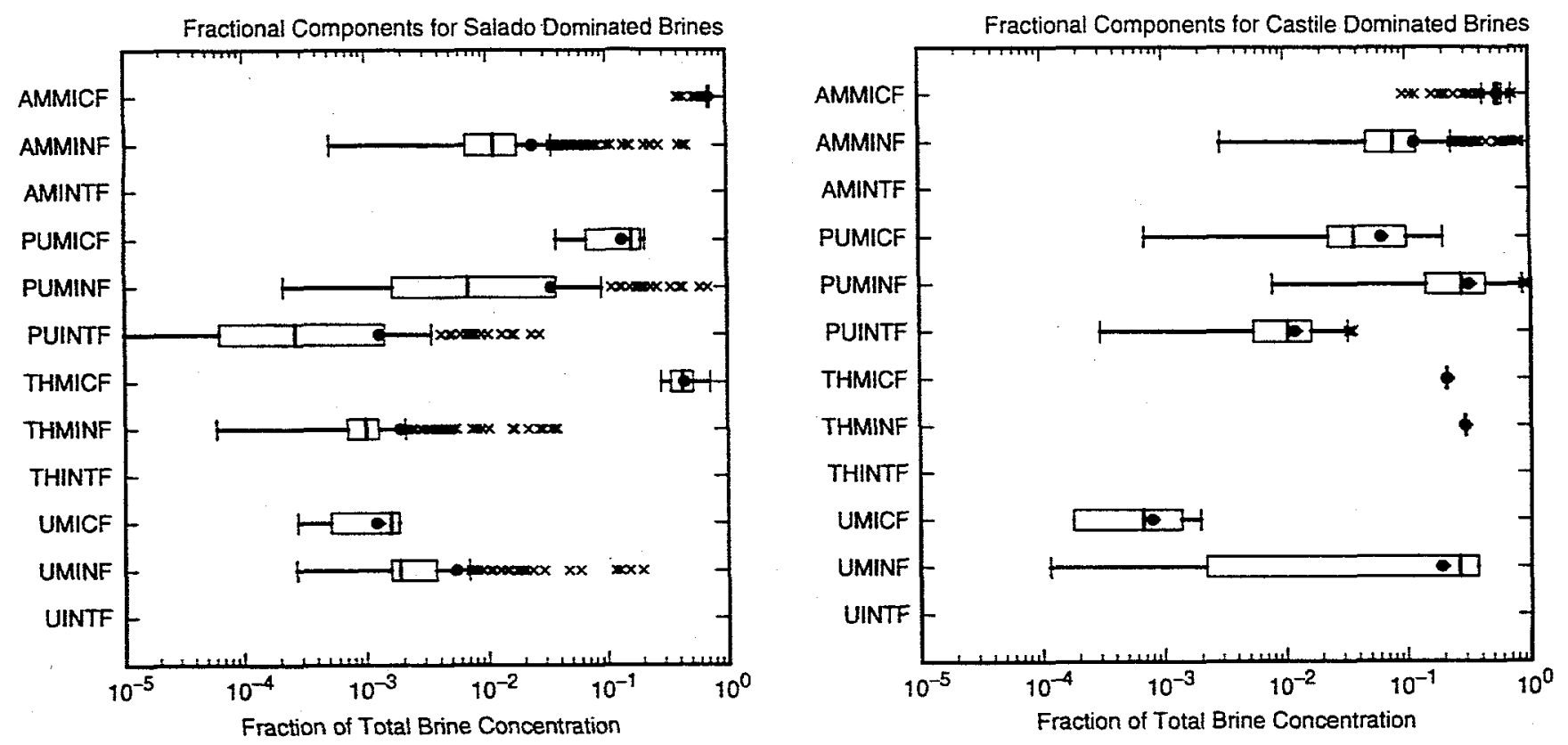

TRI-6342-5159-0

Fig. 12. Fraction of total radionuclide concentration in brine (EPA units $/ \mathrm{m}^{3}$ ) attached to microbial, mineral fragment and actinide intrinsic colloids: (12a) Salado-dominated brines, and (12b) Castile-dominated brines (key: $\mathrm{Am}, \mathrm{Pu}, \mathrm{Th}, \mathrm{U}$ correspond to americium, plutonium, thorium, uranium; MICF, MINF, INTF correspond to microbial fraction, mineral fragment fraction, actinide intrinsic fraction). 

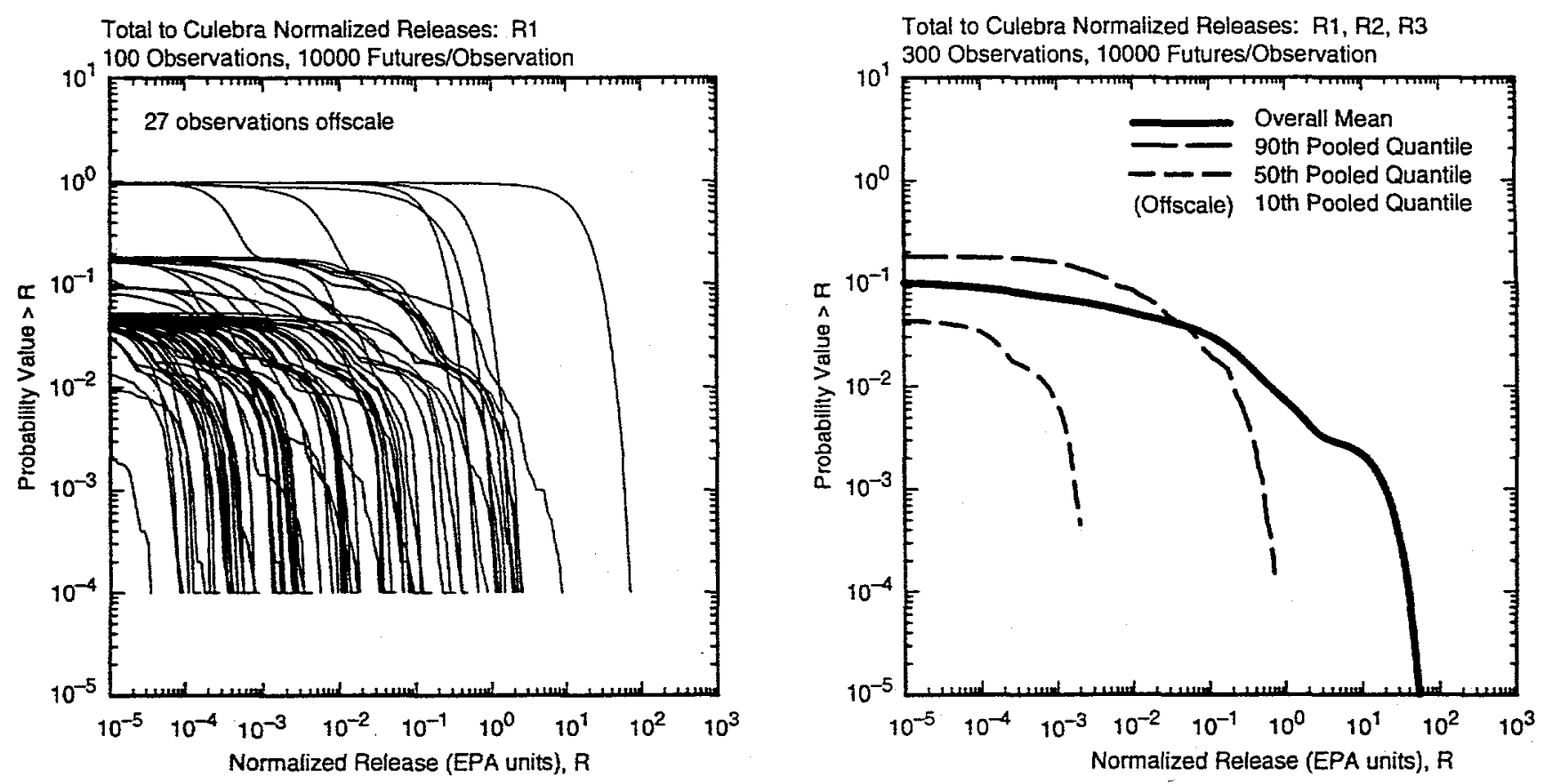

TRI-6342-4996-0

Fig. 13. Distribution of CCDFs for normalized release to Culebra Dolomite over 10,000 yr: (13a) CCDFs for replicate R1, and (13b) mean and percentile curves obtained by pooling replicates R1, R2 and R3.
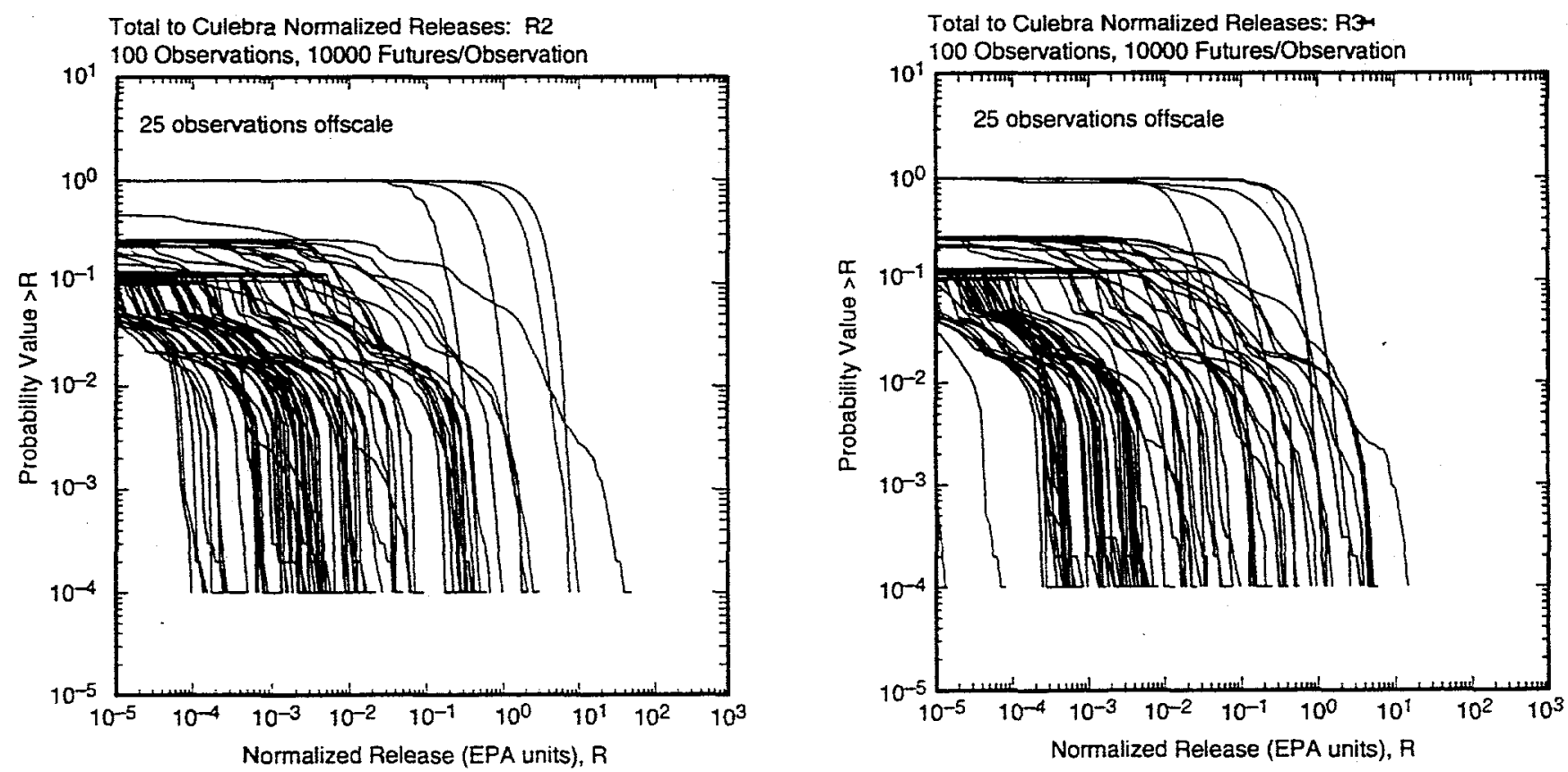

TRL-6342-4998-0

Fig. 14. Distributions of CCDFs for normalized release to the Culebra Dolomite over 10,000 yr: (14a) repiicate R2. and (14b) replicate $R 3$. 
Total to Culebra Am-241 Normalized Releases: A1
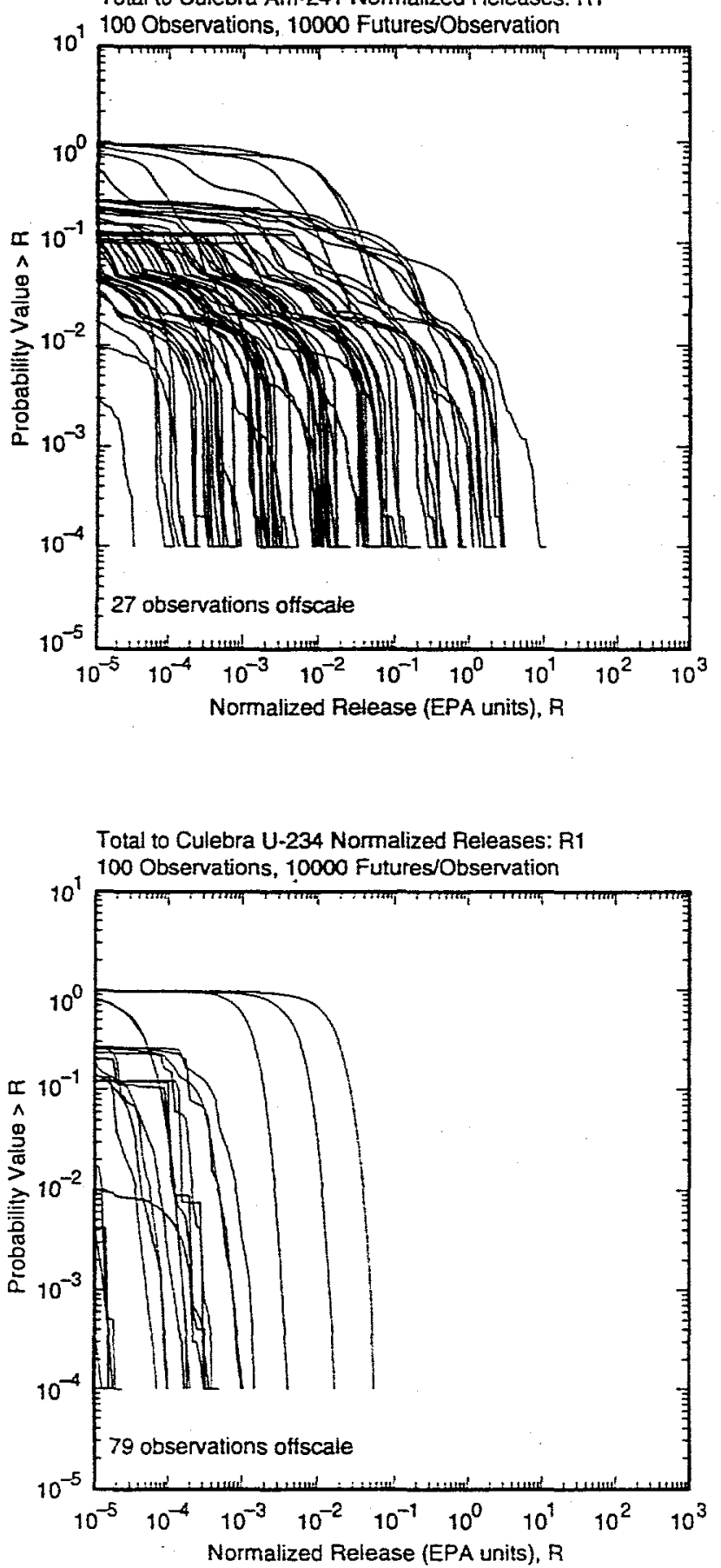

Total to Culebra Pu-239 Normalized Releases: R1 1100 Observations, 10000 Futures/Observation
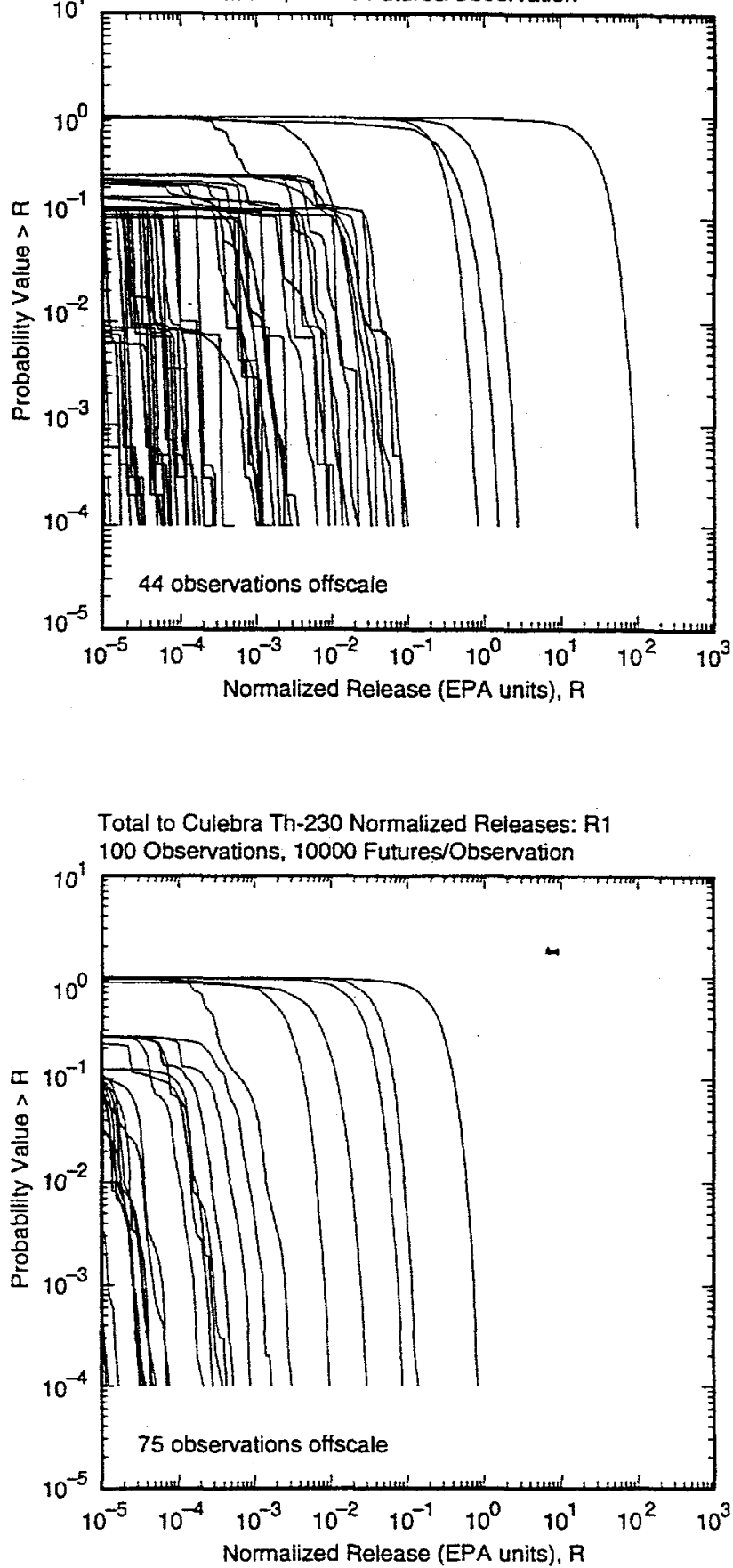

TR1-6342-5178-0

Fig. 15. Distributions of CCDFs for replicate R1 for normalized release of individual radionuclides (dissolved and colloidally-transported) to Culebra Dolomite over $10.000 \mathrm{yr}$. 

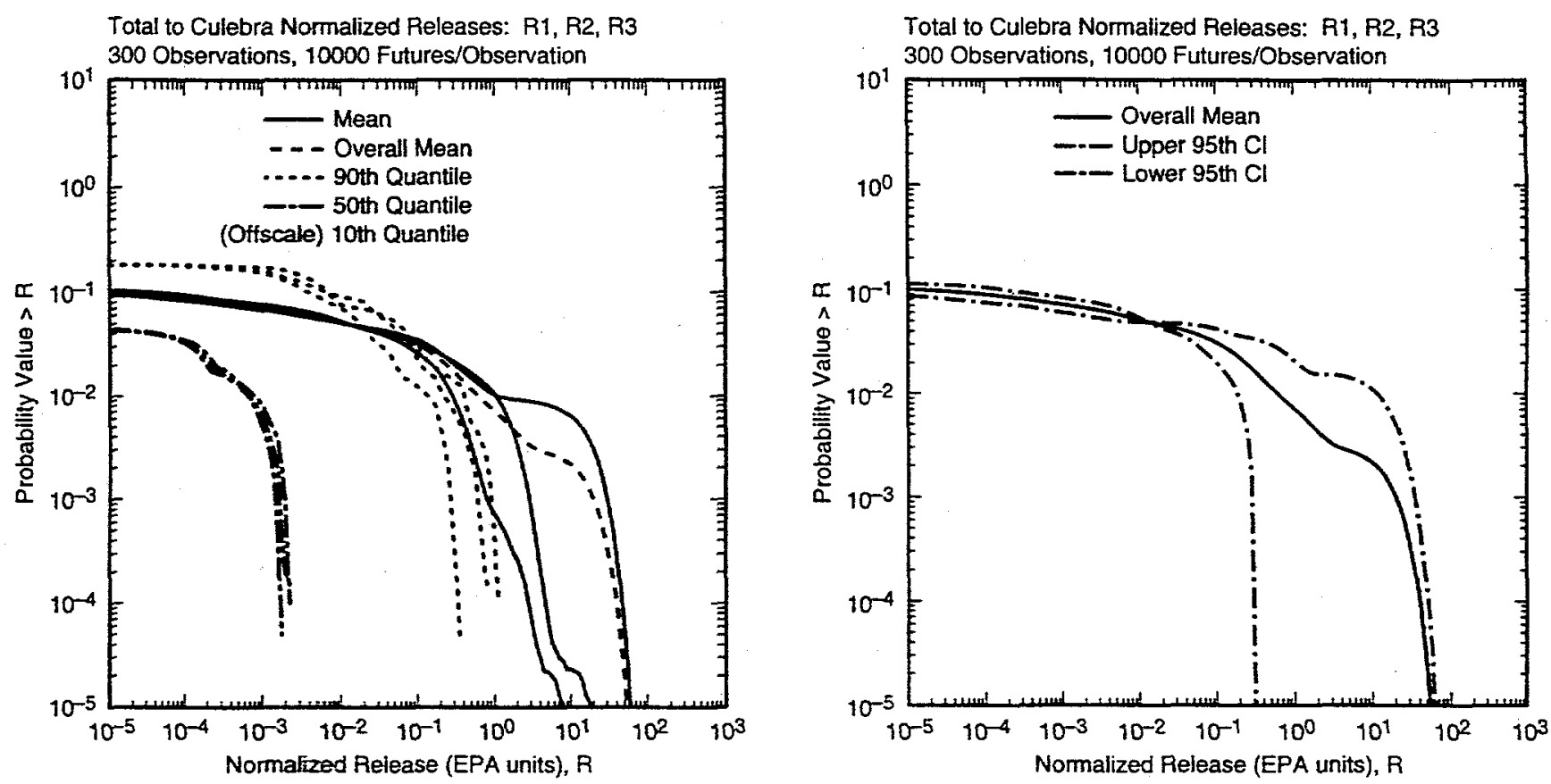

TR1-6342-4997-0

Fig. 16. Outcome of replicated sampling for distribution of CCDFs for normalized release to the Culebra Dolomite over 10,000 yr: (16a) mean and percentile curves for individual replicates, and (16b) confidence intervals (CIs) on mean curve obtained from the three replicates.
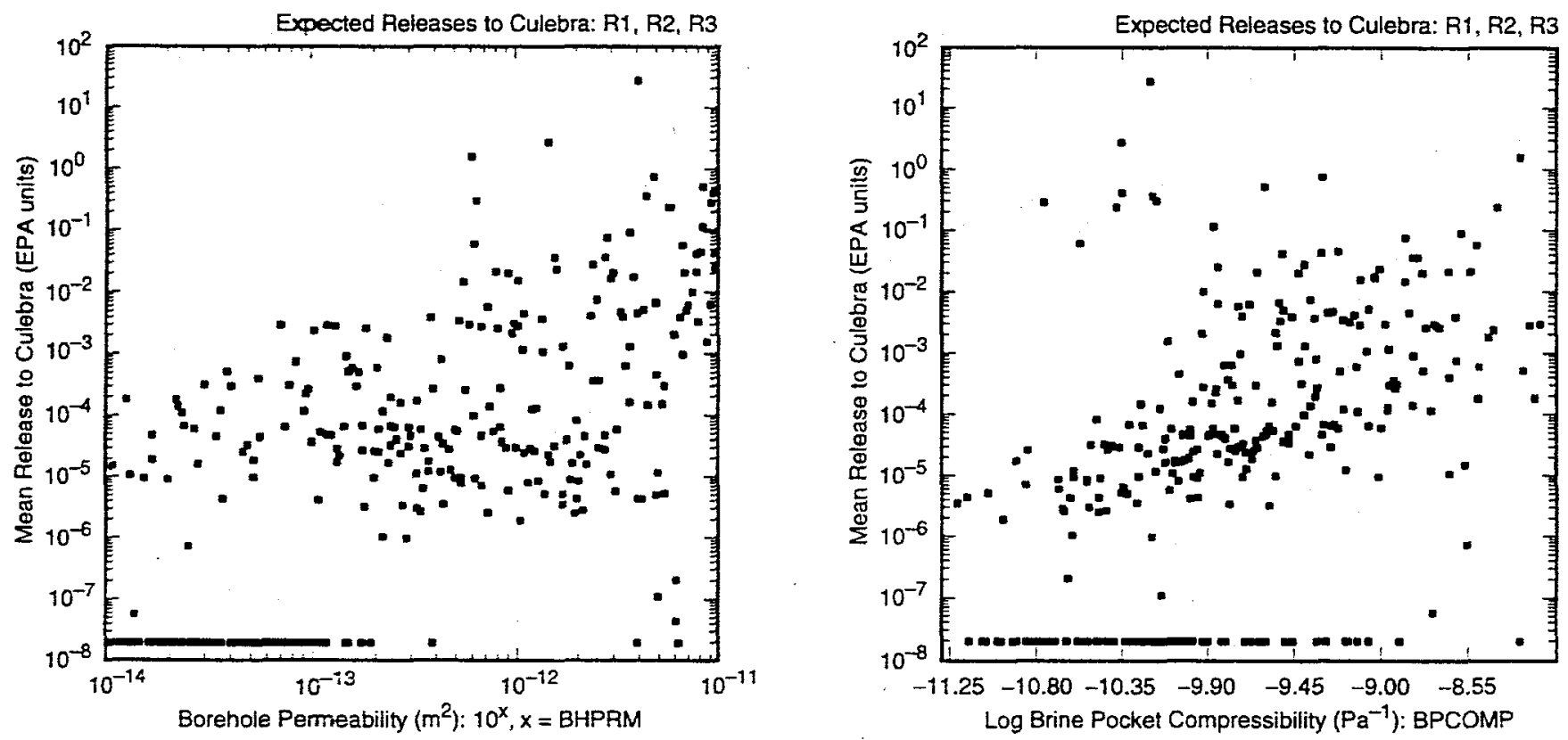

TRI-6342-5160-0

Fig. 17. Scatterplots for expected normalized releases associated with individual CCDFs for total release to the Culebra Dolomite versus BHPRM and BPCOMP. 
NUTS (E0, R1, R2, R3)

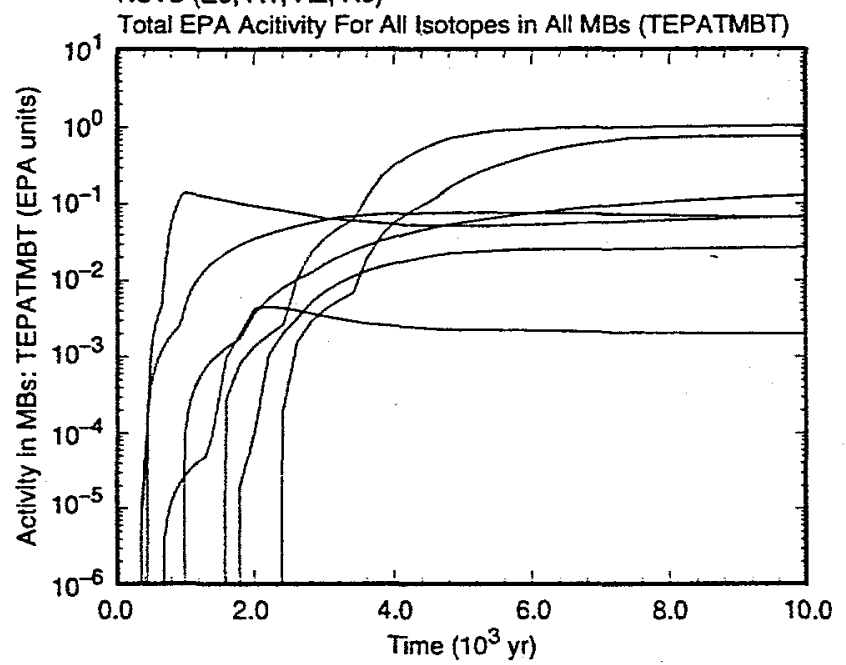

NUTS (E1 at $1000 \mathrm{yr}, \mathrm{R} 1$ )

Total EPA Acitivity For All Isotopes in All MBs (TEPATMBT)

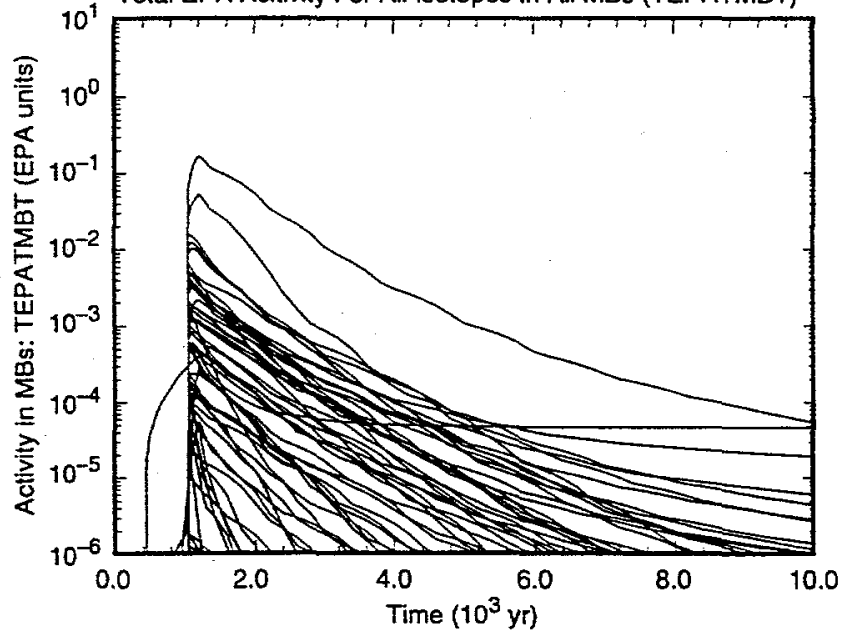

TR1-6342-5235-0

Fig. 18. Normalized inventory in marker beds (TEPATMBT): (18a) for undisturbed conditions, and (18b) an E1 intrusion at $1000 \mathrm{yr}$ into lower waste panel. 
Table 1. Definition of Elemental Solubilities for Salado and Castile Brines (See Ref. 20 for additional information).

Dissolved Solubility $S_{D}(B r, O x, E l)(\mathrm{mol} / 1)$ as a Function of Type of Brine $(B r \sim$ Salado, Castile), Oxidation State $(O x \sim+3,+4,+5,+6)$ and Element $(E l \sim$ americium, plutonium, uranium and thorium)

$S_{D}(B r, O x, E l)=S_{F M T}(B r, O x) 10^{U F(B r, O x, E l)}$

where

$S_{F M T}(B r, O x)=$ dissolved solubility (mol/1) calculated by FMT model (Ref. 21) for brine type $B r$ and oxidation state $O x$ (definition given below)

$U F(B r, O x, E l)=$ logarithm (base 10) of uncertainty factor for solubilities calculated by FMT expressed as a function of brine type $B r$, oxidation state $O x$ and element $E l$ (definition given below)

Dissolved Solubilities $S_{F M T}(B r, O x)$ Calculated with FMT (mol/1)

\begin{tabular}{|l|c|c|c|c|}
\hline \multicolumn{1}{|c|}{$\mathrm{Br} / \mathrm{Ox}$} & +3 & +4 & +5 & +6 \\
\hline Salado & $5.83 \times 10^{-7}$ & $4.4 \times 10^{-6}$ & $2.3 \times 10^{-6}$ & $8.7 \times 10^{-6}$ \\
\hline Castile & $6.52 \times 10^{-8}$ & $6.0 \times 10^{-9}$ & $2.2 \times 10^{-6}$ & $8.8 \times 10^{-6}$ \\
\hline
\end{tabular}

Uncertainty Factor $U F(B r, O x, E l)$ for Solubilities Calculated by FMT

\begin{tabular}{|c|c|c|c|c|c|c|}
\hline$B r / O x, E l$ & $+3, \mathrm{Am}$ & $+3, \mathrm{Pu}$ & $+4, \mathrm{Pu}$ & $+4, \mathrm{U}$ & $+6, U$ & $+4, \mathrm{Th}$ \\
\hline Salado & WSOLAM $3 S^{a}$ & WSOLPU3S & WSOLPU4S & WSOLU4S S $^{a}$ & WSOLU $6 S^{a}$ & WSOLTH4S \\
\hline Castile & WSOLAM3C ${ }^{a}$ & WSOLPU3C ${ }^{a}$ & WSOLPU4C & 0 & WSOLU6C & 0 \\
\hline
\end{tabular}

Total (Colloidal and Dissolved) Solubility $S_{\Upsilon}(B r, O x, E l)$ (mole/1) as a Function of Type of Brine ( $\left.B r\right)$, Oxidation State $(O x)$ and Element $(E l)$

$S_{7}(B r, O x, E l)=S_{D}(B r, O x, E l)+S_{H u m}(B r, O x, E l)+S_{M i c}(B r, O x, E l)+S_{A c t}(E l)+S_{M n}$

where

$S_{H u m}(B r, O x, E l)=$ solubility (i.e., concentration expressed in mol/1) in brine type $B r$ of element $E l$ in oxidation state $O x$ resulting from formation of humic colloids

$=\min \left\{S F_{H u m}(B r, O x, E l) S_{D}(B r, O x, E l), U B_{H u m}\right\}$

$S F_{H u m}(B r, O x, E l)=$ scale factor used as a multiplier on $S_{D}(B r, O x, E l)$ in definition of $S F_{H u m}(B r, O x, E l)$ (definition given below)

$U B_{H u m}=$ upper bound (i.e., cap) on solubility (i.e., concentration expressed in mol/1) of individual actinide elements resulting from formation of humic colloids

$=1.1 \times 10^{-5} \mathrm{~mol} / 1$

$S_{M i c}(B r, O x, E l)=$ solubility (i.e., concentration expressed in mol/1) in brine type $B r$ of element $E l$ in oxidation state $O x$ resulting from formation of microbial colloids 
Table 1. (Continued)

$=\min \left\{S F_{M i c}(O x, E l) S_{D}(B r, O x, E l), U B_{M i c}(O x, E l)\right\}$

$S F_{M i c}(O x, E l)=$ scale factor used as multiplier on $S_{D}(B r, O x, E l)$ in definition of $S_{M i c}(B r, O x, E l)$ (definition given below)

$U B_{M i c}(O x, E l)=$ upper bound (i.e., cap) on solubility (i.e., concentration expressed in mol/1) of element $E l$ in oxidation state $O x$ resulting from formation of microbial colloids (definition given below)

$S_{A c t}(E l)=$ solubility (i.e., concentration expressed in $\mathrm{mol} / 1$ ) of element $E l$ resulting from formation of actinide intrinsic colloids

$=\left\{\begin{array}{lll}1 \times 10^{-9} \mathrm{~mol} / 1 & \text { if } E l \sim \text { plutonium } \\ 0 & \mathrm{~mol} / 1 & \text { otherwise }\end{array}\right.$

$S_{M n}=$ solubility (i.e., concentration expressed in mol/1) of individual actinide element resulting from formation of mineral fragment colloids

$=2.6 \times 10^{-8} \mathrm{~mol} / 1$

Scale Factor $S F_{Y u m}(B r, O x, E l)$ Used in Definition of $S_{H u m}(B r, O x, E l)$

\begin{tabular}{|l|c|c|c|c|c|c|}
\hline \multicolumn{1}{|c|}{$B r / O x, E l$} & $+3, \mathrm{Am}$ & $+3, \mathrm{Pu}$ & $+4, \mathrm{Pu}$ & $+4, \mathrm{U}$ & $+6, \mathrm{U}$ & $+4, \mathrm{Th}$ \\
\hline Salado & 0.19 & 0.19 & 6.3 & 6.3 & 0.12 & 6.3 \\
\hline Castile & WPHUMOX $3^{\mathrm{a}}$ & WPHUMOX $^{\mathrm{a}}$ & 6.3 & 6.3 & 0.51 & 6.3 \\
\hline
\end{tabular}

Scale Factor $S F_{M i c}(O x, E l)$ and Upper Bound $U B_{M i c}(O x, E l)(\mathrm{mol} / 1)$ Used in Definition of $S_{M i c}(B r, O x, E l)$

\begin{tabular}{|l|c|c|c|c|c|c|}
\cline { 2 - 7 } \multicolumn{1}{c|}{} & $+3, \mathrm{Am}$ & $+3, \mathrm{Pu}$ & $+4, \mathrm{Pu}$ & $+4, \mathrm{U}$ & $+6, \mathrm{U}$ & $+4, \mathrm{Th}$ \\
\hline$S F_{M i c}(O x, E l)$ & 3.6 & 0.3 & 0.3 & $2.1 \times 10^{-3}$ & $2.1 \times 10^{-3}$ & 3.1 \\
\hline$U B_{M i c}(O x, E l)$ & 1 & $6.8 \times 10^{-5}$ & $6.8 \times 10^{-5}$ & $2.1 \times 10^{-3}$ & $2.1 \times 10^{-3}$ & $1.9 \times 10^{-3}$ \\
\hline
\end{tabular}

${ }^{a}$ See Table 1, Ref. 12. 
Table 2. Radionuclides Considered for Transport in the Vicinity of the Repository in the 1996 WIPP PA with Time 0 yr Corresponding to Year 2033 (Refs. 23, 24)

\begin{tabular}{|c|c|c|c|c|c|c|c|c|}
\hline Isotope & $\begin{array}{l}\text { Half life } \\
\text { (years) }\end{array}$ & $\begin{array}{c}\text { Release } \\
\text { Limit }\end{array}$ & $\begin{array}{c}0 \text { years } \\
\mathrm{Ci}\end{array}$ & $\begin{array}{c}0 \text { years } \\
\text { EPA Units }\end{array}$ & $\begin{array}{c}100 \text { years } \\
\text { EPA Units }\end{array}$ & \begin{tabular}{|l|}
350 years \\
EPA Units
\end{tabular} & $\begin{array}{l}10000 \text { years } \\
\text { EPA Units }\end{array}$ & $\begin{array}{c}\text { MAX EPA } \\
\text { Units }\end{array}$ \\
\hline Pu-238 & $8.77 \mathrm{E}+01$ & 344 & $1.94 \mathrm{E}+06$ & $5.63 \mathrm{E}+03$ & $2.55 \mathrm{E}+03$ & $3.54 \mathrm{E}+02$ & $1.32 \mathrm{E}-22$ & $5.63 \mathrm{E}+03$ \\
\hline Pu-239 & $2.41 E+04$ & 344 & $7.95 \mathrm{E}+05$ & $2.31 E+03$ & $2.30 \mathrm{E}+03$ & $2.29 \mathrm{E}+03$ & $1.73 \mathrm{E}+03$ & $2.31 \mathrm{E}+03$ \\
\hline Am-241 & $4.32 \mathrm{E}+02$ & 344 & $4.88 \mathrm{E}+05$ & $1.42 \mathrm{E}+03$ & $1.24 \mathrm{E}+03$ & $8.31 \mathrm{E}+02$ & $1.55 \mathrm{E}-01$ & $1.42 \mathrm{E}+03$ \\
\hline $\mathrm{Pu}-240$ & $6.54 \mathrm{E}+03$ & 344 & $2.14 \mathrm{E}+05$ & $6.23 \mathrm{E}+02$ & $6.17 \mathrm{E}+02$ & $6.01 \mathrm{E}+02$ & $2.16 \mathrm{E}+02$ & $6.23 \mathrm{E}+02$ \\
\hline Cs-137 & $3.00 \mathrm{E}+01$ & 3440 & $9.31 \mathrm{E}+04$ & $2.71 \mathrm{E}+01$ & $2.68 \mathrm{E}+00$ & $8.32 \mathrm{E}-03$ & $0.00 \mathrm{E}+00$ & $2.71 \mathrm{E}+01$ \\
\hline Sr-90 & $2.91 E+01$ & 3440 & $8.73 E+04$ & $2.54 \mathrm{E}+01$ & $2.35 \mathrm{E}+00$ & $6.12 \mathrm{E}-03$ & $0.00 \mathrm{E}+00$ & $2.54 \mathrm{E}+01$ \\
\hline$U-233$ & $1.59 \mathrm{E}+05$ & 344 & $1.95 \mathrm{E}+03$ & $5.67 \mathrm{E} \div 00$ & $5.66 \mathrm{E}+00$ & $5.66 \mathrm{E}+00$ & $5.44 \mathrm{E}+00$ & $5.67 \mathrm{E}+00$ \\
\hline U -234 & $2.45 E+05$ & 344 & $7.51 \mathrm{E}+02$ & $2.18 \mathrm{E}+00$ & $3.28 \mathrm{E}+00$ & $4.07 \mathrm{E}+00 \mid$ & $4.09 \mathrm{E}+00$ & $4.09 \mathrm{E}+00$ \\
\hline Th-230 & $7.70 \mathrm{E}+04$ & 34 & $3.06 \mathrm{E}-01$ & $8.88 \mathrm{E}-03$ & $3.41 \mathrm{E}-02$ & $1.20 \mathrm{E}-01$ & $3.56 \mathrm{E}+00$ & $3.56 \mathrm{E}+00$ \\
\hline $\mathrm{Pu}-242$ & $3.76 E+05$ & 344 & $1.17 \mathrm{E}+03$ & $3.40 \mathrm{E}+00$ & $3.40 \mathrm{E}+00$ & $3.40 \mathrm{E}+00$ & $3.34 \mathrm{E}+00$ & $3.40 \mathrm{E}+00$ \\
\hline Th-229 & $7.34 \mathrm{E}+03$ & 344 & $9.97 \mathrm{E}+00$ & $2.90 \mathrm{E}-02$ & $8.19 \mathrm{E}-02$ & $2.12 \mathrm{E}-01$ & $3.40 \mathrm{E}+00$ & $3.40 \mathrm{E}+00$ \\
\hline Np-237 & $2.14 \mathrm{E}+06$ & 344 & $6.49 \mathrm{E}+01$ & $1.89 \mathrm{E}-01$ & $2.32 \mathrm{E}-01$ & $3.15 \mathrm{E}-01$ & $4.82 \mathrm{E}-01$ & $4.82 \mathrm{E}-01$ \\
\hline $\mathrm{Cm}-245$ & $8.53 E+03$ & 344 & $1.15 \mathrm{E}+02$ & $3.33 \mathrm{E}-01$ & $3.31 \mathrm{E}-01$ & $3.24 \mathrm{E}-01$ & $1.48 \mathrm{E}-01$ & 3.33E-01 \\
\hline $\mathrm{Ra}-226$ & $1.60 \mathrm{E}+03$ & 344 & $1.14 \mathrm{E}+01$ & $3.32 \mathrm{E}-02$ & $3.19 \mathrm{E}-02$ & $2.94 \mathrm{E}-02$ & $2.77 \mathrm{E}-01$ & $2.77 \mathrm{E}-01$ \\
\hline $\mathrm{Pb}-210$ & $2.23 E+01$ & 344 & $8.75 \mathrm{E}+00$ & $2.54 \mathrm{E}-02$ & $3.19 \mathrm{E}-02$ & $2.96 \mathrm{E}-02$ & $2.77 \mathrm{E}-01$ & $2.77 \mathrm{E}-01$ \\
\hline U - 238 & $4.47 \mathrm{E}+09$ & 344 & $5.01 \mathrm{E}+01$ & $1.46 \mathrm{E}-01$ & $1.46 \mathrm{E}-01$ & $1.46 \mathrm{E}-01$ & $1.46 \mathrm{E}-01$ & $1.46 \mathrm{E}-01$ \\
\hline$U-236$ & $2.34 \mathrm{E}+07$ & 344 & $6.72 \mathrm{E}-01$ & $1.95 \mathrm{E}-03$ & $3.79 \mathrm{E}-03$ & $8.29 \mathrm{E}-03$ & $1.16 \mathrm{E}-01$ & $1.16 \mathrm{E}-01$ \\
\hline $\mathrm{Am}-243$ & $7.37 \mathrm{E}+03$ & 344 & $3.25 \mathrm{E}+01$ & $9.45 \mathrm{E}-02$ & $9.36 \mathrm{E}-02$ & $9.14 \mathrm{E}-02$ & $3.69 \mathrm{E}-02$ & $9.45 \mathrm{E}-02$ \\
\hline$U-235$ & $7.04 \mathrm{E}+08$ & 344 & $1.75 \mathrm{E}+01$ & $5.08 \mathrm{E}-02$ & $5.10 \mathrm{E}-02$ & $5.16 \mathrm{E}-02$ & $7.06 \mathrm{E}-02$ & $7.06 \mathrm{E}-02$ \\
\hline $\mathrm{Cm}-243$ & $2.91 \mathrm{E}+01$ & 344 & $2.07 \mathrm{E}+01$ & $6.03 \mathrm{E}-02$ & $5.30 \mathrm{E}-03$ & $1.21 \mathrm{E}-05$ & $0.00 \mathrm{E}+00$ & $6.03 \mathrm{E}-02$ \\
\hline U - 232 & $6.89 E+01$ & 344 & $1.79 \mathrm{E}+01$ & $5.21 \mathrm{E}-02$ & $1.99 \mathrm{E}-02$ & $1.79 \mathrm{E}-03$ & $0.00 \mathrm{E}+00$ & $5.21 E-02$ \\
\hline$C-14$ & $5.72 \mathrm{E}+03$ & 344 & $1.28 \mathrm{E}+01$ & $3.72 \mathrm{E}-02$ & $3.68 \mathrm{E}-02$ & $3.57 \mathrm{E}-02$ & $1.11 \mathrm{E}-02$ & $3.72 \mathrm{E}-02$ \\
\hline Th-232 & $1.41 \mathrm{E}+10$ & 34 & $1.01 \mathrm{E}+00$ & $2.92 \mathrm{E}-02$ & $2.92 \mathrm{E}-02$ & $2.92 \mathrm{E}-02$ & $2.92 \mathrm{E}-02$ & $2.92 \mathrm{E}-02$ \\
\hline Ac- 227 & $2.18 \mathrm{E}+01$ & 344 & $5.05 \mathrm{E}-01$ & $1.47 \mathrm{E}-03$ & $1.43 \mathrm{E}-03$ & $1.69 \mathrm{E}-03$ & $1.28 \mathrm{E}-02$ & $1.28 \mathrm{E}-02$ \\
\hline Pa-231 & $3.28 \mathrm{E}+04$ & 344 & $4.67 \mathrm{E}-01$ & $1.36 \mathrm{E}-03$ & $1.46 \mathrm{E}-03$ & $1.72 \mathrm{E}-03$ & $1.28 \mathrm{E}-02$ & $1.28 \mathrm{E}-02$ \\
\hline $\mathrm{Cm}-248$ & $3.39 \mathrm{E}+05$ & 344 & $3.72 \mathrm{E}-02$ & $3.72 \mathrm{E}-04$ & $3.72 \mathrm{E}-04$ & $3.71 \mathrm{E}-04$ & -04 & $3.72 \mathrm{E}-04$ \\
\hline Pu-244 & $8.26 \mathrm{E}+07$ & 344 & $1.51 \mathrm{E}-06$ & $1.51 \mathrm{E}-08$ & $1.54 \mathrm{E}-08$ & $1.61 \mathrm{E}-08$ & $4.34 \mathrm{E}-08$ & $4.34 \mathrm{E}-08$ \\
\hline Sm-147 & $1.06 \mathrm{E}+11$ & 344 & $4.55 \mathrm{E}-10$ & $4.55 \mathrm{E}-12$ & $4.55 \mathrm{E}-12$ & $4.55 \mathrm{E}-12$ & $4.55 \mathrm{E}-12$ & $4.55 \mathrm{E}-12$ \\
\hline $\mathrm{Pm}-147$ & $2.62 \mathrm{E}+00$ & & $8.10 \mathrm{E}-04$ & & & & & \\
\hline $\mathrm{Ra}-228$ & $5.75 \mathrm{E}+00$ & & $1.00 \mathrm{E}+00$ & & & & & \\
\hline Cf -252 & $2.64 \mathrm{E}+00$ & & $1.72 \mathrm{E}-04$ & & & & & \\
\hline $\mathrm{Cm}-244$ & $1.81 \mathrm{E}+01$ & & $7.44 \mathrm{E}+03$ & & & & & \\
\hline $\mathrm{Pu}-241$ & $1.44 \mathrm{E}+01$ & & $3.94 \mathrm{E}+05$ & & & & & \\
\hline
\end{tabular}


Table 3. Construction of Initial Inventories Associated with Reduction of 10 Radionuclides to 5 Radionuclides

\begin{tabular}{|c|c|c|}
\hline Conversions & Conversion Procedure & $\begin{array}{c}\text { New Inventory } \\
A(0)\end{array}$ \\
\hline${ }^{233} \mathrm{U} \rightarrow{ }^{234} \mathrm{U}$ & $\begin{array}{c}1.95 \times 10^{3} \mathrm{Ci}^{233} \mathrm{U} \rightarrow 1.95 \times 10^{3} \mathrm{Ci}^{234} \mathrm{U}=1.33 \times 10^{3} \mathrm{~mol}^{234} \mathrm{U} \\
\text { Original: } 7.51 \times 10^{2} \mathrm{Ci}^{234} \mathrm{U}=5.14 \times 10^{2} \mathrm{~mol}^{234} \mathrm{U}\end{array}$ & $\begin{array}{l}2.70 \times 10^{3} \mathrm{Ci}^{234} \mathrm{U} \\
4.32 \times 10^{2} \mathrm{~kg}^{234} \mathrm{U}\end{array}$ \\
\hline $\begin{array}{l}{ }^{240} \mathrm{Pu} \rightarrow{ }^{239} \mathrm{Pu} \\
{ }^{242} \mathrm{Pu} \rightarrow{ }^{239} \mathrm{Pu}\end{array}$ & $\begin{array}{c}2.14 \times 10^{5} \mathrm{Ci}^{240} \mathrm{Pu} \rightarrow 2.14 \times 10^{5} \mathrm{Ci}^{239} \mathrm{Pu}=1.44 \times 10^{4} \mathrm{~mol}^{239} \mathrm{Pu} \\
1.23 \times 10^{3} \mathrm{~mol}{ }^{242} \mathrm{Pu} \rightarrow 1.23 \times 10^{3} \mathrm{~mol}^{239} \mathrm{Pu}=1.83 \times 10^{4} \mathrm{Ci}^{239} \mathrm{Pu} \\
\text { Original: } 5.35 \times 10^{4} \mathrm{~mol}^{239} \mathrm{Pu}=7.95 \times 10^{5} \mathrm{Ci}^{239} \mathrm{Pu}\end{array}$ & $\begin{array}{l}1.03 \times 10^{6} \mathrm{Ci}^{239} \mathrm{Pu} \\
1.65 \times 10^{4} \mathrm{~kg}^{239} \mathrm{Pu}\end{array}$ \\
\hline${ }^{229} \mathrm{Th} \rightarrow{ }^{230} \mathrm{Th}$ & $\begin{array}{c}9.97 \times 10^{0} \mathrm{Ci}^{229} \mathrm{Th} \rightarrow 9.97 \times 10^{0} \mathrm{Ci}^{230} \mathrm{Th}=2.15 \times 10^{0} \mathrm{~mol}^{230} \mathrm{Th} \\
\text { Original: } 6.57 \times 10^{-2} \mathrm{~mol}{ }^{230} \mathrm{Th}=3.05 \times 10^{-1} \mathrm{Ci}^{230} \mathrm{Th}\end{array}$ & $\begin{array}{l}1.03 \times 10^{1} \mathrm{Ci}^{230} \mathrm{Th} \\
5.09 \times 10^{-1} \mathrm{~kg}^{230} \mathrm{Th}\end{array}$ \\
\hline${ }^{241} \mathrm{Pu} \rightarrow{ }^{241} \mathrm{Am}$ & $\begin{array}{c}1.59 \times 10^{1} \mathrm{~mol}^{241} \mathrm{Pu} \rightarrow 1.59 \times 10^{1} \mathrm{~mol}^{241} \mathrm{Am}=1.31 \times 10^{4} \mathrm{Ci}^{241} \mathrm{Am} \\
\text { Original: } 5.89 \times 10^{2} \mathrm{~mol}^{241} \mathrm{Am}=4.87 \times 10^{5} \mathrm{Ci}^{241} \mathrm{Am}\end{array}$ & $\begin{array}{l}5.01 \times 10^{5} \mathrm{Ci}^{241} \mathrm{Am} \\
1.46 \times 10^{2} \mathrm{~kg}^{241} \mathrm{Am}\end{array}$ \\
\hline
\end{tabular}

Table 4. Initial Value and Boundary Value Conditions for $C_{b l}(x, y, t)$ and $C_{s l}(x, y, t)$

Initial Value Conditions for $C_{b l}(x, y, t)$ and $C_{s l}(x, y, t)$

$C_{b l}(x, y, 0)=A_{l}(0) / V_{b}(0) \quad$ if $x, y$ point in repository (i.e., in regions 23, 24 of Fig. 1, Ref. 13), where $A_{l}(0)$ is the amount $(\mathrm{kg})$ of radionuclide $l$ present at time $t=0$ (Table 3 ) and $V_{b}(0)$ is the amount $\left(\mathrm{m}^{3}\right)$ of brine in repository at time $t=0$ (from solution of Eqs. (2) - (7) of Ref. 13 with BRAGFLO) for all $x, y$.

$=0 \quad$ otherwise

$C_{s l}(x, y, 0)=0 \quad$ if $x, y$ point in repository

Boundary Value Conditions for $C_{b l}(x, y, t)$

$f_{f}(\mathrm{~B}, t)=\int_{B} \mathbf{v}_{b}(x, y, t) C_{b l}(x, y, t) \alpha(x, y) \bullet \mathbf{n}(x, y) d s$, where $\mathrm{B}$ is any subset of the outer boundary of the computational grid in Figs. 1 and 3 of Ref. 13, $f_{l}(\mathrm{~B}, t)$ is the flux $(\mathrm{kg} / \mathrm{s})$ at time $t$ of radionuclide $l$ across $\mathrm{B}, \mathbf{v}_{b}(x, y, t)$ is the Darcy velocity $\left(\left(\mathrm{m}^{3} / \mathrm{m}^{2}\right) / \mathrm{s}\right)$ of brine at $(x, y)$ on $\mathrm{B}$ and is obtained from the solution of Eqs. (2) - (7) of Ref. 13 by BRAGFLO, $\mathbf{n}(x, y)$ denotes an outward-pointing unit normal vector, and $\int_{\mathbf{B}} \sim d s$ denotes a line integral along $B$ 
Table 5. Calculations Performed with BRAGFLO, NUTS and PANEL to Estimate Radionuclide Releases to the Culebra Dolomite

\begin{tabular}{ll}
\hline BRAGFLO Calculation & NUTS/PANEL Calculations \\
\hline E0 & NUTS: E0 (no release to Culebra) \\
E1 at $350 \mathrm{yr}$ & NUTS: E1 at 100, 350 yr \\
$\mathrm{E} 1$ at $1000 \mathrm{yr}$ & NUTS: E1 at $1000,3000,5000,7000,9000 \mathrm{yr}$ \\
$\mathrm{E} 2$ at $350 \mathrm{yr}$ & NUTS: E2 at $100,350 \mathrm{yr}$ \\
$\mathrm{E} 2$ at $1000 \mathrm{yr}$ & NUTS: E2 at $1000,3000,5000,7000,9000 \mathrm{yr}$ \\
E2E1 with E2 at $800 \mathrm{yr}$ and E1 at $2000 \mathrm{yr}$ & PANEL: E2E1 at $100,350,1000,2000,4000,6000$, \\
& 9000 yr (Note: an E2E1 intrusion is the same as the \\
& E1E2 intrusion referred to in the CCA) \\
\hline
\end{tabular}

Table 6. Stepwise Regression Analyses with Rank-Transformed Data for Cumulative Radionuclide Releases over 10,000 yr from the Repository to the Culebra Dolomite for an E2E1 Intrusion with the $\mathrm{E} 1$ Intrusion Occurring at $1000 \mathrm{yr}$

\begin{tabular}{|c|l|c|c|c|c|c|c|c|c|c|c|c|}
\multicolumn{1}{c|}{} & \multicolumn{4}{|c|}{ Am-241 } & \multicolumn{4}{c|}{ Pu-238 } & \multicolumn{3}{c|}{ Pu-239 } & \multicolumn{4}{c|}{ U-234 } \\
\hline Step $^{\mathrm{a}}$ & Variable & SRRC & $R^{2 \mathrm{~d}}$ & Variable & SRRC & $R^{2}$ & Variable & SRRC & $R^{2}$ & Variable & SRRC & $R^{2}$ \\
\hline 1 & BHPRM & 0.61 & 0.37 & BHPRM & 0.57 & 0.34 & BHPRM & 0.59 & 0.36 & BHPRM & 0.58 & 0.35 \\
2 & BPCOMP & 0.52 & 0.64 & BPCOMP & 0.54 & 0.63 & BPCOMP & 0.52 & 0.63 & BPCOMP & 0.45 & 0.55 \\
3 & SOLAMC & 0.20 & 0.68 & SOLPUC & 0.18 & 0.67 & SOLPUC & 0.16 & 0.66 & SOLUC & 0.36 & 0.69 \\
4 & BPINTPRS & 0.17 & 0.70 & BPINTPRS & 0.16 & 0.69 & WGRCOR & -0.16 & 0.68 & BPINTPRS & 0.17 & 0.71 \\
5 & WGRCOR & -0.14 & 0.72 & BPVOL & 0.12 & 0.70 & BPINTPRS & 0.16 & 0.70 & WGRCOR & -0.12 & 0.72 \\
6 & BPVOL & 0.12 & 0.74 & WGRCOR & -0.09 & 0.71 & BPVOL & 0.12 & 0.72 & BPVOL & 0.12 & 0.74 \\
7 & ANHPRM & 0.10 & 0.74 & WMICDFLG & -0.08 & 0.72 & ANHPRM & 0.09 & 0.73 & ANHPRM & 0.11 & 0.75 \\
8 & WMICDFLG & -0.07 & 0.75 & ANHPRM & 0.08 & 0.73 & WMICDFLG & -0.10 & 0.74 & WMICDFLG & -0.10 & 0.76 \\
\hline
\end{tabular}

\begin{tabular}{|c|l|r|r|l|r|c|}
\cline { 2 - 7 } \multicolumn{1}{c|}{} & \multicolumn{3}{c|}{ Th-230 } & \multicolumn{3}{c|}{ Total } \\
\hline Step $^{\mathrm{a}}$ & Variable $^{\mathrm{b}}$ & SRRC $^{\mathrm{c}}$ & $R^{2 \mathrm{~d}}$ & Variable & SRRC & $R^{2}$ \\
\hline 1 & BHPRM & 0.60 & 0.36 & BHPRM & 0.61 & 0.37 \\
2 & BPCOMP & 0.54 & 0.65 & BPCOMP & 0.52 & 0.64 \\
3 & WGRCOR & -0.16 & 0.68 & SOLAMC & 0.19 & 0.67 \\
4 & BPINTPRS & 0.17 & 0.70 & BPINTPRS & 0.17 & 0.70 \\
5 & BPVOL & 0.13 & 0.72 & WGRCOR & -0.14 & 0.72 \\
6 & ANHPRM & 0.10 & 0.73 & BPVOL & 0.12 & 0.73 \\
7 & WMICDFLG & -0.10 & 0.74 & ANHPRM & 0.10 & 0.74 \\
8 & & & & WMTCDFLG & -0.07 & 0.75 \\
\hline
\end{tabular}

${ }^{\text {a }}$ Steps in stepwise regression analysis.

${ }^{\mathrm{b}}$ Variables listed in order of selection in regression analysis with $A N H C O M P$ and $H A L C O M P$ excluded from entry into regression model due to -0.99 rank correlations imposed on the variable pairs (ANHPRM, ANHCOMP) and (HALPRM, HALCOMP) (see Sect. 7.2, Ref. 19).

${ }^{\mathrm{c}}$ Standardized rank regression coefficients in final regression model.

${ }^{\mathrm{d}}$ Cumulative $R^{2}$ value with entry of each variable into regression model. 
Table 7. Results Available for Use in CCDF Construction for Radionuclide Releases into the Culebra Dolomite

$r E 0\left(j, k, \omega_{l}\right)=$ cumulative release $(\mathrm{kg})$ of element $k$ of decay chain $j$ (See Eq. (21)) from the repository to the Culebra under undisturbed (i.e., E0) conditions from time 0 yr (i.e., closure of repository) through time $\omega_{l}, \omega_{l}=100,150,200, \ldots, 10,000$ yr (i.e., $\omega_{l+1}=\omega_{l}+50$ yr for $l \geq 1$ ), due to brine flow. Source: NUTS (See Table 5).

$r E 1\left(\tau_{i}, j, k, \omega_{l}\right)=$ cumulative release $(\mathrm{kg})$ of element $k$ of decay chain $j$ (See Eq. (21)) from the repository to the Culebra from time $\tau_{i}$ to time $\omega_{l}, \omega_{l}=\tau_{i}+50 \mathrm{yr}, \tau_{i}+100 \mathrm{yr}, \ldots, 10,000 \mathrm{yr}$, due to brine flow with an E1 intrusion occurring at time $\tau_{i}, \tau_{i}=100,350,1000,3000,5000,7000,9000$ yr. Source: NUTS (See Table 5).

$r E 2\left(\tau_{i}, j, k, \omega_{l}\right)=$ cumulative release $(\mathrm{kg})$ of element $k$ of decay chain $j$ (See Eq. (21)) from the repository to the Culebra from time $\tau_{i}$ to time $\omega_{l}, \omega_{l}=\tau_{i}+50 \mathrm{yr}, \tau_{i}+100 \mathrm{yr}, \ldots, 10,000 \mathrm{yr}$, due to brine flow with an E2 intrusion occurring at time $\tau_{i}, \tau_{i}=100,350,1000,3000,5000,7000,9000$ yr. Source: NUTS (See Table 5).

$r E 21\left(\tau_{i}, j, k, \omega_{l}\right)=$ cumulative release $(\mathrm{kg})$ of element $k$ of decay chain $j$ (See Eq. (21)) from the repository to the Culebra from time $\tau_{i}$ to time $\omega_{l}, \omega_{l}=\tau_{i}+50 \mathrm{yr}, \tau_{i}+100 \mathrm{yr}, \ldots, 10,000 \mathrm{yr}$, due to brine flow with an E2E1 intrusion occurring at time $\tau_{i}, \tau_{i}=100,350,1000,4000,6000,9000 \mathrm{yr}$. Source: PANEL (See Table 5).

$f C E O(s, j, k)=$ fraction of element $k$ of decay chain $j$ (See Eq. (21)) attached to colloid specie $s$ under undisturbed (i.e., E0) conditions (See Table 1).

$f C E 1(s, j, k), f C E 2(s, j, k)=$ same as $f C E O(s, j, k)$ but for conditions subsequent to $\mathrm{E} 1$ and $\mathrm{E} 2$ intrusions, respectively. 
Table 8. Construction of Radionuclide Releases into the Culebra Dolomite for an Arbitrary Future $\mathbf{x}_{s t}$ of Form in Eq. (1) of Ref. 11

\section{Notation:}

$n C=$ number of colloid species (i.e., $n C=4$; see Table 1 )

$n P=$ number of waste panels (i.e., $n P=10$; see Fig. 1, Ref. 11)

$n I(p)=$ number of drilling intrusions into waste panel $p, p=1,2, \ldots, n P$ (i.e., drilling intrusions for which $e_{i}$ $=1$ and $l_{i}$ is associated with waste panel $p$; see Sects. 4,5 , Ref. 11)

$t_{p i}=$ time (yr) of $i^{\text {th }}$ drilling intrusion into waste panel $p, i=1,2, \ldots, n I(p), p=1,2, \ldots, n P$ (see Sect. 3, Ref. 11)

$n E l(p)=$ number of E1 intrusions into waste panel $p$ (i.e., intrusions for which $b_{i}=1$; see Sect. 6, Ref. 11)

$n E 2(p)=$ number of $\mathrm{E} 2$ intrusions into waste panel $p$ (i.e., intrusions for which $b_{i}=0$; see Sect. 6, Ref. 11)

$n E 2 l(p)=$ number of $\mathrm{E} 2 \mathrm{E} 1$ intrusions into waste panel $p$ (see $t E 21_{p j}$ below)

$t E 1_{p j}=$ time (yr) of $j^{\text {th }} \mathrm{E} 1$ intrusion into waste panel $p, j=1,2, \ldots, n E 1(p)$

$t E 2_{p j}=$ time (yr) of $j^{\text {th }} \mathrm{E} 2$ intrusion into waste panel $p, j=1,2, \ldots, n E 2(p)$

$t E 2 l_{p 1}=$ time $(\mathrm{yr})$ of $1^{\text {st }} \mathrm{E} 2 \mathrm{E} 1$ intrusion into waste panel $p$ (i.e., time when two or more drilling intrusions have penetrated waste panel $p$, of which at least one encounters pressurized brine in the Castile Fm)

$t E 21_{p j}=$ time (yr) of each $E 1$ intrusion (i.e., $b_{i}=1$ ) into waste panel $p$ subsequent to $t E 21_{p 1}, j=2,3, \ldots$, $n E 21(p)$ (i.e., $t E l_{p j}, j=2,3, \ldots, n E I(p)$ if $t E 21_{p 1}<t E 1_{p 2}$ and $t E l_{p j}, j=3,4, \ldots, n E I(p)$ if $t E 2 I_{p 1}$ $\left.=t E I_{p 2}\right)$

Cumulative release to Culebra:

$c R D_{p}(j, k, t)=$ cumulative dissolved release $(\mathrm{kg})$ to Culebra through time $t$ of element $k$ of decay chain $j$ from waste panel $p$

$=0$ if $t \leq t_{p 1}$

$=\left[1-\sum_{s=1}^{n C} f C E l(s, j, k)\right] r E l\left(t_{p 1}, j, k, t\right)^{\mathrm{a}} \quad$ if $t E 1_{p 1}=t_{p 1}<t \leq t_{p 2}$

$=\left[1-\sum_{s=1}^{n C} f C E 2(s, j, k)\right] r E 2\left(t_{p 1}, j, k, t\right) \quad$ if $t E 2_{p 1}=t_{p 1}<t \leq t E 1_{p 1}$ 
Table 8. (Continued)

$$
\begin{array}{rl}
c & c R D_{p}\left(j, k, t E 21_{p m}\right)+\left[1-\sum_{s=1}^{n C} f C E 1(s, j, k)\right] \\
r E 21\left(t E 21_{p m}, j, k, t\right) & \\
& \text { if } t E 21_{p m}<t \leq t E 21_{p, m+1}, m=1,2, \ldots, n E 21(p)
\end{array}
$$

$c R D(j, k, t)=$ cumulative dissolved release $(\mathrm{kg})$ from repository to Culebra through time $t$ of element $k$ of decay chain $j$

$$
\begin{array}{ll}
=\left[1-\sum_{s=1}^{n C} f C E O(s, j, k)\right] r E O(j, k, t)^{b} & \text { if } t \leq t_{1} \\
=c R D\left(j, k, t_{1}\right)+\sum_{p=1}^{n P} c R D_{p}(j, k, t) & \text { if } t>t_{1}
\end{array}
$$

$c R C_{p}(s, j, k, t)=$ cumulative release $(\mathrm{kg})$ from waste panel $p$ to Culebra through time $t$ of element $k$ of decay chain $j$ sorbed to colloid specie $s$

$$
\begin{aligned}
& =0 \quad \text { if } t \leq t_{p \mathrm{1}} \\
& =f C E l(s, j, k) r E l\left(t_{p 1}, j, k, t\right) \quad \text { if } t E 1_{p 1}=t_{p 1}<t \leq t_{p 2} \\
& =f C E 2(s, j, k) r E 2\left(t_{p 1}, j, k, t\right) \quad \text { if } t E 2_{p 1} \quad=t_{p 1}<t \leq t E 1_{p 1} \\
& =c R C_{p}\left(s, j, k, t E 21_{p m}\right)+f C E l(s, j, k) r E 2 I\left(t E 2 l_{p m}, j, k, t\right) \\
& \text { if } t E 21_{p m}<t \leq t E 21_{p, m+1}, m=1,2, \ldots, n E 21(p)
\end{aligned}
$$

$c R C(s, j, k, t)=$ cumulative release $(\mathrm{kg})$ from repository to Culebra through time $t$ of element $k$ of decay chain $j$ sorbed to colloid specie $s$

$$
\begin{array}{ll}
=f C E O(s, j, k) r E O(j, k, t) & \text { if } t \leq t_{1} \\
=c R C\left(s, j, k, t_{1}\right)+\sum_{p=1}^{n P} c R C_{p}(s, j, k, t) & \text { if } t>t_{1}
\end{array}
$$

$c R T(j, k, t)=$ total cumulative release $(\mathrm{kg})$ to Culebra through time $t$ of element $k$ of decay chain $j$

$$
=c R D(j, k, t)+\sum_{s=1}^{n C} c R C(s, j, k, t)
$$

a Here and elsewhere, appearance of two undefined times implies two-dimensional linear interpolation between defined times in Table 5 .

b Here and elsewhere, appearance of an undefined time implies linear interpolation between defined times in Table 5 . 
Table 9. Stepwise Regression Analyses with Rank-Transformed Data for Expected Normalized Release Associated with Individual CCDFs for Release to Culebra Dolomite

\begin{tabular}{|c|c|c|c|c|c|c|c|c|c|c|c|c|}
\hline & \multicolumn{3}{|c|}{ Am-24l } & \multicolumn{3}{|c|}{ Pu-239 } & \multicolumn{3}{|c|}{ U-234 } & \multicolumn{3}{|c|}{ Th-230 } \\
\hline Step $^{a}$ & Variable & SRRC $^{c}$ & $R^{2 \mathrm{~d}}$ & Variable & SRRC & $R^{2}$ & Variable & SRRC & $R^{2}$ & Variable & SRRC & $R^{2}$ \\
\hline 1 & BHPRM & 0.62 & 0.38 & BHPRM & 0.61 & 0.37 & BHPRM & 0.59 & 0.36 & BHPRM & 0.61 & 0.37 \\
\hline 2 & BPCOMP & 0.56 & 0.69 & BPCOMP & 0.52 & 0.65 & BPCOMP & 0.46 & 0.57 & ВPСОMP & 0.55 & 0.68 \\
\hline 3 & BPINTPRS & 0.17 & 0.71 & WGRCOR & -0.15 & 0.67 & SOLUC & 0.31 & 0.68 & WGRCOR & -0.15 & 0.70 \\
\hline 4 & SOLAMC & 0.13 & 0.73 & SOLPUC & 0.13 & 0.69 & BPINTPRS & 0.16 & 0.70 & BPINTPRS & 0.16 & 0.72 \\
\hline 5 & BPVOL & -0.13 & 0.74 & BPINTPRS & 0.15 & 0.71 & WMICDFLG & -0.12 & 0.72 & BPVOL & 0.13 & 0.74 \\
\hline 6 & WGRCOR & -0.12 & 0.76 & BPVOL & 0.13 & 0.72 & $A N H P R M$ & 0.13 & 0.73 & WMICDFLG & -0.12 & 0.75 \\
\hline 7 & ANHPRM & 0.10 & 0.77 & WMICDFLG & -0.11 & 0.74 & BPVOL & 0.12 & 0.74 & ANHPRM & 0.11 & 0.77 \\
\hline 8 & WMICDFLG & -0.09 & 0.78 & $A N H P R M$ & 0.11 & 0.75 & WGRCOR & -0.12 & 0.76 & & & \\
\hline 9 & & & & WASTWICK & -0.07 & 0.75 & & & & & & \\
\hline
\end{tabular}

\begin{tabular}{|c|l|r|c|}
\cline { 2 - 4 } \multicolumn{1}{c|}{} & \multicolumn{3}{|c|}{ Total } \\
\hline Step $^{\mathrm{a}}$ & Variable $^{\mathrm{b}}$ & SRRC $^{\mathrm{c}}$ & $R^{2 d}$ \\
\hline 1 & BHPRM & 0.62 & 0.38 \\
2 & BPCOMP & 0.54 & 0.67 \\
3 & BPINTPRS & 0.17 & 0.70 \\
4 & WGRCOR & -0.14 & 0.72 \\
5 & BPVOL & 0.12 & 0.73 \\
6 & ANHPRM & 0.11 & 0.74 \\
7 & SOLAMC & 0.11 & 0.75 \\
8 & WMICDFLG & -0.10 & 0.76 \\
\hline
\end{tabular}

a Steps in stepwise regression analysis.

b Variables listed in order of selection in regression analysis with $A N H C O M P$ and HALCOMP excluded from entry into regression model due to -0.99 rank correlations imposed on the variable pairs (ANHPRM, ANHCOMP) and (HALPRM, HALCOMP) due to -0.99 rank correlations imposed on the variable pairs (ANHPRM, ANHCOMP) and (HALPRM, HALCOMP) (see Sect. 7.2, Ref. 19).

c Standardized rank regression coefficients in final regression model.

${ }^{\mathrm{d}}$ Cumulative $R^{2}$ value with entry of each variable into regression model. 